University of Louisville

ThinkIR: The University of Louisville's Institutional Repository

Electronic Theses and Dissertations

$5-2018$

\title{
A fractured conversation : the professional, scholarly, and disciplinary identities of two-year college writing faculty.
}

Laura Sceniak Matravers

University of Louisville

Follow this and additional works at: https://ir.library.louisville.edu/etd

Part of the Rhetoric and Composition Commons

\section{Recommended Citation}

Matravers, Laura Sceniak, "A fractured conversation : the professional, scholarly, and disciplinary identities of two-year college writing faculty." (2018). Electronic Theses and Dissertations. Paper 2941. https://doi.org/10.18297/etd/2941

This Doctoral Dissertation is brought to you for free and open access by ThinkIR: The University of Louisville's Institutional Repository. It has been accepted for inclusion in Electronic Theses and Dissertations by an authorized administrator of ThinkIR: The University of Louisville's Institutional Repository. This title appears here courtesy of the author, who has retained all other copyrights. For more information, please contact thinkir@louisville.edu. 
A FRACTURED CONVERSATION: THE PROFESSIONAL, SCHOLARLY, AND DISCIPLINARY IDENTITIES OF TWO-YEAR COLLEGE WRITING FACULTY

By

Laura Sceniak Matravers

B.A., University of Tennessee, Knoxville, 2010

M.A., University of Tennessee, Knoxville, 2012

A Dissertation

Submitted to the Faculty of the

College of Arts and Sciences of the University of Louisville

in Partial Fulfillment of the Requirements

for the Degree of

Doctor of Philosophy

in English/Rhetoric and Composition

Department of English

University of Louisville

Louisville, Kentucky

May 2018 

A FRACTURED CONVERSATION: THE PROFESSIONAL, SCHOLARLY, AND DISCIPLINARY IDENTITIES OF TWO-YEAR COLLEGE WRITING FACULTY

By

Laura Sceniak Matravers

B.A., University of Tennessee, Knoxville, 2010

M.A., University of Tennessee, Knoxville, 2012

A Dissertation Approved on

April 16, 2018

by the following Dissertation Committee:

Dissertation Director, Bronwyn T. Williams

Mary P. Sheridan

Susan Ryan

Jenn Fishman 


\section{DEDICATION}

This dissertation is dedicated to my parents:

George Sceniak,

after whose unfailing work ethic I have tried to model my own, and who has always, always supported me

and

Susan Sceniak, whose gift of a library card when I was three years old sparked my lifelong love of language and awe at the power that words can wield, and who encourages me to remain curious and follow my dreams, wherever they may lead 


\section{ACKNOWLEDGEMENTS}

I would like to thank the following people, without whom this dissertation would be little more than an idea:

My director, Bronwyn Williams, for seeing this project for what it might be long before I could, and for guiding, supporting, and encouraging me tirelessly along the way; and my committee, Mary P. Sheridan, Susan Ryan, and Jenn Fishman, for your tough questions, enthusiasm, and keen insights and perspectives.

The seven teacher-scholars who agreed to take part in this study, for your willingness to carve time our of your very busy schedules to meet with me and describe your experiences in such rich detail, and for not rushing through our time together.

My community college students, past and future, for inspiring this project.

The amazingly strong and talented women I have been lucky enough to befriend during my time in Louisville, for shaping this journey so powerfully and positively.

My family, near and far, for the many and varied ways in which you all have provided your understanding and support throughout this process - especially my parents, George and Susan, and my sister, Nicole, for always believing in me.

My husband, Eric, for joining me on this wild ride. 


\begin{abstract}
A FRACTURED CONVERSATION: THE PROFESSIONAL, SCHOLARLY, AND DISCIPLINARY IDENTITIES OF TWO-YEAR COLLEGE WRITING FACULTY

Laura Sceniak Matravers
\end{abstract}

April 16, 2018

At a time when state-sponsored policies for tuition-free two-year college

education are on the rise, this dissertation examines the place of two-year colleges within the primary discourses circulated within Composition Studies. Specifically, through its investigation of the professional practices and identities of two-year college writing faculty — who work in institutions that are often mistakenly seen as "devoid" of scholarship — this dissertation interrogates disciplinary conceptions of scholarship. This study was comprised of two modes of data collection: an examination of publication trends in prominent Composition Studies journals, and interviews with seven community college writing teachers in the Southeast.

This dissertation finds that, in contrast to some of the common narratives surrounding this particular institutional setting, upheld by publication trends in Composition Studies journals (Chapter Three), the teachers interviewed are actively engaged in inquiry and knowledge-making. However, their work is not always identified as such, and, consequently, is not always exchanged with nor recognized by the wider discipline of Composition Studies. Given the large portion of the work of teaching college writing that takes place in two-year colleges, this dissertation argues for a more 
capacious understanding of scholarship, and posits the scholarly lives enacted by participants as an alternate model of inquiry and knowledge-making. This model is shaped by the institutional settings in which participants work (Chapter Two), and is premised on professional spaces institutionally understood as sites of other professional activities - the classroom (Chapter Three) and conferences and faculty reading groups (Chapter Four), as well as collaboration, local applications of new knowledge, and the complex and overlapping relationships between faculty's different position responsibilities (Chapters Three and Four). Ultimately, this dissertation argues that wider acceptance of such alternate models of scholarship would allow for clearer recognition of the contributions of teacher-scholars (such as those interviewed for this study) to Composition Studies, and would pave the way for disciplinary unity through the increased exchange of innovative ideas and practices across institutional settings- - thus improving writing instruction for all college students (Chapter Five). 


\section{TABLE OF CONTENTS}

PAGE

DEDICATION

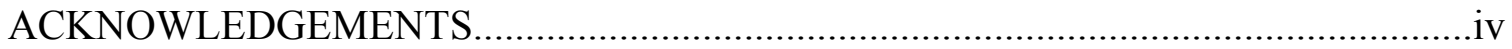

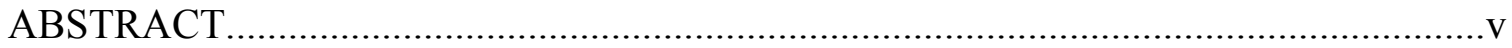



CHAPTER ONE: Introduction: Studying Two-Year Colleges in the Era of Tennessee

Promise

CHAPTER TWO: "On the Front Lines": Working in a Community College..................65

CHAPTER THREE: Two-Year College Writing Faculty as Scholars: Classroom Edition.

CHAPTER FOUR: Two-Year College Writing Faculty as Scholars: Outside the Classroom

CHAPTER FIVE: Conclusion: Towards Mending the Conversation.

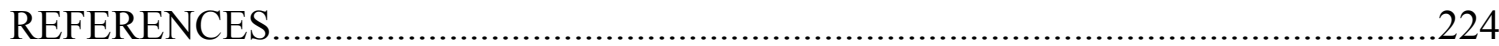



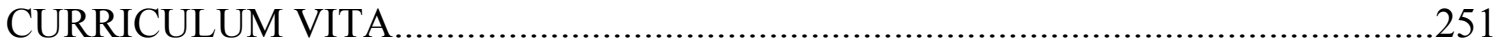




\section{LIST OF TABLES}

TABLE

PAGE

1. Interview Participant Profiles.

2. Journal Profiles.

$48-50$

3. Journals, Years, and Databases Searched.........................................................53-4

4. Articles with Two-Year College (TYC) Authors.................................................130

5. Conferences Recently Attended or Presented At, English Studies............................180

6. Conferences Recently Attended or Presented At, Outside of English Studies.........180-2

7. Results Breakdown by Journal—Articles in Four-Year Journal Group.....................250

8. Results Breakdown by Journal—Articles in Two-Year Journal Group.....................250

9. Comparison of Articles in Four-Year and Two-Year Journal Groups.......................250 


\title{
CHAPTER ONE
}

\section{INTRODUCTION: STUDYING TWO-YEAR COLLEGES IN THE ERA OF TENNESSEE PROMISE}

\begin{abstract}
"The experience of [faculty] at two-year institutions must be central to current dialogues about student writing; without their experience, these dialogues only provide a partial picture of literacy instruction in the United States." (7)

- Heather Ostman, Writing Program Administration and the Community College
\end{abstract}

The last few years have witnessed a growing trend in policies intended to promote increased student access to postsecondary education, particularly access to two-year colleges, and these policies have the potential to alter the landscape of American higher education. This national trend began in 2014, when Tennessee Governor Bill Haslam signed into law Tennessee Promise, making the state the first to implement a scholarship and mentoring program that provides qualifying students with free tuition at in-state twoyear colleges (Gang). Former President Obama followed suit in January 2015, when, during a speech at a Tennessee community college, he unveiled his America's College Promise proposal, a similar plan for two years of tuition-free community college for eligible students - both high school graduates and "non-traditional" students nationwide (Bidwell; Sheehy). Since then, numerous states have continued this trend by implementing their own promise programs (Weeden and Hultin; Lierman; College Promise Campaign). While it is too soon to know with certainty the future effects of 
these programs, given the frequency of proposed similar legislation in other states and the significant increase in college enrollment in Tennessee within the first year of Tennessee Promise (Smith, "Promise Provides"; Tamburin), it is reasonable to conclude that this trend could result in similar increases in enrollment at two-year colleges (Bidwell). In light of these ongoing policy developments, it is prudent to examine the place of two-year colleges within the primary discourses circulated within Composition Studies - for though society at large increasingly focuses on two-year colleges, they are still underrepresented in many of the discipline's conversations, seemingly remaining on the margins of much of the existing scholarship. Goggin, for example, notes the "diminished representation of authors from institutions other than universities," such as two-year colleges, in leading Composition Studies journals since the mid-1980s, pointing out that this is in stark contrast to the fact that "two-year college faculty account for a significant portion of the workforce in higher education," given the number of students enrolled in two-year institutions (161-164). Indeed, according to the American Association of Community Colleges (AACC), $41 \%$ of all first-time college students in the U.S. are community college students, and $45 \%$ —nearly half —of all undergraduate students attend community college ("Fast Facts"). With the current trend in policy changes pushing toward increased access to a community college education, which is even further incentivized by the promise of greater employment opportunities for graduates upon completion, we can likely expect to soon see even more students enrolled in community colleges, and such changes could result in more faculty hires at such 
institutions. ${ }^{1}$ However, as Goggin points out, the overwhelming majority of scholarship in Composition Studies journals is not fully representative of the actual populations of college writing students, faculty, or administrators - nor, consequently, the full range of the realities of the landscape of teaching college writing. Instead, much of the disciplinary scholarship on writing programs implies an imagined standard of the fouryear public research university as the norm in higher education; the resulting effect is that our dominant disciplinary discourse often ignores the work of writing teachers and faculty in smaller schools such as two-year colleges (Amorose; Goggin; Holmsten)-a trend that, as Goggin argues, "raises a question concerning the distribution of disciplinary practices and members" (164).

In his 2005 article, "The Teacher/Scholar: Reconstructing Our Professional Identity in Two-Year Colleges,” Andelora writes:

For all intents and purposes, two-year college English faculty have established a strong national identity within the field of rhetoric and composition. However, $a$ look at who actually contributes to the rhet/comp journals complicates the story. (312; emphasis added)

He then points out that "two-year college English faculty have never had a particularly strong presence in the journals that make up our discipline" (312). Like Andelora, and as discussed in the literature review below, many scholars over the last few decades have similarly pointed out the minimal scholarship written by two-year college faculty contributors in many of the major journal publications in Composition Studies, from Howell Raines's 1988 article, "Teaching Writing in the Two-Year College," all the way to Ostman's 2013 book Writing Program Administration and the Community College-

\footnotetext{
${ }^{1}$ These potential forecasted changes are highly dependent on specific state policies and economic conditions, though. As discussed in more depth in Chapter Two, faculty experiences within specific institutional settings vary greatly by state.
} 
the first book to offer an in-depth look at two-year college writing programs ${ }^{2}$ (Ostman 11).

Underlying this continued refrain is the generally-accepted function of written, published scholarship, which I understand as Goggin describes it:

Although scholarly journals may emerge and change in response to disciplinary practices that are already in place, they also serve to direct future practices by accepting some and rejecting others. That is, journals adjudicate the questions, the objects of study, the methodologies, and the discursive forms of a discipline through their editorial policies and practices. As such, journals serve as an important locus of disciplinary power, shaping the discipline even as they are shaped by it. It is precisely this dynamic that makes them important artifacts to study. (xvi; emphasis added)

Similarly to Goggin, Hyland understands disciplines as cultures that are both "enacted and constructed by social actors" (Disciplinary Identity 43). Academic writing, he writes, serves as a "collective social practice" within each of these cultures, with "published texts as the most concrete, public and accessible realization of these practices" (Disciplinary Discourse 1). From such a perspective, scholarly "writing [...] helps to create $[\ldots]$ disciplines by influencing how members relate to one another, and by determining who will be regarded as members, who will gain success, and what will count as knowledge" (Hyland, Disciplinary Discourse 5). Accepted scholarship — such as that comprising journal publications — so has a particular legitimizing function within a discipline. Consequently, pieces of academic writing, Hyland argues, "offer a window on the

\footnotetext{
${ }^{2}$ When discussing the teaching of writing in two-year colleges, I follow the practice of others, such as Ostman, and use the term "writing program" somewhat loosely, as much of the literature suggests that two-year colleges do not have clearly delineated writing programs, at least not as they usually exist in four-year research universities. So, the idea of the "two-year college writing program" generally refers to college writing courses at two-year colleges and/or the English departments in which those courses are usually housed-given that such courses are often the majority of those offered in two-year college English departments (Ostman).
} 
practices and beliefs of the communities for whom they have meaning" (Disciplinary Discourse 5). Goggin's description of the role of journals as essentially disciplinary gatekeepers coincides with Hyland's view of written academic discourse as a social endeavor that both influences and reveals the hierarchical structures of that discipline (Hyland, Disciplinary Discourse 155-178).

Within this framework, which sees disciplines as cultural enterprises (Hyland), and published written artifacts as both disciplinary mirror and gatekeeper (Hyland; Goggin), I also draw on Bruner's notion of cultural narratives to help understand the social functions and effects of journal scholarship. Specifically, I see a discipline's scholarly publications as contributing to what Bruner calls the "accrual" of the narratives that shape a culture ("Narrative Construction" 18-20). According to Bruner, over time, the accrual of such narratives results in a culturally understood and accepted conventions, and these "culturally shaped notions," by which individuals create meaning, are essential to "cultural cohesion" (Bruner, "Narrative Construction"; Acts of Meaning 137). Likewise, such conventions or norms also serve to help a culture's members identify socalled "breaches" of those norms-i.e., those who do not adequately adhere to cultural conventions, as established by the accrual of cultural narratives (Bruner, "Narrative Construction" 15; Acts of Meaning).

Together, Goggin, Hyland, and Bruner have shaped my thinking about this project, which is premised on these three key ideas:

1) Disciplines are cultural and social enterprises.

2) Academic writing circulated within a discipline both contributes to and is indicative of that disciplines' norms, values, and membership. 
3) As such, disciplinary journals — a common and widely-read iteration of academic writing - aid in the accrual of the cultural narratives that shape a discipline.

Under the assumption that a discipline can be understood to be a "culture" (Hyland), it is my position that the journals published within Composition Studies are one of the vehicles by which cultural narratives within the discipline accrue, and so reveal disciplinary norms and values.

In light of the popularity of legislative trends toward tuition-free two-year college education - which I believe have the potential to dramatically shift the landscape of higher education - in this study, I investigate the apparent discrepancies between the full range of settings where the work of Composition Studies actually takes place and the seemingly limited picture portrayed by much of the written scholarship published in many of our discipline's journals. More specifically, given the important role that academic journals play in the maintenance of disciplinary standards, I examine Andelora's and others' claim that two-year college English faculty have a minimal presence in our own disciplinary journals, and how the subsequent cultural narratives that "accrue" (Bruner) impact the professional identities of those who teach writing in twoyear colleges. Toward these ends, this study addresses the following research questions:

- What cultural narratives about two-year college faculty accrue in prominent Composition Studies journals? How do these narratives impact the professional identities of writing faculty at two-year colleges? 
- What is the nature of scholarship for two-year college writing faculty? How do they define and value scholarship, and how do their ideas differ from or reflect apparent disciplinary attitudes towards scholarship?

- What role does scholarship play in the professional self-identities of two-year college writing faculty?

- What factors or conditions might influence whether or not two-year college writing faculty choose to or are able to contribute to journal publications and the general circulation of scholarship in Composition Studies?

To address these questions, this study was comprised of two parts:

1) An examination of recent trends in journal publications attributed to two-year college-affiliated contributors within a selection of six major Composition Studies journals: College Composition and Communication, College English, Computers and Composition, Journal of Basic Writing, Teaching English in the Two-Year College, and WPA: Writing Program Administration.

2) Interviews with seven participants who, at the time of their interviews, taught writing courses at two-year colleges in the Southeast.

From these interviews, and by analyzing trends in the institutional affiliations of authors who contribute to six Composition Studies journals, I found that one of the key narratives of two-year college faculty that circulates within Composition Studies is that of the two-year college faculty as teacher, not scholar, and that this narrative, though it seems to be internalized by those I interviewed, is not altogether true. I began this study with the understanding that journals are key to the circulation of scholarship — and thus participation as a scholar-within our discipline (Hyland; Goggin). However, I found 
that, in the midst of a profession whose understanding of scholarship rests on such written artifacts (Kirsch and Sullivan; S. Miller, "Writing Theory : : Theory Writing”), the faculty ${ }^{3}$ I interviewed enact a different model of scholarship, one that is fostered by the institutional culture of the two-year college and so does not often result in a written end-product. As discussed in Chapters Three and Four, this model is premised on the following:

1) Professional spaces institutionally understood as sites of teaching and professional development and service, which faculty leverage as sites of inquiry and circulation of new knowledge.

2) Complex and overlapping relationships between faculty's different position responsibilities (e.g., teaching, professional development and service), and between their inquiry practices and circulation of new knowledge.

3) Highly collaborative relationships between colleagues and between faculty and students.

4) Local applications of faculty's discovered knowledge.

I argue that the creation of knowledge in this particular institutional space (the two-year college) is not recognized because of the larger cultural narratives that guide disciplinary understandings of both scholarship and the two-year college setting. As a result, the recognized body of disciplinary knowledge within Composition Studies is incomplete. This incomplete record maintains a rift within the discipline, which falls along institutional lines.

\footnotetext{
${ }^{3}$ Though it is not a title used across all two-year settings (Reynolds, "Two-Year College Teachers"), I use the term "faculty" to refer to all varieties of two-year college writing instructors, including full-time and part-time, tenure-track and non-tenure-track, as this is the way most participants described themselves, regardless of position.
} 
I maintain, however, that—simply put—those on either side of this rift have something to learn from each other. For example, in the age of neoliberal higher education (Slaughter and Rhoades; Greenwood; Barnett; Daniel; Welch and Scott; Toth et al, "Dubious"), as the wide range of institutions of higher education experience public scrutiny and budget cuts, four-year institutions increasingly face issues that have been traditionally understood to be specific to the two-year setting, such as increasing reliance on adjunct or contingent labor (e.g., Schell, "Austerity”; Schell, "Toward"). Furthermore, because they are open-access institutions, community colleges have traditionally "serve[d] a diverse student population with a diverse set of needs" ("2015 Fact Sheet"). Working with such diverse student groups is something both two-year and four-year faculty increasingly share in common. For example, Preto-Bay and Hansen argue that, with the continuation of diversifying population trends and increased access to higher education, "college composition requirements are not likely to decrease," and, as such, "changes will be needed in the way college composition is taught because the changing population will enroll in the courses" (39). Matsuda, Fruit, and Lamm similarly point out that "the student population in U.S. higher education is becoming increasingly diverse ... as institutions continue their efforts to diversify ... the student population" (11; see also Friedrich 17). Given such trends toward increasingly more diverse student populations within four-year universities, and calls for the subsequent need for college composition programs to adapt accordingly to such projected changes (Preto-Bay and Hansen; Matsuda et al.; Friedrich), it would behoove teachers and scholars of writing in four-year

\footnotetext{
${ }^{4}$ According to the American Association of Community Colleges (AACC), the majority of community college are "non-traditional": nearly half of the national community college student population is between $22-39$ years old, $17 \%$ are single parents, and $62 \%$ of full-time students are also employed ("2015 Fast Fact Sheet").
} 
settings to more fully consider the work of their counterparts in the two-year setting, where faculty have been working with diverse groups of students for decades. Overall, I suggest that interinstitutional dialogues (Toth and Jensen; Jensen and Toth; CalhoonDillahunt et al), beginning at the local level and mediated by commonalities resulting from a shared locale, are the first step towards disciplinary unity.

\section{On Terms: TYCs and CCs, Research and Scholarship, and Disciplinarity}

Before moving forward, it is important to note how I use key terms in this dissertation: two-year college and community college, research and scholarship, and disciplinarity. First, I frequently use the phrases two-year college (or TYC), and community college (or $C C$ ), interchangeably. According to the 2012 by-laws of the TwoYear College English Association (TYCA), the term, "“two-year college' encompasses community colleges, junior colleges, technical colleges, and the first two years of college" ("By-Laws" 1). In other words, community colleges are a type of two-year college: all community colleges are two-year institutions, but not all two-year colleges are community colleges. My decision to use these terms interchangeably in this dissertation reflects the literature and the terms by which my interview participants describe their work.

Second, as I discuss more thoroughly in Chapters Three and Four, I recognize that there are commonly-understood criteria for what counts as "scholarship," such as the steps involved in the research process, as well as the peer-review process and the systematic circulation of discovered knowledge (Shulman, "Course Anatomy"; Kern et

\footnotetext{
${ }^{5}$ Tribal colleges and technical colleges are also designated as two-year colleges $(A A C C)$.
} 
al.; Minter and Goodburn), but maintain that some of these conventions are based on the work that is rewarded in a traditional four-year research university (Boyer, Scholarship Reconsidered 12, 15; Glassick et al. 7-8). Because this dissertation sets forth an alternate model of scholarly activity cultivated by a different institutional setting, I align myself with a more foundational understanding of scholarship: inquiry work that results in the discovery and sharing — broadly defined — of new knowledge. Consequently, I see research and scholarship as closely linked, with research being the inquiry work that is key to the uncovering of new knowledge.

Finally, disciplinarity is a contested idea, as Goggin describes in the introduction to her study, noting that "debates over the status of rhetoric and composition as a discipline reveal that discipline is a highly contested term in the field" (xix; see also Kirsch; Kirsch and Sullivan). Goggin goes on to argue that we are a discipline, in part because of that very conflict: "Diversity, disunity, and fragmentation [three critiques brought against the disciplinary status] are not merely inevitable, [but] are necessary conditions for a discipline," she writes (xx). As a researcher and scholar, I adopt Goggin's view, à la Foucault, that

What distinguishes a discipline $[\ldots]$ are the construction and maintenance of legitimizing apparatuses that serve both to permit and encourage and to control and limit objects of inquiry, questions, methods, and discourses (xxi).

Additionally, I accept Goggin's claim that “these legitimizing mechanisms were engineered within rhetoric and composition beginning in the 1950s" (xxi), around the same time period that saw the emergence of journals such as College Composition and Communication and College English, suggesting that these journals do, indeed, serve as "legitimizing mechanisms" within the discipline. Goggin, here, is writing more broadly 
about the discipline of Rhetoric and Composition, while in this project, I use the term "Composition Studies" to name the slice of the disciplinary puzzle on which I am focused. However, I acknowledge that naming is messy and not always consistent within Rhetoric and Composition, with the common conflation of the terms "field" and “discipline" across our written scholarship; with first-year college writing programs across institutions utilizing both the terms "writing" and "composition" within their course titles; with some teacher-scholars pledging allegiance to other disciplinary titles, such as Writing Studies; with “sub-disciplines” of expertise, such as writing program administration, as evidenced, in part, by the myriad of our journal titles. Such wideranging titles reflect a celebrated truth of the discipline: Rhetoric and Composition is a vast and dynamic network of teacher-scholars whose expertise is diverse. Furthermore, the relationship between those who teach writing courses at two-year colleges and Composition Studies is complex and, according to some, also itself contested. ${ }^{6}$ However, this project is premised on the assumption that two-year college writing faculty, as teachers of writing courses that fall under the umbrella of Composition Studies, are a part of the discipline. Consequently, within this dissertation, I use the term "Composition Studies" - the traditionally-understood "composition side" of our discipline — as this term most accurately represents the journal scholarship I examined, and most clearly reflects the content of the courses my interview participants teach.

\section{Literature Review}

\footnotetext{
${ }^{6}$ As discussed in the review of the literature, below.
} 
In this section, I offer a review of existing literature that has shaped my conceptions of this study. First, I provide an overview of scholarship that has been published about the professional identities and voices of two-year college writing faculty, including two primary threads of conversation:

1) Apparent underrepresentation in existing literature

2) Material working conditions, which are often invoked in literature about two-year colleges.

Next, I explain the history of the overall institutional foundations of American community colleges and two-year college writing instruction, arguing that this history's lasting legacy has at least partially shaped cultural and disciplinary attitudes toward twoyear colleges, and has consequently informed the tenor of many relationships between four-year universities and two-year colleges. Finally, I discuss where and how this study intervenes in the literature described.

\section{Professional Identities of Two-Year College Faculty}

\section{Underrepresentation in Existing Literature}

The limited presence of two-year college writing faculty in disciplinary scholarship is an issue that has been raised and echoed by many over the last few decades, including Raines (1988; 1990); Tinberg (1993); Nist and Raines (1993; 1995); Holladay (1996); Townsend and LaPaglia (2000); Alford (2001); Sommers (2004); Reynolds (2005); Andelora (2005); Ostman (2013); Hassel (2013); and Toth (2014). Across these works, this underrepresentation seems to be implicit to some scholars' very understandings of the professional identities of two-year college faculty, fundamentally shaping how two-year college faculty are often viewed, both by themselves and others 
within Composition Studies, and contributing to the apparently prevalent idea of the "marginalized" community college writing instructor. However, these conversations also depict "the complexities of two-year college faculty's relationships with the discipline of composition" itself (Toth 335), ultimately upholding what Toth describes as the "rather conflicted theoretical portrait" of the professional and scholarly activities of two-year college writing faculty (336), a portrait that portrays both the "weak ties" they have to professional organizations within Composition Studies, as well as "robust scholarship on [their] professional identity" that, in contrast, suggests rather strong disciplinary ties (Toth 336-337). The complexity of the position two-year college faculty consequently hold in Composition Studies is evidenced, for example, by Toth, Griffiths, and Thirolf's 2013 study “'Distinct and Significant': Professional Identities of Two-Year College English Faculty," an examination of the "ways that English faculty at two-year colleges understand and enact their professional identities in professional scenes," such as disciplinary professional organizations (91). They argue that "two-year college faculty experience unique challenges when enacting their professional identities in $[\ldots]$ disciplinary $[\ldots]$ contexts," due largely to the "“four-year centric' model of professional participation" that governs disciplinary understandings of what that kind of participation looks like, and suggest that the "lack of recognition" of the "knowledge generated by two-year English faculty $[\ldots]$ within scholarly conversations in composition $[\ldots]$ is due, in part, to a lack of understanding about how these professionals [...] enact their professional identities" (Toth et al 91; 90-1).

Overwhelmingly, much of the existing literature written by two-year college faculty addresses, either through in-depth discussion or mere acknowledgement of, the 
underrepresentation of two-year college writing faculty in disciplinary scholarship. Across works spanning decades - some focusing on the underrepresentation of two-year college writing faculty, others simply mentioning it along the way toward other project goals - is the repetition of the idea that, despite the "sheer numbers" of students and faculty who populate community college campuses, the majority of scholarship in Composition Studies often ignores two-year colleges and instead centers itself around other institutional settings, primarily four-year research universities. For example, Severson, quoted in Nist and Raines' 1993 chapter, "Writing in the Margins: A Search for Community College Voices," matter-of-factly states that "two-year college professors are definitely underrepresented [in professional journals about teaching composition] even though [they] teach over fifty percent of higher education writing classes" (319). Nist and Raines themselves argue in the same chapter:

Reforms in the profession and advancements in the teaching of composition will ring hollow without the participation of community college faculty. Sheer numbers of students who take composition in community colleges mean the voices of those who teach these classes need to be included in the central narrative of composition studies. Without our stories, the text of teaching writing is incomplete. (299)

In their 1995 chapter, “Two-Year Colleges: Explaining and Claiming Our Majority,” Nist and Raines make a similar argument about the work of two-year college writing faculty, and suggest that two-year college faculty struggle against "university elitism" (64). Elsewhere, Raines points out "the infrequent and limited attention paid" to two-year colleges ("Teaching Writing" 29) and that "the dominant voices in the writing community are those of people in research universities" ("Is There a Writing Program?" 159). In her detailed and moving description, published in 1996, about what it is like to teach English in a community college setting and the students encountered there, 
Holladay invokes "the neglected majority in education" (33, emphasis added), and, in his introduction to his edited collection, The Politics of Writing in the Two-Year College, Alford describes the authors of the essays in the volume-all two-year college English faculty — as "practitioners too often silent in the debate over literacy practices, training, and assessment," noting, as many others do, "the disparity between the growth of student enrollment and the decline of active [two-year college] faculty participation in the field" (v). In her 2013 book on writing program administration at two-year colleges, Writing Program Administration and the Community College, ${ }^{7}$ Ostman similarly argues that "the experience of WPAs and instructors at two-year institutions must be central to current dialogues about student writing; without their experience, these dialogues only provide a partial picture of literacy instruction in the United States (Ostman 7, emphasis in original). Finally, in her 2013 article, Hassel describes "[her] sense that [two-year college writing faculty] are underrepresented in the publications in our field (even in [Teaching English in the Two-Year College] $)^{8}$, proportional to the number of students and instructors who are learning and teaching in two-year colleges" (353).

In contrast to this seemingly constant refrain echoed across decades of publications are the voices of other scholars who complicate this oft-repeated idea by suggesting that two-year college faculty can, already do, and should continue to engage in more traditional scholarly activities such as research and publication (Tinberg;

\footnotetext{
${ }^{7}$ This book is the first of its kind; Ostman found that, "to date, there are no other books dedicated to the specific work of the WPA in the community college" (11). ${ }^{8}$ Further complicating Hassel's claim, specifically, and the issue, overall, is Goggin's argument that the underrepresentation of community college writing faculty in leading journals such as CCC is that the journal Teaching English in the Two-Year College has "likely ... [drawn] away at least some contributors who might have sent their submissions to $C C C^{\prime \prime}(164)$.
} 
Sommers; Reynolds, “Two-Year College Teachers”; Kroll; Palmer and Vaughan; Vaughan, "Scholarship and Teaching"; Matijevich). According to Tinberg, "to this day, the 'professionalism' of community college faculty has been challenged both from within and without. [...] Many see us as teaching drones who [...] rarely engage in any kind of professional dialogue with colleagues. We do not publish nor do we attend conferences. [...] That is the perception at any rate" (12; emphasis added). Tinberg's project is to push against such perceptions, arguing that not only does the community college setting allow for faculty to attend conferences and publish articles, but that two-year college faculty are "able and willing" to do such work (13). Similarly, Sommers describes two-year college faculty as "quite well suited" for research, particularly the scholarship of teaching and learning, given the teaching environments of two-year colleges (14). Reynolds further points out the various ways in which some two-year college faculty have, indeed, contributed to journals, published textbooks, attended conferences, and participated in professional organizations (“Two-Year College Teachers" 5-7), despite the prevailing perception of "the academy" which sees two-year college faculty as "unworthy" and "insignificant" (2). Reynolds' assertions prove to exemplify the complexities of the issue of the underrepresentation of two-year college faculty (Toth; Andelora, "Teacher/Scholar") within the discipline, as he simultaneously celebrates the participation of two-year college writing faculty within the discipline, and points out the very damaging attitudes that exacerbate perceptions of underrepresentation and feelings of marginalization. Overall, these arguments urge faculty to conduct research that results in traditional written publications, thus upholding the hierarchy within academia, that imposes the values of the four-year research university (where such written products of 
research are expected and rewarded) and has, I contest, contributed to a cultural tendency towards dismissing the two-year college setting precisely because it is not "scholarly."

Townsend and LaPaglia frame their 2000 study of the perceptions of full-time faculty at community colleges with that very perception, making the all-too-familiar assertion that four-year college faculty do not view "two-year college faculty $[\ldots]$ as contributing members to their discipline" (42). Furthermore, "four-year faculty dominate the academic power structure that sets research agendas [and] privileges research over teaching"; consequently, they argue, "two-year college faculty are implicitly marginalized and devalued within academe" (Townsend and LaPaglia 42). Instead of disputing this perception, Townsend and LaPaglia's study investigates to what extent two-year college faculty "have internalized this sense of marginalization" (42), finding that, based on their survey responses, though participants "agreed that four-year college and university faculty considered them to be "on the margins of higher education,"' they "had not internalized" this assumed marginalization (47).

Toth's 2014 study of the professional practices of full-time two-year college faculty within the discipline similarly attests to Townsend and LaPaglia's findings. Admittedly, however, Toth's findings do not, at first, seem to align with their argument: Toth found that the attendance of two-year college faculty at NCTE and CCCC Annual Conventions "is much smaller than their actual role in the literacy education landscape," and that, surprisingly, only 3.5 percent of two-year college faculty attend the regional Two-Year College English Association conferences (338-340). Even after accounting for the limitations of her data, Toth concludes that "it is likely that fewer than 7 percent of

\footnotetext{
${ }^{9}$ This argument is a key component of the argument I make in Chapter Three, where it is more thoroughly discussed in relation to the findings of this study.
} 
two-year college English faculty in the United States went to any of these NCTEaffiliated conferences [CCC, NCTE, and TYCA regionals]" between 2009 and 2012 (340; emphasis added). However, Toth also found that two-year college English faculty actively participate in organizations across disciplines ${ }^{10}$ and "beyond the 'standard' NCTE associations," including organizations such as the Community College Humanities Association and the National Association for Developmental Education (347). According to Toth, then, one important aspect of this issue is that two-year college English faculty are not necessarily inactive, but that they do not consistently adhere to the disciplinary identity sponsored by NCTE (see also: Toth et al). This finding is in line with Townsend and LaPaglia's conclusion that the two-year college faculty they surveyed have not internalized the marginalization that is apparently implicit to the attitudes toward twoyear colleges of those outside of this institutional setting, such as four-year college faculty. Taken together, this body of literature suggests that the seeming underrepresentation of two-year college writing faculty within Composition Studies is itself contested by those who work in and publish out of two-year college settings, despite decades of others' persistent, echoing claims of marginalization - ultimately revealing the complexities and tensions implicit to the conflicted role of the two-year college within the discipline.

\section{Labor and Material Conditions}

Claims of underrepresentation within disciplinary scholarship are inherently intertwined with issues of labor and material conditions - i.e., the conditions of the

\footnotetext{
${ }^{10}$ This finding also falls in line with the diverse disciplinary backgrounds from which many faculty who work in English departments at two-year colleges come from (e.g., Fearing; Ostman; Tinberg).
} 
institutional settings in which most two-year college writing faculty work—and labor. Composition Studies scholars have, in recent decades, turned their attention to the material (Schell, "Materializing"). In fact, some would argue that the material conditions and economic considerations that impact the kind of work that is done-and is able to be done - are foundational to our disciplinary identities, as much of this scholarly work is centered in conversations about disciplinarity and institutional hierarchies, as well as college writing programs. ${ }^{11}$ For example, Strickland focuses on what she calls the "managerial unconscious" in Composition Studies, arguing that, though "unconscious," the managerial aspects of writing program administration have "been an integral part of the development of the field," so much so that the managerial "is also a history of the development of composition studies" (4). Whereas the oft-cited histories of the field (Strickland points to, for example, Berlin, Connors, and Harris) tell the story of composition pedagogy — contributing to the popularly-held notion of Composition Studies as a "teaching-subject" (Harris, A Teaching Subject, qtd. in Strickland 7)—what has been left out of that story's repeated re-telling is the prominent role the managerial work of WPAs has played in the development of Composition Studies itself (Strickland 5-7). Other scholars bring to light similar material aspects of the development of-and the work done in — the field: T. Miller advocates an understanding of the development of English departments as connected to "developments in literacy and literacy studies," suggesting that we "define college English in terms of the technologies that do its work

\footnotetext{
${ }^{11}$ In addition to their proliferation throughout the WPA dialogue, material conditions are also conceived of in different contexts within the field, as well-such as when we talk about materiality and its intersection with rhetorical theory (e.g., Coogan), or its relationship with multimodal composing and literacy practices (e.g., Pahl).
} 
and the economies in which that work circulates and thereby gains value through use" (19); Scott "[works] from the premise that what we do is powerfully shaped by how we do it" ("How We Do What We Do" 41); and George's edited collection offers first-hand accounts of the intersections between WPAs' personal and professional lives and their specific institutional contexts.

An important thread in these wide-ranging conversations about the material conditions that impact our work is that of labor. In the last few decades, Composition Studies scholars have become increasingly vocal about issues of labor and working conditions in college writing programs (e.g., Bousquet et al.; Bousquet; Scott, Dangerous Writing; Strickland; Welch and Scott; Horner). Like Strickland, Hendricks claims the invisibility of such conditions, pointing out "composition's double blindness to labor" (84). Despite this "blindness," however, there is a rich disciplinary dialogue about institutional hierarchies, the ethical issues surrounding higher education's reliance on contingent faculty and graduate-student instructors, and the need for change in light of these issues, including the $C C C$ "FORUM: Issues about Part-Time and Contingent Faculty” ("FORUM"; see also: Schell, “Austerity”; Schell, "Toward”; Snyder; Harris; Trainor and Godley). In her 1995 chapter, Hansen describes "the litany of disadvantages in the second tier," which includes graduate students working as TAs, non-tenure track faculty, and part-time instructors: the physical limitations of the office space and supplies provided to do one's job (if any), low wages, and job insecurity (24). Hansen further describes the ethical dilemmas that are thus created for WPAs who "lead [programs] that [are] built on exploitation" (24-25), and suggests that the "low status" of college writing programs is due, at least in part, to the historical, cultural, and institutional underpinnings 
of the late-nineteenth-century emergence of first-year composition courses and the midtwentieth-century growth of Rhetoric and Composition (25-26). Contributing to what Hansen sees as the "low status" of college writing programs is the historical association of composition, with its emphasis on teaching, with the feminine (Strickland; S. Miller, "Feminization"; Schell, “Materializing”).

Similar to the working conditions of many who teach in the name of such a "marginalized" discipline in the academy are the working conditions of those who teach in institutions that are, according to some, even further marginalized within that discipline. Indeed, across much of the existing literature on writing programs at two-year colleges and scholarship on the professionalization of two-year college writing faculty, the issue of the material conditions of working in this institutional setting-such as the emphasis that is placed on teaching over other professional pursuits; the number of parttime or contingent faculty typically employed in two-year colleges; and the consequent time constraints and financial barriers that thus limit many two-year college faculty's ability to research, write for publication, or attend conferences-come up repeatedly (Klausman, "Mapping”; Klausman, “Toward a Definition”; Worthen; Reynolds, "TwoYear College Teachers"; Nist and Raines, "Writing in the Margins"; Ostman; Trainor and Godley; Powers-Stubbs and Sommers). Furthermore, much of the scholarship about the underrepresentation of two-year college faculty within Composition Studies suggests that these conditions themselves contribute to that underrepresentation. For example, PretoBay and Hansen attribute the "lack of information about [community colleges]" in disciplinary dialogues to the fact that "two-year ... college faculty have contributed very little to leading composition journals, even though publication in all fields at all types of 
institutions, including community colleges, has risen dramatically since 1980" (44). They suggest that this is because faculty at two-year colleges have teaching loads that "are often so heavy $[\ldots]$ they lack time to do research and write about their knowledge" (45). In his introduction to the collection, The Politics of Writing in the Two-Year College, Alford similarly writes that the contributors to the volume "have, for the most part, wrangled the time to write out of the customary five-course-per-semester load facing most two-year college faculty" to contribute to the collection (v; emphasis added). Claims such as these reify the narrative that two-year college faculty are simply too busy and overworked to sufficiently contribute to disciplinary dialogues.

As such, two-year faculty are commonly understood to be teachers (who work in the realm of "practice," not scholars (who work in the realm of "theory") (North). For example, Newkirk writes,

Anyone who $[\ldots]$ overhears community college teachers trying to find a relevant session at the Conference on College Composition and Communication convention - senses the fissure between those who teach literacy and those who study or theorize about it. ("Seduction and Betrayal" 14)

Such a "fissure," I believe, stems from our disciplinary origins. T. Miller explains some of the underpinnings of the contentious foundations of Rhetoric and Composition, in his version of the inception of today's college writing course, which entails the split between Composition Studies and literature, and the eventual pairing of the study of rhetoric with composition studies. T. Miller explains that, according to Graff, around the $1860 \mathrm{~s}$ in America, it was "[proclaimed] that professors of literature would eradicate the illiteracy of undergraduates, but, as the profession became established, the teaching of composition was dismissed as work that should have been done in high school" (24). T. Miller argues that, eventually, "with the professionalization of literature, rhetoric was reduced to 
teaching first-year composition," until, finally, "composition ended up being taught by about the only instructors who could not claim a research basis" and "whose work it was to clean up students' language" (24-25). This shift happened largely because the American university was modeled after German universities of the time (Greenwood 116-117), universities which "valued research over teaching and graduate students over liberal education" (T. Miller 25). According to T. Miller, Rhetoric and Composition "was not disinterested and methodical enough to be a science," yet "too mechanical and political to be an art," and so, ultimately, the discipline "became confined to mere teaching, transmitted through the machinations of teacher-proof textbooks" (25). In his description of the split between disciplines and the resulting birth of Rhetoric and Composition, T. Miller suggests a reason for the tenuous nature of today's college composition course: the early exclusion of rhetorical education and Composition Studies from English departments. He further points out the tenuous nature of the very establishment of a cohesive identity (i.e., the pairing of rhetorical education with Composition Studies) and subsequent debates about our disciplinarity. In light of these shaky disciplinary foundations, which cast Rhetoric and Composition as "less than" in the hierarchies of university English departments, where the theories and scholarship of literature were privileged over the teaching of students unprepared for college-level writing, and because of the strong association of the community college setting with teaching composition, historically cast as feminine (Strickland; S. Miller, "Feminization"; Schell, "Materializing"), there is a tradition within Composition Studies - arguably, a “teaching subject" (Harris) — to seek scholarly and disciplinary legitimacy by distancing itself from the idea that we "merely" teach. As such, the work of teacher-scholars in two- 
year colleges, settings strongly associated with teaching and where there is not an explicit research requirement for faculty, has regularly been disassociated from "legitimate" disciplinary knowledge (Kitzhaber; North). Overall, this disciplinary history helps illustrate Hyland's claim that "disciplines are [...] sites of power and authority which influence differential access to resources for creating knowledge and which define discipline approved realities," upholding his argument that "there is a political dimension underlying academic practices" in disciplinary discourse (155). Hyland's further invocation of Bourdieu's "notion of symbolic capital" to explain the exclusion of those without "the same experience or training" from disciplinary communities—which "[reinforces] the legitimacy of certain [disciplinary] practices"-offers a framework by which to understand the complicated relationships between two-year college writing faculty and Composition Studies (157). Such a framework largely precludes the inclusion of the knowledge of two-year college faculty in mainstream disciplinary discourse, as that knowledge is not seen as "legitimate" because it is not derived from the same inquiry practices commonly rewarded within the four-year institution, and because of its close association with teaching.

\section{Institutional Histories and Identities of Two-Year Colleges}

From one perspective, the underrepresentation and apparent marginalization of two-year college writing faculty in much of the scholarship that circulates within the field's "mainstream," or more prominent journals could, in part, be due to the lasting effects of the legacy of the very foundations of what Vaughan calls "the community college story," and how that legacy has persisted throughout the unfolding of that story (Nist and Raines, "Two-Year Colleges"; Reynolds, "Two-Year College Teachers"; 
Reynolds, "Introduction"; Ostman; Fearing). In other words, the history of two-year colleges has had a lasting effect on the general attitudes held toward two-year colleges and their students and faculty, attitudes that are engrained in our very cultural and disciplinary conceptions of higher education. In this section, I provide an overview of that history, describe writing instruction in two-year colleges, and discuss the relationships between two-year colleges and four-year research universities. The Two-Year College Legacy: Democratic and Economic Missions

"The educational hierarchy that resulted in the establishment of the community college by leaders of prominent four-year institutions will not," writes Ostman, “voluntarily dismantle itself" (181). The hierarchy to which Ostman refers was borne out of and solidified during the early twentieth century, a time of growth for American higher education, and the time during which the story of the two-year college unfolds (Cohen and Brawer 6). The first public two-year college, Joliet Junior College, was opened in 1901, marking the beginning of that story (Vaughan, Community College Story 39; American Association of Community Colleges $[A A C C])$. In the late nineteenth and early twentieth centuries, as student populations at secondary schools grew, so, too, did "the demand for access to college" to continue that education at the post-secondary level (Cohen and Brawer 6). Furthermore, because of the challenge of "global economic competition facing the U.S." at this time, "national and local leaders realized that a more skilled workforce was key to the country's economic strengths" (AACC).

Just as the formation of Composition Studies has had a lasting impact on disciplinary attitudes toward teaching and scholarship, ${ }^{12}$ the impetus of the ideas that laid

${ }^{12}$ As discussed in the previous section 
the foundations of the first two-year college have similarly shaped prevalent attitudes toward community colleges. For example, community colleges are commonly seen as less academically prestigious than four-year research universities, and this perception was, according to Cohen and Brawer, foundational to their very formation. Cohen and Brawer suggest that a major reason junior colleges were opened to meet increasing demands for higher education at the beginning of the twentieth century - instead of simply increasing enrollment at public four-year universities - is that "several prominent nineteenth- and early twentieth-century educators wanted [...] universities to abandon their freshman and sophomore classes and relegate the function of teaching adolescents to a new set of institutions" (7). These educators believed that such institutions "should relieve the university of the burden of providing general education" and "insisted that the universities would not become true research and professional development centers until they relinquished their lower-division preparatory work" (Cohen and Brawer 7, emphasis added). Such an attitude toward first- and second-year general education courses mirrors the tensions that subsequently shaped the emergence of Rhetoric and Composition as a discipline, as T. Miller describes, and which I discuss in the previous section. This conception of "junior" colleges has historically placed two-year colleges at the bottom of a hierarchy of American higher education (Fearing 185). From this perspective, two-year colleges were instituted primarily as a means of uplifting the more "senior" research and education of four-year research universities, by shouldering the "burden" of general education courses (such as first-year composition), and, as discussed in the previous section, remnants of this perspective still persist today (e.g., Ostman 66-67). 
In response to similar economic and democratic concerns as those of the early 1900s, in the 1940s, Congress passed the Servicemen's Readjustment Act of 1944, commonly known as the G.I. Bill (Vaughan, Community College Story 28-29; Cohen and Brawer 31). Because of the resounding success of the G.I. Bill, the two decades following its passage saw the number of two-year colleges in the U.S. nearly double (Vaughan, Community College Story 30). Similarly, the Higher Education for American Democracy report, or the Truman Commission Report, published in 1947 by President Truman's Commission on Higher Education, also impacted the expansion of two-year colleges (Cohen and Brawer 14; Vaughan, Community College Story 29). This report proposed "the creation of a network of public, community-based colleges to serve local needs," and called for individual colleges in this proposed network to "charge little or no tuition; serve as cultural centers; be comprehensive in their program offerings with emphasis on civic responsibilities; and serve the area[s] in which they were located" (Vaughan, Community College Story 42). By the 1960s, such a national network of community colleges was thriving (Vaughan, Community College Story 29-30; Cohen and Brawer 35$41)$.

Such moments offer an example of how larger political discourse and policy changes have influenced two-year colleges, the narratives that persist about this setting, and the shape of the discipline of Composition Studies. As Andelora explains, because the mid-twentieth century saw "a new breed of student [...] entering college," the "phenomenon" of the boom in community colleges was of no small concern to university English faculty" ("Professionalization" 8). For example, Kitzhaber, in a 1963 NCTE report, describes the two-year college as "a unique kind of educational institution" 
experiencing "spectacular growth," and argues that this institutional setting is "certainly one of the most remarkable phenomena of American higher education at the present time [mid-1960s]"; he continues:

This kind of institution has multiplied until it now makes up more than a third of all the institutions of higher education in this country and enrolls about one-fourth of all college students. [...] Without exception, these young people [TYC students] are required to take at least a semester and usually two of freshman English. [...] In light of these circumstances [...] it is clear that the state of English teaching in the nation's two-year colleges must be a matter of pressing concern. (1-2)

Teaching English in the two-year college was "a matter of pressing concern" for Kitzhaber, then-president of NCTE, because such colleges face "a number of serious problems" for which he offers lists of suggested solutions (13). Kitzhaber unabashedly blames some of these problems, in part, on two-year colleges themselves. For example, "the junior college system itself," he writes, "is at fault for often making it so easy" for terminal students (those students who do not intend to transfer to a four-year university) to jump the tracks of education to that intended for transfer students (16). Furthermore, Kitzhaber notes the conditions of many junior colleges: "excessive workloads, unevenly prepared staffs, [...] [and] often an unintellectual if indeed not an anti-intellectual atmosphere" (15). "Under such conditions," he is apt to remind us, "no academic course can be taught as well as it deserves" (Kitzhaber 15). Ultimately, Kitzhaber's harsh critiques of TYC English teachers and students has "had a devastating impact on the status of two-year college English faculty and their programs" (Andelora 9). Kitzhaber is not the sole source of blame, though, as such attitudes toward the academic atmosphere of TYCs echoes the intentions of those nineteenth- and twentieth-century educators who 
strove to house "junior" education in institutions separate from universities, and captures well a perspective of two-year college students and teachers that has prevailed.

Despite attitudes such as Kitzhaber's, the mid-twentieth century was a time of positive growth for the two-year college setting. For example, the Truman Commission's call for community involvement hailed the shift from the then-common name junior college to the now more familiar community college (Vaughan, Community College Story 42). Not only did the Commission contribute to the growing presence of two-year colleges in higher education, it also impacted both the very nature of such institutions and the terms by which they are described. Today, the dual nature of the community college — with its mission to democratize higher education intertwined with national and state economic interests - continues. Indeed, today's two-year colleges are still organized around the democratic ideals espoused by the Truman Commission Report and inherent to the foundation of the national network of community colleges seen in the 1960s; the mission statements of many community colleges include general commitments to "[serve] all segments of society through an open-admissions policy that offers equal and fair treatment to all students," and to "[serve] the community as a community-based institution of higher education" Vaughan, Community College Story 3-8). As Ostman points out, access to higher education is an "opportunity for $[\ldots]$ social and economic mobility" (58). ${ }^{13}$ At the beginning of the twentieth century, community colleges - then called junior colleges - were established in response to democratic and economic demands, and such dual demands have continued to impact the development of the

\footnotetext{
${ }^{13}$ Ostman also points out that, on the other hand, community colleges might also be seen as "an attempt to fortify the American caste system by [...] providing training suitable for jobs at designated socioeconomic levels" (58).
} 
community college tradition (Vaughan, Community College Story 39-48; Ostman 5758) - such as the inverse relationship between the economy and student enrollment at two-year colleges; ${ }^{14}$ the hallmark characteristic of two-year colleges, open admissions; and the continued tradition of community-serving college missions (AACC; Vaughan Community College Story; Ostman). The network of community colleges established in the 1960s thrives today, with institutions still enacting those democratic and civic ideals, and, with recent trends in legislation paving the way for increased economic access to two-year college program (i.e., promise programs), the proliferation of community colleges within American higher education is likely to continue.

\section{Access, "Basic" Writing, and Writing Programs in Two-Year Colleges}

Alford argues that "if we $[\ldots]$ value a literacy that is democratic, inclusive, and critical, we will start by focusing on the two-year colleges" (viii) because of the setting's hallmark open-admissions policy. By its strictest definition, a two-year college is a regionally accredited postsecondary institution that "offers the associate degree as its highest degree" (Vaughan, Community College Story 1; see also: Cohen and Brawer). ${ }^{15}$ However, in practice, as just one site where the work of Composition Studies takes places, two-year colleges are "multiple, complex, and ever-changing" (Holmsten 429). They are economic conditions in motion, and — because of their open-admissions policies - democracy at work. Today, this issue is even more pronounced, as lawmakers seek to create even greater economic access to higher education, with a recent surge in promise programs providing free community college tuition (Weeden and Hultin). One

\footnotetext{
${ }^{14}$ I describe this relationship in my discussion of the larger economic forces that shape the material working conditions of my interview participants in Chapter Two.

${ }^{15}$ Interestingly, however, some two-year colleges are beginning to offer bachelor's degrees in certain programs $(A A C C)$.
} 
conceivable result of this trend is that student populations at institutions of higher education will continue to push against the imagined standard of the "traditional," college-ready student (Ostman 26; see also: Preto-Bay and Hansen). Ostman argues that the dual democratic and economic missions of the community college have fundamentally shaped "the development of [two-year college] writing programs" (58). Disciplinary discussions of two-year colleges embody some of the tensions between these two extremes, as we have struggled to answer the question: What does it mean to provide education to students who would otherwise not have access to college?

This question came to a head in the 1970s, with Shuaghnessy's seminal works on basic writing ("Diving In: An Introduction to Basic Writing," 1976; Errors and Expectations: A Guide for the Teacher of Basic Writing, 1977), in the wake of CUNY's controversial adoption of an open-admissions policy ("Open Admissions: American Dream or Disaster"; Vaughan, Community College Story 44). With increased access to higher education resulting from open-admissions policies such as CUNY's and the boom in community colleges nationwide, the mid-twentieth century, according to Andelora, "witnessed both a rapid rise in the number of two-year colleges being built and in the number of students walking through their doors ("Professionalization" 8). Indeed, since Shaughnessy's important work in the 1970s, the discipline's rich dialogue about basic, remedial, or developmental writing has been carried on by scholars such as Bartholomae (1985); Bizzell (1986); Rose (1985, 1989); Moran and Jacobi (1990); Lu (1991); Hull et al. (1991); Gunner (1998); McNenny and Fitzgerald (2001); and Soliday (2002), whose collective body of work represents Composition Studies' struggle to respond to the tensions that arise when access to higher education is opened up to more diverse student 
populations. Bartholomae's 1985 description of the discourses of higher education (605) reveals one of these tensions. He describes the act of writing in college as learning "to speak our language, to speak as we do," and portrays the student writer as having "to invent the university" (Bartholomae 605-606). While his calls to "demystify" the conventions of our specific academic discourse community and to use more "precise" language in our explanations of those conventions is commendable, his situation of student writers as necessarily at odds with dominant academic discourses is problematic in its assumption of student deficit, particularly in the case of "basic writers" (614-615).

Ostman points out that, "instead of viewing the open admissions policies as a democratizing initiative, many academics $[\ldots]$ misread the purpose of the policies, subsequently reifying long-held assumptions about community colleges as inferior institutions" (14; see also: Trainor and Godley). Shaughnessy's seminal works were published amidst a climate of negative attitudes toward two-year colleges, just over a decade after Kitzhaber published his report containing harsh critiques of two-year college English faculty and students for being "ill-prepared" for the academic rigors of "true" postsecondary education, as well as what he terms the problematic "split mission" of twoyear colleges to educate both transfer and terminal students (Andelora, "Professionalization" 9); according to Andelora, this report "became an indictment [of the teaching of English in two-year colleges]" ("Professionalization" 8-9). In a sense, so, too, has the association of community colleges with "basic writing" and "remedial" or "developmental" students. Perhaps due in part to their open-admissions policies, two-year colleges are often perceived to be synonymous with student deficit. 
While it is important not to equate two-year colleges solely with basic writing, it is just as important not to dismiss that two-year college faculty are indeed active in dialogues about developmental writing. For example, in his 2003 article, "What is 'College-Level' Writing?," Sullivan urges us to define "college-level” writing because "if we can't clearly define for ourselves what we mean by' college-level' writing, how can we hope to do this for our students?" (377). Establishing such a definition "is especially important for open-admissions colleges that offer developmental courses [...] because developmental courses are typically defined as "precollege"” (Sullivan 377). Sullivan ultimately argues that "any meaningful dialogue about $[\ldots]$ how best to serve our developmental students must proceed from a broadly shared consensus about standards related to college-level work" (384). In their 2006 book of the same title, Sullivan and Tinberg push this project even further, describing the question, "What is 'college-level' writing?" as "one of the most important questions in our profession" (xiii). Though twoyear colleges do tend to enroll many developmental writing students, and four-year settings are associated with students who are better prepared for college, the dialogue on these two bodies of teaching knowledge must happen across institutions, as developmental students eventually feed in to first-year college courses. As such, as Sullivan and Tinberg point out, we need a shared disciplinary understanding of "collegelevel" writing.

Finally, if the project of defining "college-level" writing is "one of the most important in our profession," then the work of describing and identifying two-year college writing programs is equally so, in light of conflicting narratives about this institutional setting. As Holmsten puts it, “community college English departments do 
not house writing programs so much as they are writing programs" (429, emphasis added). She further describes "composition" as "what we do" (432), explaining that, in the community college, "most of our courses are composition courses," and faculty "are not marginalized members of a department that is primarily focused on teaching literature to English majors" (Holmsten 432). Consequently, Holmsten concludes, "we are a writing program" (432). Similarly, in her description of writing "programs" at two-year colleges, Ostman echoes Holmsten, detailing the intrinsic nature of writing courses to community college English departments (or their equivalent):

Many community colleges do not have a writing program per se, but offer a core of composition-based classes. [...] And just as two-year colleges do not always have a designated writing program, but may have instead a collection of composition courses, they also do not always have an English department. A broader division or another department may offer the writing program or writing courses. (Ostman 9)

Writing programs, then, are essentially "embedded” (Gladstein and Regaignon 96) within two-year college English departments or divisions, as well as the community college curriculum — since such courses are often, if not always, part of the general education requirements. As a result, much of the work that is done in two-year college writing "programs" is not as easily recognizable as the more clearly-defined writing programs that exist at their four-year counterparts. Consequently, much of the existing literature on writing instruction in two-year colleges seeks to bring to light that work, by identifying, describing, and defining it (Klausman, "Mapping"; Klausman, “Toward a Definition”; Holmsten; Taylor; Nist and Raines; Calhoon-Dillahunt; Holladay; Raines). Such recovery projects are key to the participation of two-year faculty in disciplinary conversations, as well as towards the end of affecting policy changes affecting higher education (Toth et al, "Dubious"). 


\section{Relationships between Two-Year Colleges and Four-Year Universities}

Despite — or perhaps because of - the complexities of the professional and institutional identities described above, much of the existing literature containing descriptions of or references to the relationships between two-year colleges and four-year universities suggests that those relationships tend to be fraught with tensions between those who inhabit these two institutional sites. Attitudes toward two-year colleges as "less than," as sites where basic writing is taught to underprepared students-a reification of the attitudes that shaped the founding of the first two-year colleges in the early twentieth-century—are still apparent (e.g., Schwalm; Nist and Raines; Trainor and Godley; Powers-Stubbs and Sommers; Reynolds, "Two-Year College Teachers"; Reynolds, "Introduction"; Choseed). These tensions manifest themselves as either local tensions between a specific two-year college and university (e.g., Trainor and Godley), or the more general attitudes of four-year research university faculty toward two-year college faculty (e.g., Choseed). Indeed, Fearing explicitly points out "the sometimes tenuous relationship between the university and the two-year college" (185).

Ultimately, the uneven representation of the work of Composition Studies in written disciplinary scholarship has the potential to leave future writing instructors illequipped to work with more diverse groups of students from a wide range of educational backgrounds, or new faculty struggling to successfully navigate institutional or local settings that are different from the assumed norm in much of the scholarship they most likely read — and likely internalized — as graduate students. Powers-Stubbs and Sommers describe the attitudes toward two-year colleges that some in graduate programs in fouryear research universities hold, an "elitism" that is "based primarily on the prestige 
attached to research versus the devalued position of teaching" (28-29; see also: North). The perpetuation of such attitudes is problematic for many reasons, not least of which is the partnership between these two types of postsecondary institutions in terms of graduate student training and teacher preparation-i.e., English graduate programs' willingness and ability to offer opportunities that would help prepare future two-year college faculty (Fearing; Madden; Choseed; Griffiths), particularly in light of the potentially-shifting landscape of higher education. Indeed, the Two-Year College English Association (TYCA) 2016 "Guidelines for Preparing Teachers of English in the Two-Year College" makes the "radical" recommendation that

all graduate students should be made knowledgeable about two-year colleges and their students and faculty, regardless of whether they plan to teach and/or research in these settings. This shift aligns with recent calls in the Modern Language Association (MLA) to reform graduate education from a 'narrative of replication to a narrative of transformation' (MLA Task Force 12). Such transformation should, the Guidelines argue, include presenting all English studies professionals with an accurate and fair-minded representation of the actual landscape of postsecondary literacy instruction in the United States. (Jensen and Toth 562-3)

Such a transformation in graduate education would necessarily rely on stronger interinstitutional ties and dialogues, and interrupting the cultural narratives about the institutional settings in which the work of Composition Studies takes place.

\section{Conclusion}

The literature reviewed suggests that the idea of the underrepresentation and apparent marginalization of two-year colleges within higher education overall and twoyear college writing faculty within the discipline more specifically has essentially become a cultural trope, a stock disciplinary narrative that imbues the nearly-mythical figure of the two-year college writing instructor with traits and attitudes that are heavily contested by some (e.g., Tinberg), while just as strongly upheld by others (e.g., Nist and 
Raines). Institutional histories of two-year colleges further reify the tensions of the twoyear college identity/ies, on the one hand painting a picture of an institution democratizing education and uplifting communities, on the other, portraying an institution caught in the lower ranks of the hierarchical systems of education-while, with an unlikely third, describing a site instituted primarily to serve the economy by producing trained workers. These various institutional identities further complicate the professional identities of two-year college faculty, and those who teach writing at twoyear colleges seem to disagree on whether they do or do not, as a collective, actively participate in traditional scholarly activities such as conducting research and publishing. As Toth points out, the picture of two-year college writing faculty painted by the existing disciplinary literature is complex and conflicted. To that end, this study intervenes at the intersection of these conflicting identities, by investigating the recent presence of twoyear college faculty within some of the discipline's prominent journals, to see what is actually in the record of scholarly publications, and by interviewing two-year college writing faculty about their professional practices and identities, including and beyond their teaching.

\section{Methods and Methodology}

The research I conducted for this dissertation was comprised of two modes of data collection:

1) Conducting keyword searches within six prominent Composition Studies journals

2) Interviewing individuals who currently (at the time of the interview) taught at least one writing course at a two-year college in the Southeast 
I chose to collect data from both of these sources because, while other studies have investigated similar research questions to mine—e.g., Palmer (1992); Nist and Raines (1993); Goggin (2000); ${ }^{16}$ Taylor (2009); Hassel (2013); and Toth (2014)—with the exception of Toth's, none take the same approach as my study. And, while Toth's study does have two sources of data, Toth's data is derived interviews and from two-year college writing faculty's participation at conferences and in professional organizations sponsored by NCTE—not journal publications, as mine is. Furthermore, in her study, Toth sought data on the institutional affiliations from NCTE members and conference attendees, in order to get a sense of how involved two-year college faculty are in such organizations. She later chose to add an interview component, and then conducted interviews based on the data collection and analysis that took place in the first portion of her study. Given the similarities between our research questions, and because these later interviews illuminated Toth's initial findings, instead of focusing solely on journal publications, I decided to build interviews into my initial plans for this study. Furthermore, while the data I gathered from the journals has provided a broad view of the public, published face of the scholarly contributions of two-year college writing faculty, it did not provide information on the reasons behind why two-year college writing faculty do (or do not) publish in the journals I analyzed—nor answer questions about their perceptions of the complex identities that are seen in existing literature, or their own professional practices and self-identities. As such, and because I sought to examine and understand the professional voices of two-year college faculty in Composition Studies, it

\footnotetext{
${ }^{16}$ Goggin's study of disciplinary journals, though foundational to how I have conceptualized the journal component of my own study - and impressive in its comprehensive scope-was published nearly two decades ago, and I seek to examine more recent publication trends.
} 
was important to me, as a researcher, to listen to those individual voices themselves, and to examine how faculty's own lived experiences match or further complicate the narratives of two-year college faculty established in our disciplinary discourse.

\section{Interviews}

In Spring 2017, I interviewed seven individuals who, at the time, taught at least one writing course at a community college in the Southeast. In order to seek participants, I used a combination of convenience sampling and a limited version of snowball sampling: As a former community college instructor who has networked in two-year college (TYC) circles at national conferences and attended regional TYC conferences, such as the Two-Year College English Association-Southeast (TYCA-SE), I first reached out to a selection of existing contacts who either were or knew community college writing faculty. I relied on such contacts because of the documented tensions between two-year and four-year settings. ${ }^{17}$ Initially, I asked these contacts (1) If they were eligible and would be willing to be interviewed for the study, and (2) If they knew of any colleagues who might also be interested in participating. Some replied with suggestions of specific individuals to contact, and others requested my permission to circulate my IRB-approved recruitment email ${ }^{18}$ among their colleagues. To my knowledge, the recruitment email was circulated through at least two college-wide English departments or divisions. Participation in the study was voluntary, and those who responded to my recruitment email self-selected to participate. In order to get as wide a range of participant voices as possible (Maxwell 89), the criteria to participate in my study was minimal-eligible participants were:

${ }^{17}$ Described in more depth in the preceding literature review.

${ }^{18}$ See Appendix A. 
1) Employed at a two-year college, and

2) Teaching at least one writing course at the two-year college.

In all, seven full- and part-time faculty from four community colleges chose to participate in the study (see Table 1).

Table 1: Interview Participant Profiles ${ }^{19}$

\begin{tabular}{|c|c|c|c|}
\hline Participant & School(s) & \# Years at CC & Position at CC \\
\hline Amelia & $\begin{array}{c}\text { Rock Creek Community } \\
\text { and Technical College } \\
\text { (Sycamore and Chestnut } \\
\text { Campuses) }\end{array}$ & 12 & $\begin{array}{l}\text { Associate Professor } \\
\text { (English) }\end{array}$ \\
\hline Audrey & $\begin{array}{c}\text { Bradford State } \\
\text { Community College } \\
\text { (South and East } \\
\text { Campuses) }\end{array}$ & 2 & $\begin{array}{l}\text { Part-time adjunct } \\
\text { instructor (English); } \\
\text { Tutor (Writing Center) }\end{array}$ \\
\hline Donna & $\begin{array}{c}\text { Rock Creek Community } \\
\text { and Technical College } \\
\text { (Sycamore and Chestnut } \\
\text { Campuses) }\end{array}$ & 18 & Professor (English) \\
\hline Henry & $\begin{array}{c}\text { Mountain Hill } \\
\text { Community and } \\
\text { Technical College }\end{array}$ & 4 & $\begin{array}{l}\text { Assistant Professor } \\
\text { (English) }\end{array}$ \\
\hline Lois & $\begin{array}{l}\text { Forest Lake Community } \\
\text { and Technical College; } \\
\text { Valley Way University }\end{array}$ & 12 & $\begin{array}{l}\text { Part-time adjunct } \\
\text { instructor (English) }\end{array}$ \\
\hline Ruby & $\begin{array}{c}\text { Bradford State } \\
\text { Community College } \\
\text { (North Campus) }\end{array}$ & 10 & $\begin{array}{l}\text { Assistant Professor } \\
\text { (English) }\end{array}$ \\
\hline Sally & $\begin{array}{c}\text { Rock Creek Community } \\
\text { and Technical College } \\
\text { (Pine and Oak } \\
\text { Campuses) }\end{array}$ & 12 & Professor (English) \\
\hline
\end{tabular}

I interviewed each participant once during March and April 2017, and all interviews were scheduled at the convenience of participants. Each interview took place in person, on or near one of the participant's campuses (all but two participants, Ruby and Lois, teach on multiple campuses) — times and locations were selected by and

${ }^{19}$ All participant and school names used are pseudonyms. 
convenient to participants. Interviews ranged from forty minutes to seventy-five minutes, and were audio-recorded and transcribed. At the beginning of each interview, prior to turning on the audio recorder, I explained the purpose of my study and the IRB-approved informed consent form, and asked participants to sign informed consent documents, a copy of which they were given for their records. I also offered participants a copy of the interview questions I had prepared, ${ }^{20}$ so they could see the topics I planned to cover; asked participants what pseudonyms they wanted me to use in my writing about the study; and asked if they had a specific time that they needed to end the interview. Throughout this pre-interview process, I gave participants opportunity to ask any questions before proceeding with the interview itself. Once I confirmed that participants were ready, I turned on the audio recorder and began with the first interview question I had prepared. While all of the interviews began with the same first, open-ended question (Anderson and Jack $24^{21}$ ), each conversation took a different direction and shape, depending on the participant. In general, though, participants and I discussed their professional lives, including their workload and the different components of their positions at their community colleges. In doing so, we also talked about how frequently they write for publication or present at conferences, their experiences doing so (or not doing so), and why or why not they choose to pursue publication and/or present at conferences; what kinds of things they most often read and write, either for work or outside of work; the conditions that allow or constrain their ability to conduct research,

\footnotetext{
${ }^{20}$ See Appendix B.

${ }^{21}$ Anderson and Jack write specifically about collecting oral histories. I acknowledge that the interviews I conducted were not oral histories; however, the interactive interview strategies to promote listening that they discuss are applicable to other kinds of interviews, as well.
} 
write for publication, or present at conferences; what is generally rewarded or valued professionally in their institutional setting; and what kinds of professional communities they see themselves as belonging to. Additionally, some participants shared or offered to share documents with me that were related to the topics we discussed. ${ }^{22}$ Throughout the interviews, I remained conscious of the time, so as to respect participants' time. ${ }^{23}$

While I acknowledge that my research design did not allow for the type of true collaboration and deep relationship-building described by feminist researchers such as Kirsch and Powell and Takayoshi-as I only interviewed participants once-it is important for me to also acknowledge that such feminist methodologies have shaped the way that I think about the ethics of qualitative research in general, and have informed how I conducted this study. For example, Powell and Takayoshi point out that "feminist researchers are deeply concerned $[\ldots]$ about the roles of researchers and participants, $[\ldots]$ and about honoring the voices of all participants" (8). Such concerns are especially significant for this study, as I sought what appeared to be - based on the literature reviewed - the largely unheard stories of two-year college writing faculty. As such, it has remained important to me, both personally and as a researcher, to honor the range of my participants' voices. To the best of my ability, I tried set up the interviews so that participants were able to guide me through their telling of their own stories. Toward that end, interviews were semi-structured (Selfe and Hawisher) and interactive (Anderson and Jack). Though participants were asked the same basic set of questions, copies of which

\footnotetext{
${ }^{22}$ For example, Henry came to the interview prepared with notes about topics he wanted to mention during the interview, as well as documents such as advising handouts, to aid in his descriptions of the various facets of his job responsibilities.

${ }^{23}$ While respect for participants' time is a consideration for all qualitative researchers, it was especially important for this group of participants, in light of the serious time constraints they described to me during their interviews (discussed in Chapter Two).
} 
they were offered beforehand, we did not follow a script: interviews were conversational and tended to flow from topic to topic, follow-up questions were based on participants' individual responses, and, as much as possible within the constraints of the interview, participants guided the course of the conversation. Additionally, my listening to participants interviews was influenced by the tradition of feminist oral history. Anderson and Jack write that, "in order to learn to listen, we need to learn to attend more to the narrator than to our own agendas" as researchers (12). In their discussion of oral history interviews they had previously conducted, Anderson and Jack reflect on how their interview strategies did not always foster deep listening on their parts. Anderson notes how, during one interview, she found herself "already thinking about patterns" while the participant was answering the previous questions (15), and Jack describes the strategies she has developed to "listen to interviews without immediately leaping to interpretations," arguing that "the first step is to immerse ourselves in the interview" (19). Toward that end, I remained open to participants guiding the conversation toward topics as they came up, and I made a conscious decision to put my pen down during the interviews (which were audio-recorded), so that I could focus my attention on listening, not taking notes about my own observations, thoughts, or interpretations.

My conception of the design and implementation of this study was also influenced by Grabill's discussion of the importance of clearly articulating one's research stance, which he describes as "something like a 'position' relative to issues like purposes, goals, and methods for research"; "in other words," Grabill continues, "one's stance as a researcher is an answer to [questions of]" one's identity and purposes as a researcher, as well as questions of power and ethics (215). I must acknowledge, then, that given the 
complexities of the professional identities of two-year college faculty portrayed in the reviewed literature, as well the long, tension-fraught history that looms over many relationships between two-year colleges and four-year research universities, my own position - a researcher from a four-year university, who used to work in a two-year college before leaving to pursue the doctoral degree for which this study was conducted — may have complicated how my participants and I related to one another. To some of these faculty, such as Sally and Donna, I may have appeared to embody or reflect some of those interinstitutional tensions, as the fact of my university-status seemed to be a point of discord,$^{24}$ whereas for others, such as Amelia, my dual university and two-year college experiences provided common ground and, thus, identification between our shared professional interests.

Throughout the study, I strove to remain mindful of how I approached potential participants and conducted interviews, and worked to be continually cognizant of how my positionality took shape in—and shaped—our conversations, by paying close attention to how participants responded to me (Chiseri-Strater 125). Toward that end, I maintained a research journal throughout the study, and, immediately after each interview, I noted my initial thoughts and impressions, and reflected on the interaction between myself and the participant, including how each participant seemed to relate or respond to me, as well as I to them, and ways to improve. Such reflections influenced how I approached each subsequent interview.

My analysis of interview data was informed by The Listening Guide, a "specific interpretive method" developed within the discipline of Psychology in the 1980s and

\footnotetext{
${ }^{24}$ Discussed more thoroughly in Chapters Three and Four.
} 
1990s by Lyn Mikel Brown, Carol Gilligan, and others (Tolman and Miller 600-601; Gilligan 69-70). This analytical tool is premised, in part, on the idea of responsive listening (Gilligan and Eddy 80). Tolman and Miller explain that "The Listening Guide is one of the few specifically psychological systematic approaches for examining multiple layer of meaning in experiential narratives and descriptions" it is "is a very flexible method that can be applied to many types of narrative data" (Tolman and Miller 601), and has been used to analyze a wide range of data, including written documents (Gilligan 70-71). This analytical method is distinct from coding, and "incorporate[es] aspects of thematic and narrative analysis as well as elements of a grounded theory approach" (Gilligan and Eddy 76-77); one of its distinguishing features is the series of successive “"listenings,"” each of which "guid[es] a different path through the narrative" (Gilligan and Eddy 78). In other words, each "listening" of a narrative has a specific focus. Such an approach allowed me to maintain the importance of listening to my own stance as a researcher and in my interactions with my participants, as described above.

After conducting the interviews, I transcribed each using the program, InqScribe. Because I transcribed each interview in its entirety, the act of transcribing was, in itself, a first "listening," the focus of which was listening for the "features" of each narrative "landscape" (Gilligan and Eddy 78). Furthermore, because The Listening Guide is a way of "listening for what is unspoken as well as for what is said" (Gilligan and Eddy 76), I also noted in my transcripts nonverbal cues, such places where participants paused or laughed (e.g., "[short pause]"; "[long pause]"; "[laughs]"; "[both laugh]"). The inclusion of cues helped guide subsequent readings of participants' responses and apparent attitudes (Anderson and Jack 17). As noted above, The Listening Guide has 
been adapted to analyze a variety of data, including written documents; upon finishing transcribing, I printed out the transcripts, and read each multiple times. During the first reading (or "listening") of the transcripts, I read without making any marginal notes, so as to, once again, familiarize myself with the "terrain" of each (Gilligan and Eddy 78), now that it was in a different medium (written, not audio). After this first round of reading, I reflected in my research journal on the prominent themes I observed. Then, I read the transcripts multiple times, focusing on the following themes:

- Working with students;

- Collaboration and relationships between colleagues;

- Research, writing for publication, and scholarly teaching;

- Participants' professional identities and positions, including how they came to work in a community college, and the stages they were at in their careers;

- Differences between two-year and four-year institutional settings;

- The material conditions of participants' workplaces, including workload, time, money, and specific institutional policies; and

- The impact of location on their work (e.g., state-level policies or economic conditions; specific community needs).

During and after each reading, I took marginal notes and reflected in my research journal on the connections I saw between themes and transcripts. Additionally, I returned to the audio recordings as necessary, to confirm the accuracy of my transcriptions.

\section{Journals}

In addition to the interviews of writing faculty at two-year colleges, I also examined patterns and trends in the scholarly conversations circulated within six 
prominent disciplinary journals (see Table 2). I chose these journals in order to attempt to capture as wide a range of the field as possible, while at the same time attempting to keep the size of this particular component of my study reasonable, given the time constraints for completing this study. In general, I consider each journal a sample of a larger strand of disciplinary conversation, as explained in the journal descriptions in Table 2, below.

Table 2: Journal Profiles

\begin{tabular}{|c|c|}
\hline Journal & $\begin{array}{c}\text { Description, \# Issues/Year, and } \\
\text { Avg. \# Articles/Issue }\end{array}$ \\
\hline $\begin{array}{c}\text { College } \\
\text { Composition } \\
\text { and } \\
\text { Communication } \\
\text { (CCC) }\end{array}$ & $\begin{array}{l}\text { "College Composition and Communication publishes research and } \\
\text { scholarship in rhetoric and composition studies that supports college } \\
\text { teachers in reflecting on and improving their practices in teaching } \\
\text { writing and that reflects the most current scholarship and theory in the } \\
\text { field. The field of composition studies draws on research and theories } \\
\text { from a broad range of humanistic disciplines-English studies, } \\
\text { rhetoric, cultural studies, LGBT studies, gender studies, critical } \\
\text { theory, education, technology studies, race studies, communication, } \\
\text { philosophy of language, anthropology, sociology, and others-and } \\
\text { from within composition and rhetoric studies, where a number of } \\
\text { subfields have also developed, such as technical communication, } \\
\text { computers and composition, writing across the curriculum, research } \\
\text { practices, and the history of these fields." (NCTE) } \\
\text { \# Issues/Year: } 4 \\
\text { Avg. \# Articles/Issue: } \mathbf{5} \\
\text { Based on } 2016 \text { issues }\end{array}$ \\
\hline $\begin{array}{l}\text { College English } \\
\qquad(C E)\end{array}$ & $\begin{array}{l}\text { "College English is the professional journal for the college scholar- } \\
\text { teacher. } C E \text { publishes articles about literature, rhetoric-composition, } \\
\text { critical theory, creative writing theory and pedagogy, linguistics, } \\
\text { literacy, reading theory, pedagogy, and professional issues related to } \\
\text { the teaching of English. Issues may also include review essays. } \\
\text { Contributions may work across traditional field boundaries; authors } \\
\text { represent the full range of institutional types." (NCTE) }\end{array}$ \\
\hline
\end{tabular}

${ }^{25}$ I found this number by hand-counting the number of articles included in each issue of the journal (either from 2016 or last four years, as indicated), then calculating the average for the number of issues counted from. It does not include reviews, chair letters and talks, comments and responses, or other types of pieces included — only articles and essays. 


\begin{tabular}{|c|c|}
\hline & $\begin{array}{c}\text { \# Issues/Year: } 4 \\
\text { Avg. \# Articles/Issue: } \mathbf{6} \\
\text { Based on } 2016 \text { issues }\end{array}$ \\
\hline $\begin{array}{c}\text { Computers and } \\
\text { Composition: } \\
\text { An } \\
\text { International } \\
\text { Journal } \\
(\text { CandC })\end{array}$ & $\begin{array}{l}\text { "Computers and Composition: An International Journal is devoted to } \\
\text { exploring the use of computers in writing classes, writing programs, } \\
\text { and writing research. It provides a forum for discussing issues } \\
\text { connected with writing and computer use. It also offers information } \\
\text { about integrating computers into writing programs on the basis of } \\
\text { sound theoretical and pedagogical decisions, and empirical evidence. } \\
\text { It welcomes articles, reviews, and letters to the Editors that may be of } \\
\text { interest to readers, including descriptions of computer-aided writing } \\
\text { and/or reading instruction, discussions of topics related to computer } \\
\text { use of software development; explorations of controversial ethical, } \\
\text { legal, or social issues related to the use of computers in writing } \\
\text { programs; and to discussions of how computers affect form and } \\
\text { content for written discourse, the process by which this discourse is } \\
\text { produced, or the impact this discourse has on an audience. Further } \\
\text { information about the journal can also be found at a website } \\
\text { maintained by the editors." (Elsevier ScienceDirect) } \\
\text { \# Issues/Year: } 4 \\
\text { Avg. \# Articles/Issue: } \mathbf{8} \\
\text { Based on } 2016 \text { issues }\end{array}$ \\
\hline $\begin{array}{c}\text { Journal of } \\
\text { Basic Writing } \\
(J B W)\end{array}$ & $\begin{array}{l}\text { "The Journal of Basic Writing is a national refereed print journal } \\
\text { founded in } 1975 \text { by Mina Shaughnessy, who served as the journal's } \\
\text { first editor. } J B W \text { is published twice a year with support from the } \\
\text { Office of Academic Affairs of the City University of New York. } \\
\text { Basic writing, a contested term since its initial use by Shaughnessy in } \\
\text { the } 1970 \mathrm{~s} \text {, refers to the field concerned with teaching writing to } \\
\text { students not yet deemed ready for first-year composition. Originally, } \\
\text { these students were part of the wave of open admissions students who } \\
\text { poured into universities as a result of the social unrest of the } 1960 \mathrm{~s} \\
\text { and the resulting reforms. Though social and political realities have } \\
\text { changed dramatically since then, the presence of 'basic writers' in } \\
\text { colleges and universities-and the debates over how best to serve } \\
\text { them - have remained. } \\
J B W \text { publishes articles related to basic and second-language writing } \\
\text { using a variety of approaches: speculative discussions that venture } \\
\text { fresh interpretations; essays that draw heavily on student writing as } \\
\text { supportive evidence for new observations; research reports written in } \\
\text { non-technical language that offer observations previously unknown or }\end{array}$ \\
\hline
\end{tabular}




\begin{tabular}{|c|c|}
\hline & $\begin{array}{l}\text { unsubstantiated; and collaborative writings that provocatively debate } \\
\text { more than one side of a critical controversy." ( } J B W \text { website) } \\
\text { \# Issues/Year: } 2 \\
\text { Avg. \# Articles/Issue: } 2 \\
\text { Based on last four years (2013-2016) }\end{array}$ \\
\hline $\begin{array}{c}\text { Teaching } \\
\text { English in the } \\
\text { Two-Year } \\
\text { College } \\
\text { (TETYC) }\end{array}$ & $\begin{array}{l}\text { "Teaching English in the Two-Year College (TETYC), the journal of } \\
\text { the Two-Year College English Association (TYCA), is for instructors } \\
\text { of English in two-year colleges as well as for teachers of first- and } \\
\text { second-year composition in four-year institutions. TETYC publishes } \\
\text { theoretical and practical articles on composition, developmental } \\
\text { studies, technical and business communication, literature, creative } \\
\text { expression, language, and the profession. Published September, } \\
\text { December, March, and May." (NCTE) } \\
\text { \# Issues/Year: } 4 \\
\text { Avg. \# Articles/Issue: } 4 \\
\text { Based on } 2016 \text { issues }\end{array}$ \\
\hline $\begin{array}{l}\text { WPA: Writing } \\
\text { Program } \\
\text { Administration } \\
(W P A)\end{array}$ & $\begin{array}{l}\text { "WPA: Writing Program Administration publishes empirical and } \\
\text { theoretical research on issues in writing program administration. We } \\
\text { publish a wide range of research in various formats, research that not } \\
\text { only helps both titled and untitled administrators of writing programs } \\
\text { do their jobs, but also helps our discipline advance academically, } \\
\text { institutionally, and nationally. WPA Writing Program Administration } \\
\text { is published twice a year: fall and spring." (CWPA website) } \\
\text { \# Issues/Year: } 2 \\
\text { Avg. \# Articles/Issue: } \mathbf{5} \\
\text { Based on last four years (2013-2016) }\end{array}$ \\
\hline
\end{tabular}

Searching the Journals

The process of my journal searches was ongoing through the entirety of the process of conducting interviews (beginning with the IRB application and approval, all the way through transcription, analysis, and writing up findings from the interviews). From December 2016 to July 2017, I conducted keyword searches in the online archives 
of the journals named above $(C C C, C E, C a n d C, J B W, T E T Y C$, and $W P A)$, in order to find pieces published in the journals related to two-year colleges. Because I was focused specifically on recent trends, I limited my searches to the issues of these journals published in the last seven years (2010-2016). I also sought to identify trends in these journals, and so also searched a small selection of previous years_-1995, 2000, and 2005 - in order to see if there were any major changes in these trends over time. I began broadly, originally seeking pieces both written by TYC authors, as well as pieces written about two-year colleges. However, because of the large amount of data yielded (e.g., the total number of results yielded for keyword searches in all of the journals, except for TETYC, ${ }^{26}$ was 384$)$, I instead chose to focus my attention only on pieces returned in the searches that were written by at least one author affiliated with a two-year college at the time of publication, as indicated in the journal (out of the 384 search results yielded, only 66 pieces fall into this category, or approximately $17 \%$ of the search results from $C C C$, $C E, C a n d C, J B W$, and $\left.W P A^{27}\right)$. By including only pieces that indicate the author currently — at the time of publication/writing — is affiliated with a current $\mathrm{TYC}^{28}{ }^{28}$ journal data is kept in line with interview data (i.e., all participants, at the time of their interviews, teach at a two-year college).

Because past issues of the journals I selected are archived differently (e.g., $C C C$ and $C E$ are available in both the JSTOR and Literature Online databases, with different years available in each database, while each past issue of $W P A$ is housed as a

\footnotetext{
${ }^{26}$ My collection of data from TETYC differed from the other five journals, as described below.

${ }^{27}$ See previous footnote.

${ }^{28}$ For example, the institutional affiliation of Andrews in the 2000 TETYC issue 28.2, is listed as Penn State Abington, "a former two-year, now a four-year branch," and so this author would not count as a TYC author for the purposes of my data collection.
} 
downloadable-PDF on the Council of Writing Program Administrators' website), I had to navigate the search functions of each specific database or archive differently. Generally, though, I conducted keyword searches of the following terms: "two-year college," "community college," "technical college," and "junior college." Data collection for all of the journals began in this way; however, as described in more detail below, eventually differed for $W P A$ and, more notably, TETYC, as I had to adapt and refine my search methods for each individual journal as I continued my data collection.

My selection of the four original keywords ("two-year college," "community college," "technical college," and "junior college") was based on language used by the American Association of Community Colleges, my own knowledge of two-year colleges, and preliminary keyword searches in College Composition and Communication, College English, and WPA: Writing Program Administration that I began in Fall 2015. These preliminary searches began with a total of six potential keywords, and entailed searching the entirety of the journals' archives (beginning with their first issues) in order to get a sense of how and where the keywords show up over decades of publications. Based on the results yielded from these exploratory preliminary searches, the four keywords listed above ("two-year college," "community college," "technical college," and "junior college") proved to be the most productive keywords to searching the journals for mentions of two-year colleges, which then led me to pieces authored by TYC-affiliated contributors.

As noted above, each iteration of my search in the online archives of $C C C, C E$, CandC, JBW, TETYC, and WPA was, out of necessity, different, and those differences were based on the housing of the online archives of journal back issues (see Table 3 
below for a brief description of where searches for each journal were conducted). Though the databases Literature Online and Communications \& Mass Media Complete do contain journal archives for most of the years I searched within $C C C, C E$, and $J B W$, I elected to use JSTOR for searches up to 2012 (when its availability ends), because of its ease of use, and because its archives seem to be better tagged and organized than those in $L I O N$.

Table 3: Journals, Years, and Databases Searched

\begin{tabular}{|c|c|c|}
\hline Journal & Years Searched & Database \\
\hline \multirow{2}{*}{$\begin{array}{c}\text { College Composition and } \\
\text { Communication } \\
(\text { CCC })\end{array}$} & $\begin{array}{c}\text { 1995, 2000, 2005, 2010 } \\
2011,2012\end{array}$ & JSTOR \\
\hline & 2013, 2014, 2015, 2016 & Literature Online (LION) \\
\hline \multirow{2}{*}{$\begin{array}{l}\text { College English } \\
\qquad(C E)\end{array}$} & $\begin{array}{c}1995,2000,2005,2010 \\
2011,2012\end{array}$ & JSTOR \\
\hline & $2013,2014,2015,2016$ & Literature Online $(L I O N)$ \\
\hline $\begin{array}{c}\text { Computers and } \\
\text { Composition: An } \\
\text { International Journal } \\
(\text { CandC })\end{array}$ & $\begin{array}{c}1995,2000,2005,2010 \\
2011,2012,2013,2014 \\
2015,2016\end{array}$ & Elsevier Science Direct \\
\hline \multirow[b]{2}{*}{$\begin{array}{c}\text { Journal of Basic Writing } \\
(J B W)\end{array}$} & $\begin{array}{c}1995,2000,2005,2010 \\
2011,2012\end{array}$ & JSTOR \\
\hline & $\begin{array}{c}2013,2014,2015 * \\
\text { *2016 data unavailable at } \\
\text { time of JBW search }\end{array}$ & $\begin{array}{l}\text { Communications \& Mass } \\
\text { Media Complete }(C M M C)\end{array}$ \\
\hline $\begin{array}{c}\text { Teaching English in the } \\
\text { Two-Year College } \\
\text { (TETYC) }\end{array}$ & $\begin{array}{c}1996^{*}, 2000,2005,2010 \\
2011,2012,2013,2014 \\
2015,2016\end{array}$ & $\begin{array}{l}\text { Literature Online (LION) } \\
\text { and the National Council of } \\
\text { Teachers of English (NCTE) } \\
\text { website }\end{array}$ \\
\hline
\end{tabular}




\begin{tabular}{|c|c|c|}
\hline & $* 1995$ data unavailable & \\
\hline $\begin{array}{c}\text { WPA: Writing Program } \\
\text { Administration } \\
(W P A)\end{array}$ & $\begin{array}{c}1995,2000,2005,2010, \\
2011,2012,2013,2014,\end{array}$ & $\begin{array}{c}\text { PDFs of each issue } \\
\text { downloaded from Council } \\
\text { of Writing Program } \\
\text { Administrators (CWPA) } \\
\text { website }\end{array}$ \\
\hline
\end{tabular}

Overall, searching within $C C C, C E$, $C a n d C$, and $J B W$ was fairly straightforward. Each search began by accessing the journal in the database (as indicated above in Table 3) through the University of Louisville's library website, and a separate Boolean phrase keyword search was conducted for each keyword within the range of each year for each publication. Once results were returned, I exported the results (i.e., their citations) into EndNote, tagging each citation with the keyword that yielded it, to be able to account for multiple keywords fetching a single piece, so as to not count a single piece multiple times. In addition to my EndNote library, I also took careful and detailed notes in a separate document, in which I listed the results yielded for each keyword for each year of each journal.

$W P A$ searches differed slightly from $C C C, C E$, Cand $C$, and $J B W$, as back issues of this journal are not housed in a database, but, instead, are available as downloadable PDFs on the CWPA website. Instead of conducting my keyword searches within online databases such as JSTOR, for WPA, I searched within each issue's PDF itself, using the "Search" function in Preview, a PDF-viewer, to search each PDF for each keyword. Preview's "Search" function also allowed me to navigate through each PDF to places in the issue where a keyword was located; I highlighted at least one instance of each keyword on each page it appeared (not highlighting, in other words, multiple keyword 
results on a single page), so as to be able to find results in each PDF without having to repeat a search. As with $C C C, C E, C a n d C$, and $J B W$, I took careful and detailed notes of each search, noting each article or other type of piece within a journal that contained the keywords I was searching, and the keywords they contained. Because I downloaded the PDFs I was searching, and was not searching within a database, I did not export citations for $W P A$ search results to EndNote.

Finally, TETYC was more difficult to search than the other journals. Initially, I conducted Boolean phrase keyword searches of TETYC in Literature Online, as I did other journals housed in that database. After compiling my lists of the search results for each year, I discovered that the keyword search, "two-year college," yielded the entire contents of each journal issue, as this keyword is included in the title of the journalwhich is printed on every page of every issue. Consequently, I was forced to repeat these searches anew. So that I did not have to download each separate piece of each issue as a PDF, ${ }^{29}$ I viewed all of the contents of each year's issues within my web browser, checking for the institutional affiliation of the author of each piece, and cross-checking against the online archives of back issues on the NCTE website if necessary. If a piece had an author with a two-year college affiliation, I noted it on my list and spreadsheet. The only difference in my TETYC documents is that results are not tagged with the keyword that returned them, because I ultimately did not use the keywords to find the institutional affiliations of authors (the keywords did not work as intended for this particular journal).

\footnotetext{
${ }^{29}$ Issues of the journal are not available as one PDF; instead, each piece contained in an issue is available as a separate PDF.
} 
Once my initial searches were complete, and my lists compiled, I created a spreadsheet for each journal. These master spreadsheets are a compilation of data: year, volume and issue number, author(s), institutional affiliation(s) of author(s), title of piece, type of piece (e.g., article, co-authored article, review, front matter), keyword(s) that yielded the result (except for TETYC), and any additional notes. I found the institutional affiliation of each author based on what was listed in the journal, as all of these journals include institutional affiliations for contributors. In some cases, if it was not clear from the name of the institution (e.g., if it was not something as straightforward as, say, LaGuardia Community College, or if an institution name seemed to indicate a regional campus - the University of Wisconsin system, for example, includes regional two-year campuses), I looked the institution up online to determine whether or not an author had a two-year college affiliation. Because some two-year colleges now offer Bachelor's degrees in certain areas $(A A C C)$, and understandings of two-year colleges vary (Vaughan, Community College Story), it is sometimes difficult to typify this kind of institution. If a school's website did not explicitly describe the institution as a two-year or community college, I based my classification on these three characteristics (in line with the AACC website and Vaughan's descriptions of this institutional setting): open admissions, primarily associate's degree-granting, and community-focused mission.

Once authors' institutional affiliations were determined, I then marked by highlighting the pieces that had at least one author affiliated with a two-year college at the time of publication (except for TETYC, because all of the results on the spreadsheet for this journal were from TYC-affiliated contributors). TYC-results were then put into separate spreadsheets, so that I could focus my analysis only on those pieces with a TYC- 
affiliated author. For $C C C, C E, C a n d C, J B W$, and $W P A$, all of the keyword searches for the ten years I focused on, a total of $384^{30}$ results were returned; of those 384 , only $66-$ or $17 \%$-were pieces that were contributed by at least one TYC-affiliated author. And, of these 66 pieces, only $36-54.5 \%$ - were articles, the majority of which were co-authored. In addition to these master spreadsheets, I also created two documents for coding purposes, one for $C C C, C E$, Cand $C, J B W$, and $W P A$ results (journals primarily associated with four-year institutions), and one for TETYC results. I kept these two documents separate because of the disparity in the number of results for these two groups. These documents include the following information for each piece contributed by a TYCaffiliated author: title of piece, author(s) and their institutional affiliation, volume and issue number of journal, type of piece, and abstract. Finally, it is important to note that I chose not to include pieces from FORUM: Issues about Part-Time and Contingent Faculty in my tabulated data, as it is a separate journal that is published within TETYC and $C C C$; similarly, I chose not to include the "TYCA to You" Newsletter in TETYC, because it, too, appears to be a separate publication, and is not included in the Tables of Contents for TETYC back issues on the NCTE website.

\section{Analysis of Journal Data}

As discussed in the opening of this chapter, my decision to include disciplinary journals as a source of data in this project is premised on a framework provided by Hyland, Goggin, and Bruner. From this perspective, I understand disciplines to be social and cultural enterprises (Hyland); the written scholarship published within a discipline, such as journal articles, both reflects and shapes the social practices of these "cultures"

\footnotetext{
${ }^{30}$ Number adjusted to account for pieces that came up in multiple keyword searches.
} 
(Hyland; Goggin), as they are a key means by which a discipline's cultural narratives accrue, and so help establish cultural norms (Bruner). My initial approach to the collection and analysis of journal data was influenced by the techniques of distant reading, a methodology first articulated in 2000 by Moretti, who describes a technique of reading a large quantity of texts, in which one reads "the primary texts at one level removed" (Erlin and Tatlock 2-3). Moretti offers distant reading as an alternative to close reading, and argues that "distance [...] is a condition of knowledge: it allows you to focus on units that are much smaller or much larger than the text: devices, themes, tropes-or genres and systems" (57, emphasis in original). For the purposes of my own study, I intended to engage in a distant reading of the themes of works by two-year college faculty: Moretti argues that distant reading allows for "[understanding] the system in its entirety" (57), and I sought to better understand the role of two-year college faculty in the landscape of disciplinary scholarship, and the subsequent cultural narratives that accrue within that system.

To engage in such a close reading, I planned to look for works contributed by two-year college faculty, including the types of journal publications attributed to two-year college faculty, the subjects of those publications, and where in the journals TYC faculty contributions are located. More specifically, I sought to identify and analyze the following:

- The institutional affiliations of contributors to the journal, and the kinds of journal contributions that are attributed to two-year college faculty (e.g., article, review, etc.), as well as the percentage of the journal contributions ascribed to two-year college faculty. 
- Patterns or trends in the subject or topic of those contributions, in order to get a sense of what two-year college faculty write about in these journals (depending on the volume of search results, I planned to code the titles, abstracts, and/or full articles)

- The type (e.g., article, book review, instructional note) and placement (e.g., front matter or back matter, CFPs, special issues, etc.) of two-year college-affiliated contributors within the journal

The thematic analysis I planned (second item on the list above) was to be guided by a recent similar study of journal scholarship: Hassel's 2013 study of the journal Teaching English in the Two-Year College, in which she similarly analyzed thematic trends in journal articles. Specifically, Hassel's study “provides an assessment of the research achievements in two-year college English," identifying gaps and making recommendations for areas of future research for two-year college English teacherscholars (343). Hassel reviewed forty-five issues of TETYC, focusing specifically on "Feature" articles, as these are the pieces "most likely to engage in longer, sustained arguments and to draw from systematic research," and, using Strasma and Resnick's 1999 essay identifying "identifying areas of needed research," categorized these articles, first, by methodology, and then subcategorized them by theme (343-4). I intended to similarly identify and categorize TYC-contributed pieces thematically, based on titles and abstracts, and drawing on Hassel's thematic categories (because of her similar focus on two-year college English). 
However, due to the sheer amount of data my keyword searches yielded, ${ }^{31}$ in conjunction with the time constraints of this study, as dictated by my dissertation schedule, for this dissertation, I was only able to accomplish the first item on the list above, and my analysis of the journal data I collected was restricted to the institutional affiliations of contributors to these journals. Still, the data was rich and the findings illuminating, as thoroughly discussed at the beginning of Chapter Three. To analyze this data, I first identified that TYC-authored pieces that were more traditional research articles (in line with Hassel's 2013 study); then, through a series of careful calculations, I found the average number of such articles that appear in each journal annually (based on the number of issues annually published, noted in Table 2, above). ${ }^{32}$ This restricted analysis of journal data (the institutional affiliations of contributors) is one of the limitations of this study, and a thematic analysis of other components of the journal data collected (e.g., titles and abstracts of articles) is an area for further research.

\section{Limitations and Areas for Future Research}

Two of the limitations of this study are the small sample size of participants, and the criteria for participation, which stated that participants must be teaching a writing course at a community college during the semester in which they were interviewed. Consequently, some of the participants did not identify strictly or primarily as part of the discipline of Composition Studies; however, this reflects the tendency toward departmental or divisional interdisciplinarity in community colleges. Another potential limitation is the selection of participants. Potential participants were sought using

\footnotetext{
${ }^{31}$ Described above.

32 These calculations are described in more detail in Chapter Three.
} 
convenience sampling and limited snowball sampling; those who responded to my recruitment email were excited about my project and eager to share their experiences with me, and several indicated their commitment to research as a reason for wanting to participate. However, other faculty who may not have shared such a commitment, or those who may have felt unwilling to discuss their work with someone from a four-year research university, may have chosen not to participate in this study.

This study was also limited by the time in which I had to complete it, which was constrained by my dissertation schedule. This impacted the number of interviews I was able to conduct, and, consequently, the sample size. Additionally, this constrained my ability to fully analyze the entirety of the data I collected from the journals. As such, my analysis of the journal data was limited to trends in the institutional affiliation of contributing journal authors. However, I also collected titles and abstracts of the articles contributed by those with two-year college affiliations. The analysis of this additional data, in order to more closely examine two-year college faculty's contributions to written disciplinary scholarship, is another area for further study.

Another potential limitation is the region in which I conducted the study, which focuses on the experiences of two-year college faculty in the Southeast. Because of the strong local ties that are characteristic of this institutional setting, faculty in other regions may have experiences that differ greatly from those of my participants. Finally, this study is limited by the position each participant held at the time of their interviews. Of the seven participants, only two held part-time, adjunct positions at a community college; of those two, one had a full-time job at a university, and the other was seeking full-time employment. That the majority of participants held full-time jobs may reflect that some 
part-time adjunct faculty may have been interested in participating but felt unable to provide the time necessary to be interviewed. Furthermore, the limited number of parttime, adjunct faculty who participated in my study provides another possible area for future research. The basis of the alternate model of scholarship I set forth rests on experiences described primarily by full-time faculty. However, to more fully understand the experiences of those who teach in the name of our discipline, a more thorough investigation of the experiences of part-time, adjunct faculty is needed, as well.

\section{Overview of Chapters}

In Chapter Two, “'On the Front Lines': Working in a Community College,” I provide an overview of participants' working conditions. This overview rests on the assumption that the community college is a distinct academic workplace, one that is impacted by many different factors. First, I describe the larger contexts in which participants work, providing background on state-level economic conditions that influence participants' various institutional settings, and their institutions' responses to those conditions. Then, I shift my focus to the material conditions that subsequently impact participants' professional lives, highlighting two specific material constraints that participants face: money and time. Finally, I end this chapter with a discussion of a less visible material condition: the emotional labor in which participants engage, largely due to the material conditions of their students' lives. Because I argue that participants' scholarly activity is shaped by their institutional settings, this chapter provides the basis for the following two chapters, in which I examine how participants leverage professional 
sites that are understood to be sites of teaching and professional development as sites of scholarly activity, as well.

In Chapter Three, “Two-Year College Writing Faculty as Scholars: Classroom Edition," I examine the first of three sites where some community college writing faculty engage in inquiry and circulate or apply the results of that inquiry: the classroom. Specifically, I focus on the classroom practices of two-year college faculty, presenting those practices as examples of scholarly teaching (Shulman, "From Minsk to Pinsk"). I begin with a short overview of the separation of practice from inquiry. Drawing on North's conception of "Practitioners" as distinct from "Scholars" and "Researchers," I contend that the institutional structures that tend to separate teaching from scholarship have contributed to the trope of the two-year college faculty as teacher, not scholar. In the next section, I show how the narrative of two-year college faculty as teacher is manifested in some of the prominent journals in Composition Studies. Following this discussion of journal data, I describe how this narrative - and that of practice as separate from inquiry - plays out in the attitudes and self-perceptions of most of the faculty I interviewed. Finally, I discuss the scholarly teaching in which my participants engage. In Chapter Four, "Two-Year College Writing Faculty as Teacher-Scholars: Outside the Classroom," I focus on the last two sites where some community college writing faculty engage in inquiry and circulate or apply the results of that inquiry, sites that are institutionally understood to be for professional development and service: conferences and faculty reading groups. First, I describe what constitutes professional development and service for community college writing faculty, based on participants' descriptions of their job responsibilities. Next, I discuss the prominent role participants' 
conference attendance plays in the recursive relationship between their professional development, scholarly inquiry, and teaching. Then, I shift attention to another site of professional development and service, faculty reading groups, and examine the role participants' engagement in such groups plays in their conceptions of their professional identities, utilizing the conception of the teacher-scholar-activist (Jensen and Toth; Toth and Jensen; Toth et al., "Distinct"; Toth et al., "Dubious"; Hassel et al. "TYCA White Paper”; Griffiths, "Professional Autonomy”; Sullivan, “Teacher-Scholar-Activist”; Andelora, "Teacher/Scholar") as a framework by which to understand those identities. In Chapter Five, “Conclusion: Towards Mending the Conversation,” I provide a brief summary of my overall argument, and review the implications of this project for the discipline of Composition Studies. I suggest interinstitutional dialogues at the local level as a key starting place where Composition Studies teacher-scholars can begin to recognize alternate models of scholarly work - and, thus, the range of contributions to our disciplinary body of knowledge. 


\section{CHAPTER TWO}

\section{“ON THE FRONT LINES”: WORKING IN A COMMUNITY COLLEGE}

Donna: "[...] But again, money and time."

Laura: "It seems like it keeps coming back to that."

Donna: "It always does."

"So things I think I want you to know: That the challenge is the good part. Like, it's intellectually stimulating and rewarding in a way that I can't codify [...] but it's just there, and it's part of the fun stuff. [...] I feel like all of us are on the front lines. I am resentful and angry at the politics, $[\ldots]$ that make this work harder. And it's going to hurt more people who are already marginalized, and I'm so angry at that. So it both renews what I want to do and why I want do it, and makes me want to run and scream [laughs]. Like, every day, all at the same time. [Briefly pauses]. I just, I love this place. I love this place. I love the students, I like the energy. I want some people to be more, I know some people want me to do more. Right, like all of that weird stuff that comes when you work together for a while. But I think it would be awesome for everybody to teach here. But it would have to be like two years, you can't do a semester [...] it has to be-you have to be able to feel the pace of what it means to really do this."

- Amelia

In their oft-cited volume, The American Community College-a volume described as "the nearest thing to a comprehensive work on the community college" (Frye 3) Cohen and Brawer include the following description of the typical workload of community college faculty:

Faculty workload. The term usually connotes the hours spent in the classroom each week times the number of students enrolled, occasionally with a nod to committee service. No one speaks of the community college professor's research load, scholarship load, or consulting load. Teaching is the ponderous portion of the profession, the burden to be carried. (91) 
Works such as Cohen and Brawer's have helped to establish this particular narrative of the busy, overworked community college teacher who does not have the time to do anything other than teach. However, as Chapters Three and Four reveal, participants' descriptions of their work challenge many common assumptions about what it means to work in a community college, including a number of Cohen and Brawer's assertions, such as their claims that "no one speaks of" any part of the job other than teaching, and that community college faculty "rarely conduct research or scholarly inquiry" and “dislike administrative work" $(84 ; 104)$. Ultimately, works such as Cohen and Brawer's fail to take into consideration the complexities that comprise the realities of the working lives of community college faculty.

This dissertation explores those realities. In the following two chapters, I examine the ways in which participants leverage professional sites that are understood to be sites of teaching and professional development to also engage in scholarly activity. These sites double for participants as sites where they both fulfill the responsibilities of their positions, as well as where they carve out their own teacher-scholar identities; I argue that participants' scholarly activity is thus shaped by their institutional settings - or, from a slightly different perspective, that their institutional settings foster such scholarly activity. In order for the reader to understand these sites, and how they fit in to the context of participants' professional lives and institutional settings, this chapter provides an overview of participants' working conditions. This overview rests on the assumption that the community college is a distinct academic workplace, one that is impacted by many different factors. My overall argument—-that participants' institutional settings foster a different model of scholarship — rests on understanding this institutional setting. 
However, while it is necessary to point out the material conditions that shape participants' professional lives, as I do in this chapter, what is even more important to point out is that these are not always prohibitive conditions. For example, participants recounted detail after detail that revealed their innovative and creative endeavors to lead rich professional lives - despite what Cohen and Brawer typify as burdensome teaching loads. In fact, these teaching loads contribute much to - and are thus intertwined withfaculty's inquiry practices and their identities as teacher-scholars. ${ }^{33}$

\section{Chapter Overview}

This chapter discusses the working conditions of participants, how those working conditions are shaped by statewide policies, and how those conditions then foster the teacher-scholar model that I am arguing my participants enact. First, I describe the larger contexts in which participants work, providing background on state-level economic conditions that have influenced participants' various institutional settings, and their institutions' responses to those conditions. Then, I shift my focus to the material conditions that subsequently impact participants' professional lives, highlighting two specific material constraints that participants face: money and time. Finally, this chapter ends with a discussion of a less visible material condition, the emotional labor in which participants' engage, largely due to the material conditions of their students' lives.

\section{Background: State Economic Conditions and Institutional Settings}

In order to understand participants' material working conditions, it is important to also understand the economic conditions and state-level governmental policies that shape

${ }^{33}$ As I explore in-depth in Chapters Three and Four. 
the institutional contexts in which participants work. Economic and global concerns have influenced public two-year colleges since their very inception, with both positive and negative economic conditions and outlooks fueling the drive toward the general population's increased access to higher education via the route of the two-year college (AACC; Vaughan, Community College Story; Cohen and Brawer). Interestingly, the relationship between the conditions of the economy and community colleges is inverse. Henry, who works at Mountain Hill Community and Technical College in Kentucky, explained this phenomenon:

When the economy does badly, community colleges do better, because people are trying to change careers, get education to make themselves more competitive. When the economy does better, community colleges do a bit worse, because people are kind of happy where they are, [because] they've got jobs.

In other words, as unemployment rates improve, indicating improving economic conditions, TYC enrollments, which dictate financial success for these institution, tend to decrease ("Watching the Economy for Enrollment Trends"; Juszkiewicz). The inverse relationship between the economy and community colleges seems to be common knowledge among those who are employed in such institutional settings, as it came up in interviews with several other participants, with some linking this phenomenon directly to their material working conditions. For example, Amelia explained that the exhaustion she felt while trying to balance her full-time job at Rock Creek with her dissertation work has been magnified by recent college-level shifts at Rock Creek, ${ }^{34}$ due to the college having been grossly in debt because of improving economic conditions: "We were in dire, I mean like, dire, financial straits [because of] a sudden drop in enrollment, as the economy increased, and people don't need community colleges quickly." Similarly, when

\footnotetext{
${ }^{34}$ These shifts are discussed in more detail below.
} 
I asked Lois, who works as an adjunct instructor at Forest Lake, how many classes she typically teaches in a semester, she responded that, "as the economy's improved, and people have gone back to work, they've [Forest Lake] had a lesser need for as many English classes, and so, this semester, for instance, I'm only teaching two. [...] Because I'm adjunct $[\ldots]$ my usefulness is based on enrollment. So, since enrollments are going down, then, my class load goes down." Not only do economic conditions, by way of unemployment rates, impact community college enrollment trends, they consequently, fundamentally, shape the material conditions of participants' professional lives.

There are distinct differences between trends in higher education funding between Kentucky and Tennessee, according to the 2017 Center on Budget and Policy Priorities report, "A Lost Decade in Higher Education Funding” (Mitchell, Leachman, and Masterson). This report specifically examines per-student funding of higher education at the state-level "since the Great Recession hit" (Mitchell, Leachman, and Masterson, "A Lost Decade"). Mitchell, Leachman, and Masterson make clear that, overall, state-level efforts to restore funding to higher education since the economic recovery from the recession are insufficient. However, the degrees of progress taking place in Kentucky and Tennessee differ significantly. The report finds that, as of 2017, per-student funding for higher education was down an average of $16 \%$ nationally from where it should be, based on where such funding was before the recession hit, and adjusted for inflation (Mitchell, Leachman, and Masterson, “A Lost Decade"). In contrast to this national average, in Kentucky, per-student state funding for higher education (adjusted for inflation), is 26.4\% "below pre-recession levels"- - ten percentage points greater than the national average (Mitchell, Leachman, and Masterson, “A Lost Decade”). In Tennessee, however, the 
state's per-student funding cuts were, as of 2017 , at $13.9 \%$ - below the national average of 16\% (Mitchell, Leachman, and Masterson, “A Lost Decade”). Furthermore, Tennessee is among the majority of states that have increased per-student higher education funding — up 5.2\% in Tennessee over the 2016-2017 academic year-whereas Kentucky has seen per-student funding cut for the last three years (Mitchell, Leachman, and Masterson, “A Lost Decade”; Mitchell, Leachman, and Masterson, "Funding Down, Tuition Up"). Though Tennessee is, like the vast majority of other states, not doing enough to restore higher education funding now that "state revenues have returned to prerecession levels," it is, nevertheless, making strides toward doing so, whereas Kentucky is one of the few states where per-student higher education funding is actually continuing to decrease, despite overall economic improvements (Mitchell, Leachman, and Masterson, “A Lost Decade”).

Participants' descriptions of their workplaces roughly align with these differences in state funding for higher education, with those who work in Tennessee, where funding for higher education is improving, generally describing stronger systems of institutional support. Specifically, I suggest that some of the differences I noticed between participants' descriptions of the institutional support and overall climate of the colleges where they work - differences that seem to fall along state lines - could be attributed, at least in part, to some of the differences between the overall climate of support for higher education in each of those states. In other words, whereas most participants from Kentucky seemed, at times and to varying degrees, to feel they are working within less supportive institutional climates, Audrey and Ruby, who both work at the same community college in Tennessee, frequently referred to the strong systems of institutional 
support their college offers. Before proceeding with this discussion, however, it is important to note that:

1) Audrey did occasionally express frustration with some of the limitations of her position as an adjunct, such as not having access to departmental travel funding, nor to the college's data on her students, which she discovered when she tried to move forward with a research project. These limitations, however, are currently not present for full-time faculty, a fact to which Ruby attested.

2) Ruby and Audrey work at the same community college. While I do not claim to be able to make generalizations about the statewide community college scene in either Kentucky or Tennessee, I did interview people from only one Tennessee college, and so do not know if the positive environment they described transcends the walls of Bradford State. Similarly, participants from Kentucky represent only three community colleges in the state.

Regardless, it is apparent that state-level policies have a tremendous impact on the daily working lives of all seven participants, as discussed below.

\section{Funding and Institutional Responses in Kentucky}

Overall, the findings from Mitchell, Leachman, and Masterson's report align with the recent funding policy changes within the Kentucky Community and Technical College System (KCTCS), which participants from community colleges in Kentucky frequently mentioned. Such funding issues have dramatically shaped these participants' professional lives. Henry, for example, explained how these changes have impacted his professional development:

I haven't done any research in - or really gotten involved in conferences or anything like that for-over a year now. In part, because of the budget crunch. 
We don't have out-of-state travel funding. [...] You can apply for, you know, certain grants and funds, but they're, you know, they're often not enough. And so we look to the school to help subsidize that, and that's been gone.

While travel funding for out-of state conferences used to be more readily available for faculty at Mountain Hill, due to the recent statewide cuts, such funding is now extremely limited, so that faculty have less support to travel to conferences outside of Kentuckyand, as discussed below, one of the side effects of this limited funding is the amount of time it now takes faculty to apply for travel grants, should they seek out-of-state professional development opportunities. This limits faculty's ability to engage in professional development opportunities.

Funding issues impact more than just support for faculty development, though. Henry elaborated on other consequences of funding cuts, including curricular changes: "Retention is a bigger problem at a two-year school, and [...] the budgets are slimmer, and so many more students are on financial aid. And if they don't graduate, then they can't get the job they wanted, and they default, the school pays the money back to the government, and the school has to try to collect from the students." One institutional response that Henry has seen in action is for colleges to try "to streamline the requirements for students to get them in and out quicker" so they do not accrue as much student loan debt — which lessens the potential future financial burden on the college. For example, Henry recounted how, recently, business writing was made optional for students in business degree tracks, instead of a required course, as it once was. Funding issues are thus fundamentally shaping the curriculum, and, consequently, the degrees that students earn. Furthermore, because business writing "was a course that English held," a lot of his colleagues are angry about the decision, adding to an environment where faculty seem to 
feel discouraged and disconnected from the goals of their administration. Henry, himself, sees such curricular changes as "symptomatic" of the administration's streamlining of requirements, a common institutional response to the retention issues many community colleges face.

The two-year institutions in which participants work have been drastically affected by recent improving economic conditions. Amelia's college, for example, had "grown too much and couldn't adjust soon enough" to a shrinking enrollment due to improving economic conditions. As a result, the new college president, in an effort to "truly cut expenses," made drastic job cuts across the college's faculty and staff, even including some tenured positions. Amelia explained that,

when that happened, we now had [...] fewer faculty. And while we did have fewer students, the emotional labor didn't go down. And now you had fewer employees who needed to do the same things, and how do you run student organizations, when those faculty just got laid off? And [...] how do you do internal service and have all these great committees that deal with women's issues and Black History Month and all, everything else that we know we do. And trying to make that happen. [...] It was, it was horrible. I mean. It was soul-sucking. And like, the grieving of that.

Unsurprisingly, This recent dramatic shift at Rock Creek, also came up in both Donna's and Sally's interviews. Donna, for example, put most of her answers to my questions in terms of "before" and "after" these dramatic job cuts, which she identified as "The Purge." She also noted that now "people are a lot more angry and upset and don't know where to put it sometimes. In fact, I would argue that half our faculty are suffering from post-traumatic stress disorder." ${ }^{, 35}$ Amelia echoed Donna's point, describing the fallout of the job cuts for the faculty who remain at Rock Creek as "soul-sucking," a time of

\footnotetext{
${ }^{35}$ Donna was also careful to add, "but that may take away from severe trauma, and so I don't want to do that."
} 
"grieving." Sally, though she does not explicitly describe the job cuts as Amelia and Donna did, nor does she express all of the same negative reactions, mentioned that, "with all the changes to the college, people have been kind of, depressed, I guess, is the best word, and the feel is a little different this year." Sally also discussed how her job responsibilities have changed as a result, describing the "restructuring" of the college and how she has taken on an additional administrative role in the department "to get us through the transition." Additionally, all three of these women (Donna, Amelia, and Sally) now teach on two different campuses one semester out of each academic year, because, after the job cuts, some of the campuses in the Rock Creek college system no longer have any full-time English faculty. This policy is a direct result of those job cuts; before they happened, each full-time faculty member had a single campus where they worked. Though Amelia, Donna, and Sally seem to have varying reactions to the new presidents' job cuts, one thing is clear: A trickle-down effect has occurred. The economic climate impacted college enrollment, which impacted college funding, which impacted the daily lives of the faculty and staff of Rock Creek Community and Technical College - both those who were let go and those who remain.

\section{Funding and Institutional Responses in Tennessee}

The experiences of Amelia and Ruby, who teach at a community college in Tennessee, at times stand in stark contrast to those of Amelia, Donna, Sally, Henry, and Lois. While Tennessee is one of the many states that disproportionately cut funding to higher education in response to the recession and is not, according to Mitchell, Leachman, and Masterson ("Funding Down, Tuition Up"), making great enough strides toward remedying those cuts, this state is unique in its position on the importance of 
higher education to the state's economy. This position is evidenced through the higher education programs Tennessee Governor Bill Haslam has implemented since taking office in 2011, programs designed to ultimately improve the state's economy ("Bill Haslam, $49^{\text {th }}$ Governor of Tennessee"). These programs are part of Governor Haslam's "Drive to 55" initiative, an initiative with the goal of fifty-five percent of Tennesseans having a college degree or certificate by the year 2025 ("Drive to 55 Alliance"). Towards the end of reaching this goal, in 2014, Tennessee became the first state to offer eligible high school graduates two tuition-free years at an in-state community or technical college, with the Tennessee Promise scholarship and mentorship program; since then, the state has also passed Tennessee Reconnect, an expansion of Tennessee Promise to include adults of all ages across the state ("Tennessee Promise"; "Tennessee Reconnect").

In their critique of academic capitalism, Slaughter and Rhoades argue that "the neoliberal state focuses not on social welfare for the citizenry as a whole but on enabling individuals as economic actors. To that end, neoliberal states move resources away from social welfare functions toward production functions" (20); in such a neoliberal state, “colleges and universities are viewed as playing an important part in state economic growth, contributing to general prosperity" (5). Admittedly, Tennessee Promise and Reconnect enact such an ideology, with Haslam's support for these programs framed in terms of economic growth for the state. However, what is unique about these programsaside from being the first of their kind passed at the state-level-is the variety of requirements that their benefactors must fulfill in order to remain eligible. Though driven by economic concerns, Tennessee Promise and Reconnect ultimately take a holistic 
approach to both individual participants' academic success, as well as the betterment of their communities. For example, the official Tennessee Promise website explains:

While removing the financial burden is key, a critical component of Tennessee Promise is the individual guidance each participant will receive from a mentor who will assist the student as he or she navigates the college admissions process. This is accomplished primarily via mandatory meetings that students must attend in order to remain eligible for the program. In addition, Tennessee Promise participants must complete eight hours of community service per term enrolled, as well as maintain satisfactory academic progress $(2.0 \mathrm{GPA})$ at their institution. ("Tennessee Promise")

Under Tennessee Promise, the state does not simply provide free tuition to students; the program is also dedicated to ensuring that participants stay enrolled in college and complete their degrees on time, by meeting with a mentor and maintaining a certain GPA, as well as giving back through community service hours. This approach has led to some resounding successes and positive change in Tennessee. In a February 2017 report from the Tennessee Higher Education Commission, Governor Haslam is quoted as saying that "the results [of Tennessee Promise] so far are incredibly encouraging" ("Tennessee Promise Sees Increased Enrollment"). For example, Tennessee Promise students have "performed a million hours of community service across [the] state"; the first-time freshman enrollment rate in public higher education in the state has increased by $13 \%$ since 2014 , including a $30 \%$ increase at community colleges specifically; community college retention rates for Tennessee Promise students are higher than for students not participating in the program; and, perhaps most remarkably, "Tennessee has seen a $17 \%$ decrease in the number of students taking out loans" ("Tennessee Promise Sees Increased Enrollment"). It is wholly unsurprising, then, that the number of students participating in the program is increasing (“Tennessee Promise Sees Increased Enrollment”), further contributing to its success. 
The holistic approach to student success in higher education that is woven into state-level programs like Tennessee Promise echoed throughout Ruby's and Audrey's descriptions of their jobs at Bradford State-for example, in their descriptions of their involvement with the Student Advocacy Project, a faculty reading and activist group committed to breaking down non-academic barriers to student success. ${ }^{36}$ For example, Ruby, through her participation in the Student Advocacy Project, was, at the time of our interview, planning an intervention to foster a sense of belonging for her students, in order to aid in their academic success. She explained:

Students have to have some intangible qualities, or they can develop skills, that will, that are not just academic. And so we [the Student Advocacy Project] looked at ways - [...] it's also kind of wrapped up in poverty, that, you know, children in poverty tend to have fewer resources, not just money, but other types of resources. Like knowing college behaviors, and knowing people in college, and using them as a bridge - it turned from that into, we looked at many ways that we could actually, you know, $[\ldots]$ be that person to instill college behaviors. Can we be that person to be a mentor for them?

Through her intervention, ${ }^{37}$ Ruby hoped to foster students' sense of belonging at the college, in order to ultimately aid in their academic success. This kind of approach to student success mirrors the holistic approach enacted by Tennessee Promise.

Furthermore, Ruby and Audrey both described working at Bradford State as a resoundingly positive experience. Audrey, though she did, at times, express frustration with the limitations of her adjunct position, said that, overall, "I've had a good experience being adjunct and requesting classes and getting them, and, not driving all over town at

\footnotetext{
${ }^{36}$ Discussed in more detail in Chapter Four.

${ }^{37}$ The intervention Ruby planned was to ask students to actively participate in certain college behaviors, and then reflect on their participation in campus events, in an attempt to help boost their sense of belonging at the college. Ruby's rationale behind this was that, "I've learned that if you force them [to go to a campus event or visit a professor during office hours], if it's part of an assignment, and they have to do it, that kind of takes away some of their [...] fears. Because they say, "well, I have to go do this."
} 
crazy hours. I really have. Like, I usually get a decent schedule. [...] I'm never commuting between campuses during the day." Furthermore, she explained that, at Bradford State, "adjuncts get first right of refusal for tutoring hours, that we get paid hourly for. [...] I get my teaching hours, and then, I can get a certain amount of tutoring hours, up to that. Up to the equivalent of twenty-nine hours a week of work." Ruby similarly expressed her positive experience working at the college, noting, for example, that Bradford State is "remarkably generous about [travel funding for] conferences.",38 Indeed, Ruby described her positive work experience as "ideal": "I really think the wellkept secret is with the community college classroom, the community classroom setting is, is so ideal."

\section{Discussion}

While my Kentucky participants all express their commitment to their jobs and, more notably, for their students, none went so far as to describe the community college setting as an "ideal" place to work, as Ruby did. While their commitment to their jobs and to their students is notable, and I do not wish to take away from or devalue that commitment in any way, they do, for the most part, seem to see their jobs, to varying degrees, as being at odds with larger college-, system-, and/or state-level policies that significantly impact their working conditions. Overall, there is a stark difference between the descriptions of working at a community college between Kentucky and Tennessee participants. Those who work in Tennessee tended to have fewer complaints about the larger institutional policies that impact their jobs, and they seemed to see their jobs as more secure. Generally, Ruby and Audrey both gave the impression that they have not

\footnotetext{
${ }^{38}$ Ruby's participation in conferences is discussed in more detail in Chapter Four.
} 
recently felt the same kinds of stresses and pressures of institutional funding issues and budget cuts as participants from Kentucky have-e.g., recent budget and job cuts. Lois, for example, who teaches part-time, frequently described herself as "lucky" for having her full-time university job, suggesting the financial unsustainability of her community college position. Though neither Ruby nor Audrey discussed Tennessee Promise and Reconnect at length, I believe that these programs contribute, at least in part, to such a positive working environment, given their holistic approach to student success, as well as the high value placed on education that they seem to suggest.

\section{Material Constraints}

In her essay, "Passing," Patricia Sullivan writes, "but of course, bodies do matter," (237). Sullivan's personal account serves as a reminder of the material conditions that shape our personal and academic lives, and the importance of not only recognizing those material aspects of our lives, but breaking the silence that so often surrounds them (Sullivan, "Passing" 232; 251). As such, my discussion of the professional lives of writing faculty in community colleges - an institutional setting commonly understood in academe to have rigorous working conditions and constrained resources - necessitates an examination of the material conditions impacting my participants' working lives. Across much of the existing literature on two-year college writing programs and scholarship on the professionalization of two-year college writing faculty, the issue of the material conditions of working in this institutional setting - such as the emphasis that is placed on teaching over other professional pursuits; the number of part-time or contingent faculty typically employed in two-year colleges; and the 
consequent time constraints and financial barriers that thus limit many two-year college faculty's ability to research, write for publication, or attend conferences-come up repeatedly (e.g., Klausman, “Mapping”; Klausman, “Toward a Definition”; Worthen; Reynolds, “Two-Year College Teachers"; Reynolds, "Building”; Nist and Raines, "Writing in the Margins"; Ostman; Trainor and Godley; Powers-Stubbs and Sommers). Perhaps unsurprisingly, participants' material working conditions came up across all of my conversations with them. Given this chapter's overall purpose- to discuss these faculty's working conditions, in order to set the stage for Chapters Three and Four, in which I discuss how they work within those conditions, leveraging the constraints of their institutions to engage in scholarly work and carve out unique identities for themselves as teacher-scholars - this section focuses on the material conditions of participants' professional lives. First, I discuss the general workload of participants, then shift my focus to two material constraints that drastically impact participants' work: financial constraints and time constraints.

\section{General Workload}

Participants' descriptions of their professional lives generally align with common understandings of the typical workload of community college faculty (e.g., Ostman). Given that community colleges tend to have a reputation as "teaching" schools (Cohen and Brawer; Vaughan, Community College Story; Vaughan, "Scholarship and Teaching"; Ostman; Reynolds, “Two-Year-College Teachers"; Reynolds, "Building”), it is unsurprising that teaching is the primary job responsibility for participants. Indeed, several participants mentioned that the community college's focus on teaching, a distinguishing feature of this institutional setting, makes it a preferred workplace for them 
over a university setting (e.g., Lois, Audrey, Ruby, Sally, Donna). However, participants do engage in numerous other kinds of work. While there were some variations in the amount of time individuals described putting toward individual job responsibilities in a given week, month, or semester, overall, participants' descriptions of their jobs included the following areas:

- Teaching, including:

- Course preparation and planning, such as creating assignment sheets, slideshows, and other course materials

○ Grading student work and providing feedback to students ${ }^{39}$

- Being available for students, during or outside of office hours or via email

- Tutoring in writing center or learning commons (listed here because these tutoring hours are considered part of the teaching load for all of the fulltime faculty I interviewed ${ }^{40}$ )

- Academic advising

- Professional development (e.g., presenting at conferences, publication) $)^{41}$

- Internal service, or service to the college (e.g., serving on faculty committees)

- External service, or service to the community (e.g., representing the school in community charity events)

This list is a composite of the varying descriptions participants shared with me of the breakdown of their jobs, as outlined in their contracts with their individual colleges.

\footnotetext{
${ }^{39}$ For most participants, this feedback is written, but for some, such as Henry, this feedback is provided during student conferences.

${ }^{40}$ However, as a part-time adjunct instructor, Audrey's hours in the writing centers on the campuses where she teaches are counted separately from her teaching hours.

${ }^{41}$ Participants' professional development, and the wide range of work that counts as such, is discussed fully in Chapter Four.
} 
Some participants (e.g., Amelia) noted that their college has six different areas that a faculty member must fulfill each academic year; others (e.g., Audrey) list four areas. As such, the list above is a snapshot of the different kinds of work they do as community college faculty, and there are some variations in the amount of time they report putting toward each of these different areas (e.g., the number of weekly hours put toward grading ranges from just a few hours all the way up to eighty hours, depending on the different paper deadlines their students have in a given week, and the individual strategies that each teacher has developed to manage the heavy workload of grading). However, Henry nicely summed up his and his colleagues' professional responsibilities: "the full-time faculty at our community colleges here in Kentucky are responsible for [...] all levels of student life." On top of that, they are also responsible for both external and internal service, and their own professional development.

It is important, too, to point out that the list above is not comprehensive for all of these faculty. For example, Lois and Audrey, as adjuncts, also have additional jobs outside of their community college teaching positions_-Lois works full-time at a local university, and Audrey supplements her teaching with additional tutoring hours in the writing center, as well as working part-time as a farmer. Furthermore, participants are, in general, heavily involved in other kinds of projects related to their community college jobs-Audrey, for example, also runs an internship program for Bradford State students — or have taken on leadership positions in their departments, divisions, or colleges: Ruby runs "the summer bridge program" and serves "as a mentor for all the dual-enrollment faculty who teach English," and Donna has taken on a number of positions such as Director of the Writing Center over the course of her career, while also 
teaching additional courses beyond her required teaching load. To put it simply, these are very busy people, teaching heavy course loads - two to six classes a semester, depending on course release time taken for their administrative positions, with somewhere between sixty and one-hundred and ninety-six students each semester, not including their advisees — with numerous professional responsibilities beyond their teaching.

\section{Financial Constraints}

One of the key material constraints that participants face is financial—namely, the limited availability of departmental, divisional, or institutional funding for professionalization opportunities, such as conference travel $;{ }^{42}$ these financial constraints are very closely connected to participants' state-level economies. As I discuss in the literature review in Chapter One, over the last few decades, there has been a steady line of conversation focusing on issues of labor and economic and working conditions within college composition programs (e.g., Bousquet et al.; Bousquet; Scott, Dangerous Writing; Strickland; Welch and Scott; Horner). Further attention has also been paid to issues of contingent, part-time, or adjunct labor (e.g., Daniel; Schell, "Austerity”; Schell, "Toward"). Schell explains that "the past thirty years have seen significant cost cutting in the instructional budget through tenure-line positions being replaced by contingent positions," and links these "changes in the composition and working conditions of the faculty in American higher education" with changing economic conditions and the "wax[ing] and wan[ing]" of "federal and state funding" ("Austerity" 182-183).

Conversations around the problems embedded in higher education's increasing reliance on contingent faculty, including the financial constraints those in such positions are

\footnotetext{
${ }^{42}$ In Chapter Four, I discuss how important conferences are as a site of scholarly activity for participants.
} 
endowed with, are, by now, likely familiar to many in academe. However, the financial constraints my participants described are not limited to part-time faculty. The institutional financial constraints within which participants work vary by their college and position, but all — with the exception of Ruby, who holds a full-time position at her college, and Lois, who attends and presents at many conferences each year for her full-time university job - described the limited financial support their institution provides for their professional development, and the ways in which their professional identities are shaped as a result of that limited funding.

Audrey, who, at the time of our interview, was working part-time but seeking fulltime employment at Bradford State, ${ }^{43}$ was particularly frustrated by the conditions of her employment and how her part-time status was a hindrance to her professional development. She spoke at length about how difficult it is to attend conferences because of her position as an adjunct, which prevents her from receiving funding from her department for conference travel. She recounted, for example, how she was recently accepted to present at the National Council of Teachers of English (NCTE) Annual Convention; when she asked her department head what kind of travel funding was available, she found out that "there's actually a rule at [Bradford State] that adjuncts can receive no departmental funding to present at conferences," and was told by her dean, "“I would love to give you money, but I actually cannot."” Audrey continued that, "it just feels like a trap, because you want to get hired full-time, so you're trying to do these things, but $[\ldots]$ you're already not making as much money [as full-time faculty], and you

\footnotetext{
${ }^{43}$ According to Ruby, who worked part-time at Bradford State before applying for the full-time position she currently holds, and Audrey, it is typical for part-time positions at Bradford State to serve as a path to full-time positions, as many part-time instructors eventually get hired full-time.
} 
have to pay out of pocket." After expressing her frustration, Audrey was quick to add that she was able to attend the NCTE convention, because of an intervention from another source of funding at her college:

But, our college is awesome, and they figured out a work-around, because I was presenting on service-learning in the English classroom, so the service-learning department [...] said, 'I've got money! And I'm not an academic silo, I'm student life. So I can give you money." [...] So, I did get to go to a conference, and present, which was great.

However, Audrey was clear that this was not a sustainable source of funding, and acknowledged that she will not be able to attend other national conferences such as NCTE "unless [she gets] hired full-time." For Audrey, the specific institutional constraints of her position as an adjunct instructor are what have kept her from attending more conferences. She explained, "I would totally go to [...] four Cs, if I could. Gosh, there are so many that I would go to, at least once. [...] Yeah, if I had funding, I would [...] definitely, yeah, funding is the main thing that prevents me from going." Because of her position as an adjunct instructor, Audrey is unable to receive the departmental funding that is available to her full-time colleagues, thus making it more financially difficult for her to engage in professional development opportunities, such as attending and presenting at conferences, that would ultimately help her achieve full-time employment at Bradford State.

Issues of funding such as those that Audrey described are not specific to the parttime faculty with whom I spoke. Because of recent state-level budget changes, most fulltime faculty have also recently had difficulty attaining funding for conference travel. For example, when I asked Donna about what kinds of support she gets to do things like attend conferences, she responded with, "Now, support, moral support, yes, we have tons 
of. But financial support, we don't have any money. We're broke [laughs]. And none of us make very much money, either, so [continues laughing]." Donna, like Audrey, points out how important such professional development is for faculty in their departments - as I discuss in Chapter Four, the institutional culture of their colleges fosters a climate in which conference attendance is strongly encouraged among colleagues. However, both Donna and Audrey point out how financial difficulties bar them from more conference participation, which is a significant piece of their professional identities. For Audrey, it is her position as an adjunct; for Donna, who is full-time and tenured, it is the lack of money caused by recent budget cuts.

Similarly to Donna, Henry described how he and his English faculty colleagues are limited in their ability to go to conferences - especially national conferencesbecause of how hard they now have to work to receive funding for those conferences, because of recent budget cuts that have limited the amount of available funding for professional development opportunities. He explained that, because his college no longer "sign[s] off on [travel funding]" for out-of-state conferences, faculty "have to apply to competitive grants and funds a lot more to try to get money for that." This limits their ability to attend national conferences, which are often held out of state, and so Henry and his colleagues are more likely to attend state-level or regional conferences. ${ }^{44}$ Despite these financial hurdles, Henry and his colleagues are very interested in and committed to attending national conferences when they are able. For example, Henry described how, when the Conference on College Composition and Communication (CCCC) was within

\footnotetext{
${ }^{44}$ This is true for most participants, and likely the reason why everyone described their conference participation as either state, regional, or national, which I discuss in Chapter Three.
} 
driving distance of Mountain Hill, he "put together a professional development opportunity that took like six or seven of our teachers, $[\ldots]$ got it all together, got the funding secured," and drove to the conference. He followed this up with the observation that, “people are very, very interested, and they get a lot out of [conferences], it's just, you know [...] Money, money, money." The culture within Henry’s department — which values both conference participation and close collaborations between colleagues - is such that, despite the limited travel funding he and his colleagues now face, they work within and against those constraints, in order to pursue professionalization opportunities such as going to CCCC, together.

In light of limited funding, some participants have had to make strategic choices about the conferences they attend, choices which simultaneously shape and reflect their professional identities. For example, Amelia, who teaches both English and Women's Studies classes, and is heavily involved in both departments, has had to decide which disciplinary conferences to attend in order to work within the constraints of available funding; "because money is so tight at the college," she explained, she does not have the financial support to attend conferences in both disciplines. So, she solely goes to Women's Studies conferences. Similarly, Sally and her colleagues tend to orient themselves toward certain conferences and professional organizations. For Sally, her involvement in the Two-Year College English Association-Southeast (TYCA-SE) is extremely important; in fact, she has made a point to attend TYCA-SE every year for the last decade. When I asked Sally if there are other professional organizations she belongs to, she explained that her membership in other organizations, such as the Community College Humanities Association (CCHA) and the Popular Culture Association (PCA), 
has "been sporadic." But TYCA-SE is different: "Now TYCA, I go every year, I renew my membership every year, I'm very loyal, to that group. [...] Really, TYCA's it, as far as something that I'm really part of." Sally's loyalty to TYCA-SE is so strong that, despite the limited amount of travel funding she receives, which forces her to pay "a lot of it out-of-pocket," she continues to attend the conference each year: "I get so much out of that conference [TYCA-SE], I really don't mind, you know, [...] paying for some of it myself." When I asked Sally if this kind of professional participation also seems to be true of her colleagues, she explained that one of her colleagues "is in PCA like I'm in TYCA, you know. Just, just, going to go every year, no matter what, 'I have to be involved,' and, you know, [she] just loves it." Like Sally, many of her colleagues have made similar professional allegiances.

Overall, participants frequently brought up the financial constraints of their institutions, particularly as those constraints affected their access to professional development opportunities, such as conference attendance, and how those constraints, in turn, both reflect and shape their professional identities. These funding issues were not clearly connected to a particular rank or level (i.e., part-time versus full-time positions), and almost always related back to economic issues at the state-level, illustrating Slaughter and Rhoades' conception of academic capitalism which relies on an economic "network of actors" (9-10). Despite these financial constraints, however, participants have still found ways to be active participants at conferences, thus participating in the disciplines with which they align themselves and furthering their professionalization efforts.

\section{Time Constraints}


Issues of the limitations caused by the limited resource of time also came up frequently during my conversations with participants. Interestingly, though, this constraint did not always manifest itself in the lives of my participants in quite the same way as the tired narrative of the over-worked community college teacher might lead us to believe, as discussed in the literature review in Chapter One. For example, time is often the understood reason that there are not more representatives from community colleges presenting at conferences or authoring pages in our scholarly journals (Ostman 93). However, for Amelia, Audrey, Donna, Henry, Lois, Ruby, and Sally, if they do not frequently attend or present at conferences, lack of time is a reason given for not attending conferences only insofar as it relates to travel time or time spent on jumping through red tape to secure funding, not how a conference itself fits into their busy schedules.

In this subsection and the previous, I discuss time and money as two separate kinds of constraints that, at times, inhibit participants' professional growth. However, these two issues are very closely connected. For example, Donna and Henry both brought up the fact that, not only are some faculty barred from professionalization opportunities such as attending or presenting at conferences due to a current institutional lack of funding to help pay for the cost of attendance, but, in order to receive fundingespecially now that funding is more scarce and, thus, more competitive - it takes time. It takes time, according to Henry, to apply for the "competitive grants and funds" to get money to attend conferences. As Henry put it, he and his colleagues now "really have to work to get funding" to attend conferences. Donna provided a similar description of the work required to get funding: "in general," she said, in order to "apply [for funding], [...] 
we have to fill out so much paperwork your eyes are crossed." Financial constraints, then, also place an additional burden of time on faculty — namely, the amount of time it now takes to apply for additional financial resources. These two constraints are thus intertwined; as such, though this section focuses on time constraints, my discussion of those constraints, at times, also includes issues of money, as well.

Given their workload, it is perhaps unsurprising that the majority of participants brought up other issues related to time constraints during their interviews. Indeed, time seems to be a very limited resource in the community college setting overall (Choseed; Ostman; Vaughan, "Scholarship and Teaching"). Amelia, who, at the time of our interview, was also interviewing faculty at community colleges for her own dissertation, brought this point up during our conversation. While describing her workload and the different components of her job, per the terms of her contract with Rock Creek, Amelia pointed out that her experiences working at a community college in the Southeast are very similar to those her own participants - who work in a different region of the United States - described during their interviews with her. As is the case for many teacherscholars across two- and four-year institutional settings, Amelia explained that the actual lived experience of her work is different than the official story laid out on paper. Specifically, though the different responsibilities that make up her job as a whole tend to shift from semester to semester, theoretically adding up to $100 \%$ of her work time, this is not always so. In other words, Amelia and her colleagues are responsible for dividing their work time between teaching, academic advising, internal service, external service, professional development, and leadership, and each component—-beyond the $80 \%$ that is designated teaching — gets a different percentage of her attention, depending on the 
semester, but the amount of time that Amelia puts towards those responsibilities altogether often exceeds the number of hours for which she is actually compensated. ${ }^{45}$ For example, because Amelia was working on her dissertation at the time of our interview, a lot of her time was "designated professional development"; however, she explained that, "the reality is, you don't really let go of the other stuff. So I laugh when they say one-hundred percent, I'm like, alright, yeah, the number's well above onehundred, it's more like one-hundred and twelve [percent], but alright [laughs]." She continued:

And [...] that's the nature of community colleges [laughs]. Like, that's not unique to [Rock Creek], by any means. I listen — so as I'm doing my interviews [for my dissertation], I'm listening to my colleagues [out of state], and like, it's like verbatim. Like I feel, I feel like I've just said to you probably what they said to me in the interviews for my [dissertation] project, because it is, it's that same story.

Here, Amelia recognizes that her description of the heavy workload of her jobparticularly the amount of time she devotes to each individual piece that comprises the whole of her faculty responsibilities_echoes her own interview participants' descriptions of their workload. This heavy workload is, as she puts it, "the nature of community colleges."

The reality of this heavy workload is that my participants, like many faculty in two- and four-year colleges and universities alike, do much more than teach - and therein lies some of the challenges of their jobs. In the quote above, Amelia not only reflects on how her responses to my interview questions echo-or are, in her words, basically "verbatim"- -her own participants' descriptions of their jobs, she also points out that the

\footnotetext{
${ }^{45}$ As is undoubtedly true for many individuals across institutions and professions, not just two-year college faculty.
} 
different pieces that comprise the puzzle of her job description as an Associate Professor of English do not always add up neatly to one-hundred percent of her time. Instead, as she takes on more work in one area- - e.g., more professional development hours for working on her dissertation — the other pieces of the puzzle do not always shift accordingly to accommodate the increased time Amelia spends on that one piece. Instead, the other areas stay roughly the same, resulting in Amelia simply putting more hours into her work (as she said, it's more like one-hundred and twelve percent of her work time, exceeding the one-hundred percent for which she is responsible and compensated). The time constraints that Amelia described are similar to those described by other participants, as well. As it is for Amelia, time is primarily an issue when it comes to balancing the different aspects of their jobs. For example, Henry mentioned that "one of my big problems is that I spend so much time [...] on class prep that it doesn't leave much space for other things." However, these constraints do not fully inhibit participants from being involved in rich professional lives beyond their classrooms, and, as discussed in Chapter Three, often result in their innovative and scholarly teaching practices.

Overall, the challenges of such balancing acts of time and professional responsibilities are exacerbated even more by the financial constraints that some community colleges face, which, for some colleges, have resulted in fewer faculty members to take on shared departmental or divisional responsibilities, such as serving on committees, as explained in more detail above. While two-year college faculty are not alone in facing the issue of time spent on their myriad professional responsibilities exceeding the time for which they are compensated, what is unique to this institutional setting and these faculty is the ways in which they leverage the constraints of their 
professional responsibilities as sites also of scholarly activity (something that is not a required job responsibility), which I discuss fully in Chapters Three and Four.

Furthermore, the work that these faculty engage in exceeds common understandings of the work that goes on in community colleges, which see community college faculty as teachers, not scholars, and that are perpetuated by disciplinary conversations, as evidenced by publishing trends in major Composition Studies journals. ${ }^{46}$

\section{Engagement in Professional Communities}

Like their institutional financial constraints, ${ }^{47}$ participants' limited available time also shapes their professional identities by impacting the professional organizations and faculty groups with which they frequently interact. These groups tend to be groups that are either online or very local. Audrey, Amelia, and Donna, for example, frequently engage with their colleagues via social media, and Ruby belongs to several online faculty reading groups. ${ }^{48}$ Donna also engages in professional organizations online, explaining,

I often participate in online organizations, like NCTE Learn, because it's online. I can do it at three-o'clock in the morning, or [listen to a webcast] while I'm driving. [...] I like those kinds of communities, where I can participate in my own time at my own pace. So I can seek those out. [...] That's usually the only way I get involved nationally at the moment.

Donna's participation in professional organizations - particularly those that are national, such as NCTE Learn - relies on online access to such organizations, which grants her the ability to participate on her own time. In this way, despite the time constraints of her heavy workload - made heavier by the additional courses she teaches each semester—she is still able to stay involved in professional organizations, even those that are national.

\footnotetext{
${ }^{46}$ As discussed in Chapter Three.

${ }^{47}$ Discussed in the previous section.

${ }^{48}$ As discussed in Chapter Four.
} 
Donna also utilizes online spaces to stay connected to local colleagues, those at the college- and state-level; she explained, for example, that Facebook is the primary means of communication used by members of her union.

In contrast, her inability to connect with her community college colleagues is an issue for Lois, who is frustrated by her college's limited technology use for professional development opportunities and faculty meetings. She described her department's unsuccessful efforts to establish connections amongst those who teach part-time in the department, many of whom have other jobs:

They try to get us together. [...] But it's usually like, on a Tuesday afternoon in May, at two o'clock in the afternoon, when we're all like, we have jobs. [...] They try to put together these things, but then [...] the days that they choose to do the opening meeting for the semester, they do it at like seven o'clock [at night]. I live forty minutes from campus. [...] I'm not hanging around until seven o'clock. And they don't [use] Adobe Connect [...] or Blackboard Collaborate [...]. Because I would sit at home and participate, if that was an option.

Because of the demands of working full-time at another institution and the physical distance between her home and her community college, Lois does not have the time to participate in departmental meetings with her community college faculty. Consequently, her relationships with her community college colleagues are limited, in contrast to other participants, who described close collegial relationships with other faculty in their departments. Lois attributes this to her department's limited use of online tools. Furthermore, because the majority of the courses she teaches at the community college are online, Lois spends little time on the campus, and so does not have many other opportunities to interact with her colleagues there. However, Lois later added that she has been encouraging her department to use more online tools, to better allow for establishing relationships amongst English faculty at Forest Lake. 
Like Donna and Lois, Henry similarly described how his involvement with professional organizations is also determined by the time constraints of his position, limiting his involvement in professional groups and communities to those that easily lend themselves to fitting in to the time constraints of the job. As such, the groups to which he belongs tend to be very local. When I first asked him about his different professional organizations, Henry said that he used to be a member of the National Council of Teachers of English (NCTE), but "ended up letting that lapse."49 He went on to explain, "I haven't had time [recently] to read a whole lot, or go to conferences, and given the additional difficulties in travel." "But," he continued, "we do have professional development groups, and things like that, within [the Humanities division at Mountain Hill]." Henry, then, is fulfilling his need for professional development opportunities by engaging in local, college-level groups, though elsewhere in his interview he expressed his preference for national organizations, such as NCTE and CCC. It is also important to note that, though there are limited resources provided by the college for travel related to professional development, there are a number of opportunities available locally, which rely heavily on the close relationships between faculty that are fostered in the institutional setting. For example, one of Henry's colleagues "started a reading group, [for a book] called The Slow Professor." In this reading group, Henry and his colleagues are [...] talking about how the number of things, the whole constellation of responsibilities, that faculty are responsible for, impedes the kind of slow and deep consideration that we might expect from a stereotypical faculty member, [an] academic, you know. We consider these things deeply, we don't really have time to dig in to it. That the pace of the day-to-day, really isn't conducive to that [deep consideration]. Part of that is the corporatization, you know, of higher

\footnotetext{
${ }^{49}$ Henry did not specify a reason for the lapse in his NCTE membership, though it is implied, by the rest of his statement, that it was likely due to limited time and/or money.
} 
education. You have to have this number of minutes and hours into this thing, so, what - where is the space, where is the room?

In response to the pressures and demands of their jobs as full-time community college faculty, Henry and his coworkers in the Humanities division have formed a reading group around discussing those very pressures. While this group is not as explicitly activist as the group to which Audrey and Ruby belong to (discussed in Chapter Four), they are moving, or trying to move, towards change, through their conversations and initial identification of these issues that they face. It is clear, however, that Henry identifies himself as "an academic," who finds the reality of his position responsibilities at odds with what he understands the term to mean, attributing the mismatch, in part, to "the corporatization [...] of higher education" (e.g., Welch and Scott; Scott, Dangerous Writing; Bousquet).

Furthermore, Henry identifies this reading group as an opportunity for professional development that is, at least recently, ${ }^{50}$ more accessible than conference attendance or belonging to national organizations such as NCTE. Henry and his colleagues, then, are leveraging this site of professional development as a space in which to respond to the pressures of their positions. The close relationships that exist between colleagues allows for this kind of response and this site of professional development, and are key to other sites of Henry's professional identity. For instance, he explained that the "groups and communities that I'm a part of professionally tend more to be at my collegelevel, and within general education faculty_reading groups, professional development groups. Because I feel like I have more time for those, you know, because it's just down the hall [laughs]. I can just walk down there and be part of this. Those are easier to

\footnotetext{
${ }^{50}$ Due to the recent shift in available travel funding at his college.
} 
balance in many ways, for me." Henry later added, "I've got a research project that I want to do. [...] A couple, actually. But I think I'm realizing I need to make it more than just me. I need to get other people involved with it, [do] collaborative stuff, be sure that it gets done, for one. Because if it's just me, other responsibilities are going to eclipse that." For Henry, as it is for most other community college faculty, this kind of exchange of ideas through the means of "hallway conversations" is very important due to the material constraints imposed by the institution (Ostman 133), within which faculty work to leverage opportunities to carve out their own professional identities.

\section{Emotional Labor}

Just as the material working conditions of their positions as community college teachers shape their professional lives, the faculty I interviewed are also dramatically impacted by the material conditions of their students' lives, as well. This results in an aspect of the job that is not accounted for on their annual performance planning agreements (PPA) or evaluations: emotional labor, which, though a prominent part of participants' work lives, tends to remain a kind of "invisible labor" (Holt and Anderson, qtd. in Gillam 123). ${ }^{51}$ The role of emotion or affect, as well as the personal, in the teaching of writing and administering of college writing programs has increasingly been called to attention by Composition Studies scholars across institutional settings (Micciche; Jacobs and Micciche; Gillam; McLeod; Tobin; Newkirk, Performance of Self; Payne; Ostman). Ostman, writing about community college writing programs, argues

\footnotetext{
${ }^{51}$ Per Gillam's argument, part of the reason for the invisibility of such work is that it is not the kind of labor that is valued in academic culture, which, according to Horner, values "intellectual labor that can be commodified in the form of a single-authored scholarly text" (Gillam 123).
} 
that, for writing faculty and administrators in the two-year college specifically, emotion — namely, faculty's emotional intelligence — plays an important role because of the student diversity that is a hallmark characteristic of this institutional setting. Specifically, she describes "the emotional needs of many community college students, regardless of race, ethnicity, class, gender, or academic ability" noting that instructors' "awareness of some of the complexities and challenges [community college] students face is not only essential—it is often unavoidable" (Ostman 52). Ostman suggests that this is due, in part, to the "extremely diverse student body" typical of a community college setting; "in fact," so diverse are community college students on the whole, that "a general portrait of the students' diversity becomes nearly impossible" (23). Indeed, Cohen and Brawer claim that "two words sum up [community college] students: number and variety" (43; see also Osborn). Vaughan similarly describes the diversity of community college students:

For an idea of who attends community college, go to any town or city that has a community college, stand on a street corner, and watch people go by. Take away most people under 18 and most over 60, and the parade that passes will look much like students at a typical community college. Included will be men and women who work full time and part time, people from all walks of life and of diverse racial and ethnic backgrounds, unemployed and underemployed individuals, and recent high school graduates. (Community College Story 15)

Given this kind of student diversity, which tends to reflect the individual communities that different community colleges serve, Ostman argues that emotional intelligence is one of the necessary characteristics of community college administrators and instructors, in light of the diversity of their students - and the diversity of those students' needs (52-54). She explains that community college faculty "must strike their own balance in regards to how involved — or uninvolved — in the concerns of students they want or need to be," and 
argues that, no matter the level of involvement in those concerns, "awareness of some of the complexities and challenges students face is not only essential—it is often unavoidable" (52). Ostman further points out the need for faculty's "sensitivity and responses to students' personal needs and situations, and at times, their unique circumstances" (53). While all of my participants described the close relationships they tend to have with students, and how important knowledge of their students' lives outside of the classroom is to their successes as writing teachers, Henry, Audrey, and Amelia, explicitly named emotional labor-or different iterations thereof-in their discussions of their workload, attributing the material conditions of their students' nonacademic lives as a key factor that shapes their own professional lives as faculty.

\section{Henry}

Henry's discussion of his students and how he has learned to respond to their needs closely aligns with Ostman's argument about the need for community college faculty's and administrators' emotional intelligence. He noted, for example, the wide range of students with whom he works, from those "who could probably skip [the firstyear writing courses] altogether, [to those] who are barely literate," and the need to adapt to those varying levels of student preparation for college. Furthermore, while describing his typical workload each semester, when he came to the topic of his students, Henry shifted the conversation towards the range of his students' nonacademic needs. He explained that, when he first starting working at Mountain Hill, he was surprised by the demographics of the students at the community college, particularly in comparison to the 
university students he taught while he was in graduate school. ${ }^{52}$ In contrast to the students he previously taught at the university, Henry's community college students came from a wider range on the "social-economic spectrum," and this, in turn, has shaped his approach to working with students at Mountain Hill: $:^{53}$

What I've had to realize is that, I've had to become more sensitive to our student demographic. Because a lot of them are balancing work with part-time [or] fulltime jobs. [...] People who are taking care of families, who have kids, who themselves may be sick. [...] So, we do have the, the people who don't want to work, the people who just want to get the piece of paper, who don't care what you have to say. Um. And they're always frustrating. What can be equally frustrating is how to deal with students who're in a bad spot, because [...] they're not just extraordinary situations.

The tough situations that students face are not extraordinary because they "happen a lot"; as a result, Henry said, "our student demographic requires an understanding of the trials and tribulations of those students.” In his first semester at Mountain Hill, Henry had "three students $[\ldots]$ whose houses burned down," and, since then, has had other students who, for example, have 'been recently out of jail, [and] they're really, you know, afraid that, that they can't hack college." Henry elaborated on how seeing his students face such issues has impacted him as a teacher:

I can't remember who said it, or who wrote it, but $[\ldots]$ the idea that there are no small events in the lives of the poor. And we have a lot of students who are onwho cannot make college without financial aid. They need new cars, they maybe just got a computer for the first time. Or maybe they can't afford a computer, and have to hoof it to the local library to do school work. So all of these combined, these social, these economic, and [...] health problems. [...] The game is very different than it is in a four-year school. [...] It's, it's different when they don't have a car to get to you.

\footnotetext{
52 Prior to his job at Mountain Hill, Henry's only teaching experience was as a graduate teaching assistant at a four-year research university.

${ }^{53}$ In Chapter Three, I more fully discuss the responsiveness of Henry's and other participants' to student needs, and their subsequent adaptations to their pedagogy and classroom practices.
} 
The students Henry now teaches face a range of nonacademic issues. Henry draws comparisons between the material conditions of his current community college students' lives and his former university's students' lives, noticing how those material conditions more severely impact their academic performance, and, in turn, his approach to teaching his Mountain Hill students. As a result, Henry has adapted some of his classroom practices and policies since he left the university, such as making his attendance and late work policies more flexible, ${ }^{54}$ in an attempt to accommodate some of the unavoidable circumstances his students face, and, ultimately, to better facilitate their education.

Following his description of his students' demographics and the challenges they face, Henry brought up the concept of "compassion fatigue," which, he explained, he learned about while conducting research for his dissertation: "When nurses have patients who go through terrible times, or they see people die, after a while, it becomes, the emotional toll becomes a whole lot. And how can you continue to care, when it can hurt so much?" Henry said that, as a faculty member in a community college, he now finds himself

using that term [compassion fatigue] a lot more [...] because we have students who are in such, um - a lot of whom are fine - but some of them are in dire circumstances, and really, really struggling. And it becomes tough to attend to each and every situation, you know? [...] With possibly one-hundred and twentyfive students. [...] It's just, it's really tough.

In other words, as a community college faculty member, Henry identifies with the idea of "compassion fatigue," because of the range of his students' needs, which, again, often fall outside the classroom. For Henry, the emotional toll of teaching students, some of whom

\footnotetext{
${ }^{54}$ Discussed in more detail in Chapter Three
} 
are in "dire circumstances,", 55 is magnified by the sheer number of students he teaches, and his obvious desire to be there for, reach out to, and support each and every one of them.

\section{Audrey}

Similarly to Henry, Audrey made comparisons between university and community college student demographics, and the problems that the latter group tends to face. These differences, which Audrey experienced firsthand when she herself was enrolled in courses at a local community college as an undergraduate student, and her community college professors' obvious commitment to their students, motivated Audrey's desire to work in a community college. However, despite these firsthand experiences, Audrey still has struggled with the problems she sees her students face. These problems have shaped her professional identity by motivating her to do more for her students outside of the classroom.

When describing her educational background, Audrey recounted how, as an undergraduate at a large public university in the Southeast, she took a few general education courses at her college town's local community college, where she was surprised and delighted to find more diversity among her classmates than in her university classes:

[The university was] very homogenous. Everybody was kind of like me - at least, they looked like $\mathrm{me}^{56}$ - um, socioeconomically not diverse. Really, like, we were just all the same, basically. [...] And at the community college, [...] it was [the] real world. I took night classes; there were non-traditional students in there. I learned so much from them and met so many people that were, we were different

\footnotetext{
${ }^{55}$ Henry is careful to repeatedly point out, though, that not all of his students face such circumstances; the examples he brought up seemed to be extreme.

${ }^{56}$ Audrey is a young white woman, and, though she did not explicitly state it, hinted at coming from a middle class or more privileged background.
} 
from each other and we talked about those differences. And, so that's, in that classroom, I decided, "I want to teach at a community college."

While a student in a community college, Audrey was profoundly influenced by her classmates, from whom she learned a lot-because of the differences between them. The diversity of her community college classmates, as well as her community college professors and their passion for teaching, are the people to whom Audrey attributes her goal to teach in a community college.

Despite Audrey's community college background, when I asked her, "what's most surprised you about the job or the work that you do [at Bradford State]," she responded, after a long pause, the she had underestimated "the need of our students and how much they need help with the non-academic barriers to success." She went on to describe that, though she knew to expect it, because of having once taken classes at a community college, now that she works in this institutional setting, she realizes that she had underestimated "how dire the situation is for a lot of our students." Like Henry, Audrey is careful to point out that not all of her students are in "dire" situations - but many of her students, like Henry's students, do face extreme circumstances. She explained that, before teaching at Bradford State, she underestimated "how many of [her students] don't have food at home, [and] how many [...] become homeless or [are] on the verge of homelessness, due to economic situations, [and] abusive relationships." What has surprised Audrey most about working at Bradford State is how these "non-academic barriers to success" impact her job as their teacher:

I underestimated how much of my job-[slight pause]. If I open that door to my students, which I do, and I say, "if anything is going on that you need help with, come to me or someone else, 'cause we have resources at our college to help you, we have counselors, we have all this other stuff." I underestimated the emotional and relational, like, capacity that I would, I would need to build and possess to 
help my students succeed in all those ways [laughs]. [...] So. The amount of stuff that students deal with, that has a significant impact on their academic success, that has nothing to do with school. [Sighs]. Yeah. I underestimated that. I mean, I know people-Yeah. I knew to expect some. But I had no idea I would have to deal with, or be presented with, um, the things that they present me with, so [voice lowers]. Yeah.

Similar to Ostman's notion of emotional intelligence, Audrey has cultivated an "emotional and relational capacity," which she has had to develop in her two years of teaching at Bradford State because of her position as a writing instructor. In her role as their teacher, Audrey has had the opportunity to cultivate strong relationships with her students, who have more contact with her than they do with campus student support services, such as the counseling center. While the issues that Henry's students face have shaped his interactions with his students within the classroom, Audrey's response to her students' circumstances has largely been focused outside the classroom; for example, she has become heavily involved with a faculty reading and activist group, the Student Advocacy Project, which works, in part, to educate Bradford State faculty on the support services available to their students, and is discussed in more detail in Chapter Four.

\section{Amelia}

Like Audrey and Henry, Amelia has found that her students also face many "trials and tribulations," as Henry put it. Amelia also finds that the difficulties her students face influence her interactions with her students. More specifically, Amelia wrestles with what she sees as the intensely personal nature of the relationship between writing teacher and student (Tobin; Newkirk, Performance of Self), pointing out the nonacademic barriers to success that her students also face. She said she struggles with how to keep her teaching "fresh," while her students are "juggling two jobs, and their kid is sick, or they lack 
healthcare, or they're living in their car." For example, she described a recent interaction she had with a student via email:

I had a student who emailed me two nights ago, and she's like, "I have-I'm really concerned about Paper Four. I'm not-I feel like I've done the research, I'm just not sure the source really does what I want." [...] She's like, "and I just can't concentrate, um, I was assaulted and almost killed last night, and I just want to make sure I'm not late on anything." And I'm like, I mean, seriously, like, I had to get up and walk away. I'm like, "Why are you thinking about your paper?"

Amelia, like Henry and Audrey, finds herself, at times, unsure of how to respond to the difficulties her students face. When she next saw the student who emailed her about having been assaulted, Amelia said she was at a loss: "So she [the student] comes in the next day, and I'm just like, 'I-. I-."'

Amelia explicitly connected the issues some of her students face with her position, not just as their teacher, but as their writing teacher, and described "the emotional exhaustion" that ensues "because you care, and you have to care, but everything has to be so personalized, because it's writing. [...] And they are real people." For Amelia, the fact that she grades her students on their writing makes the studentteacher relationship that much more personal, and her investment as a teacher that much deeper. The resulting emotional exhaustion, Amelia said, is what has most surprised her about her work as a community college teacher, largely because of her previous career in domestic violence prevention work: "The emotional, the emotional labor. [...] Like, it's still like twelve years I'm doing this, and sometimes the emotional exhaustion catches me off guard." She elaborated that, after teaching at Rock Creek, she feels like she has finally figured out some of her boundaries, to help maintain her own health. That it has taken so long and that it has been so hard for her to establish these boundaries is surprising, 
because, like Audrey, Amelia believed that her background had prepared her for the work of teaching in a community college:

I thought I had good boundaries coming in, because I came from working, doing domestic violence prevention work. Like, I was at the hospital, I was in the court house, I mean, I knew how to set some boundaries. But it's so different, because writing is so personal. And even if they're not writing about personal stuff, I mean, that is some trust. [... " $\mathrm{Hi}$, let me write some words, and then you're going to judge me." And, there's no way that's not personal. And so trying to connect with students, and support them, and support them academically.

Much of Amelia's emotional exhaustion, then, stems from what she sees as the inherently personal relationship a writing teacher has with her students, given the nature of the course content. On top of that—because of the personal nature of writing — her students' lives outside of the classroom impact her that much more, and the emotional exhaustion is consequently magnified. Altogether, this is surprising to Amelia, given her prior experience working in domestic violence prevention, a job where she learned how to establish boundaries between herself and her clients, due to the highly emotional nature of that work.

Though Henry and Amelia did not frame their emotional labor in quite the same way that Amelia does - as being intertwined with the personal nature of writing - they did bring up emotional labor as a prominent aspect of their jobs. In response to the struggles their students face, all three of these participants (Henry, Audrey, and Amelia) bring up the toll of their emotional labor as teachers who care deeply about and are fully invested in supporting their students. In this way, the material conditions of their students' lives impact their workload and, to some extent, their professional identities. However, I do not mean to imply that writing teachers beyond the two-year college-i.e., Composition Studies faculty in four-year research universities — do not engage in 
emotional labor on behalf of their students, as the very existence scholarship on this subject refutes that claim (Micicche; Gillam; Jacobs and Micciche; McLeod; Tobin; Newkirk, Performance of Self; Payne). However, what is unique about the emotional labor of these community college faculty is that it is, as Ostman suggests, largely derived from the sheer diversity of the students with whom they work - and the range of nonacademic barriers to success, as Audrey described it, that many of those students face. Furthermore, it is also important to point out that not all of their students face such problems, as Henry was careful to frequently remind me, as was Amelia, who-as discussed in the next chapter-strongly pushes back against the common misconception of community college students as "all the students who have troubles."

\section{"The Possibility of What We Do"}

Amelia recounted that, when she first began working at Rock Creek, she "absolutely fell in love with the mission, with the possibility of what we do." While the diversity of participants' students does create invisible emotional labor for participants, so that the material conditions of many of their students' lives impact these faculty's working conditions, this diversity is also celebrated by participants. For example, when I asked Sally what has most surprised her about her job, she replied, "Honestly, I think what surprises me the most, is how much I enjoy working with these students." She then explained that part of why she enjoys working with her students is that they are so diverse. Sally, who was unfamiliar with community colleges until after she earned her Bachelor's degree, “wasn't sure what kind of student would be attracted to a community college" when she first learned about them. But, she said, "it didn't take long to realize that, everybody's attracted to [the community college]. I mean, it has something for every 
level of student, and every background, and [...] there's such a variety of student backgrounds, and goals, and just, everything." Part of the draw of teaching in a community college is, for Sally, the students and their diversity. She elaborated that "it's really interesting to talk to my students and see what brought them here, where they see themselves going. Because it's, it's all different, you know. And, and that has been a pleasant surprise.”

Lois and Ruby expressed similar reactions towards their students. Lois explained, "I'm glad I started teaching in a community college, because there's something much more rewarding about teaching people and watching them light up, and realize, 'yeah, I've got this.' That, I don't tend to get out of university students." The differences that Lois sees between her university and community college students is, in fact, one of the reasons she has continued her part-time position at the community college since taking a full-time position at the university, and she intends to stay in both positions. It is also one of the reasons why she requests, from time to time, to teach a face-to-face class at the community college, instead of her usual online classes. Ruby, too, expressed how much she enjoys working with her students, and that it didn't take her long into her time working full-time at Bradford State that, "I really do like being in the classroom. [...] And I love the students, love them."

Donna expressed a similar sentiment towards her students. At the end of our conversation, I asked Donna if there was anything she would like to add. After a brief pause, she concluded the interview with the following:

I have also had the experience [...] that community college students are very different than university students. [...] That is why I teach at a community college. [The Chestnut] campus is crazy diverse, million languages spoken, a million different entry-level skills coming in. I honestly feel like I can truly help 
people there. And, so, it becomes more of a mission. [...] My experience always was that most of those students [at other schools] were passing time. That's how I felt, that I was a blip in their lives. And, working in a community college, I feel like I actually matter to a great majority of [students], not even just a couplelike, a whole lot of them. And so, it doesn't matter to me if I can't go to a conference, it doesn't matter to me if I don't have time to publish articles, because again, I don't need it, I've already proven myself, I'm a full professor, I don't need those things. But also because that's not why I do it. I do it because I make a difference to those few people, and I'll just leave it there.

On the other side of the emotional labor explicitly named by Henry, Audrey, and Amelia, is the reason for teaching at a community college that Donna describes here- the challenges that are simultaneously rewarding. As it was for Audrey, it is this very distinction between community college and university students that Donna named as her reason for teaching in a community college. Indeed, it seems that, for most participants, though their students contribute to much of their workload (e.g., teaching, emotional labor), it is their students that keep them dedicated to their positions as community college faculty. While it is undeniable that the emotional labor of teaching in a community college exists, and is a very real part of participants' professional lives, it is also undeniable that they are, nonetheless, committed to their students.

\section{Discussion}

For Audrey, it in the form of developing an emotional and relational capacity. For Amelia, it's emotional exhaustion. For Henry, it takes the shape of compassion fatigue. For others, it came out implicitly, the backbone of their descriptions of the hours they put into supporting their students, both academically and not—providing comprehensive feedback on assignments, meeting with them outside of class or office hours, researching innovative teaching practices or ways to address issues of student involvement on campus, or serving as faculty sponsors of student groups. But the idea is the same across 
all of these descriptions: an invisible part of their jobs is emotional labor, and this emotional labor is, in large part, a product of both the diversity of their students, and the subsequent range of their students' life experiences and socio-economic conditions. In this way, the material conditions of their students' lives shape participants' professional lives and identities.

Participants' responses to the material conditions of their students are likewise shaped by the institutional cultures of their colleges - which tend to reflect state-level policies, economies, and stances toward higher education. ${ }^{57}$ Ruby and Audrey, the two participants from Tennessee, where community college education seems to be thriving under programs like Tennessee Promise and Reconnect, are actively involved with the Student Advocacy Project, ${ }^{58}$ a college-wide faculty effort to help ease the burden of students' non-academic barriers to success. One of its projects has been to educate other faculty on the resources the college provides for its students. This is important, Audrey said, because "our college has all these resources, but they [students] need someone to connect them with them, and that person is usually a teacher, because that's who they have contact with all the time." The Student Advocacy Project is working towards providing faculty with a comprehensive list of available resources, so that, should a student come to them seeking help, faculty have their own resource to help guide them in guiding their student. These efforts are supported by the college's administration. Audrey explained the powerful significance of this:

We can either be professors that pretend like it [poverty] doesn't exist, and just be like, "no, I'm not getting involved in your personal life at all." But our college, institution, has said, "no, we have resources to help them in their personal life."

\footnotetext{
${ }^{57}$ Discussed above.

${ }^{58}$ Discussed in more detail in Chapter Four.
} 
[...] We, as professors, we don't have to give them food, if our student tells us, "we can't afford to eat right now." No, it is not your responsibility. But you cannot, as a professor at this school, say, "you can't tell me that, I can't help you." Our school has said, "yes, we will help them, and it's our job to know how to connect them."

According to Audrey, then, it is the institutional position of the college that its faculty are responsible for knowing how to connect their students with the resources the college has put in place for those students, and for sharing that information with them.

In addition to educating faculty on the numerous college resources with which they can connect students, the Student Advocacy Project has also worked to effect tangible change on the college's landscape, such as creating free WiFi hotspots for students who do not have WiFi at home. Audrey attributed such successes, in part, to the institutional support the group receives from the college. She explained that, though the Student Advocacy Project was formed "ground up," it is "top-down supported" by the institution. As such, the success of this group is dependent not only upon the individual faculty who make up the campus reading groups (that comprise the college-wide group), but also on the institutional support of its mission and proposed actions. According to Audrey, the response to the work the group has done has "been really good," and she described how supportive even the president of Bradford State Community College has been. Audrey recounted, in her own words, what he said during a recent meeting of the Student Advocacy Project:

The way he put it, he was like, "you know, sixty percent of my students, our students, are housing and food insecure." He's like, "another way of putting this is sixty percent of our students are one flat tire away from dropping out this semester. One flat tire will destroy a week of their lives, and they will not come to class, and they will feel like they can't catch up, and they will just drop out." And so he gets it. 
While the success of this group clearly, obviously, undeniably stems from the hard work of the individuals involved, such as Audrey and Ruby—and their hard work is not to be diminished - it also relies heavily on this kind of institutional approval and support, including a college president who "gets it," and a campus culture that seems to recognize, as an institution, the inescapable connection between the material conditions of its students' lives and their academic success.

In contrast, Amelia described how, at Rock Creek, addressing these kinds of material conditions of students' lives solely happens on a more individual or departmental basis, and is not institutionally-sponsored as it is at Bradford State. Amelia, at the time of her interview, was working with a faculty team on a federal grant that focuses on improving student success, with a specific focus on some of the so-called "gateway courses" at the college that the majority of students take-including first-year writing. Each of the disciplines involved in the grant has "a committee of faculty within that discipline" that works to "redesign" the class in question. Amelia said of the grant that "the college wrote it, and it's a wonderful thing, but they didn't talk to faculty, they just said, 'here's what we're going to do." As a consequence, she and the other faculty working to redesign the first-year writing course have felt some frustration over the grant, as it is written by the college. Amelia explained that working on the grant involved "a little qualitative study" to get feedback from all the faculty who teach the course, in order to find out at what point in the semester students stop coming to class, and why:

[...] And then we went back, and said, "okay, if we're 'losing' people — so the people who fail or the people who withdraw — why are we losing them?" Because we, like, sitting on the grant, and going-I've told the grant administrator, [...] "you are essentially asking us to fix, through teaching, the fact that people don't have transportation and can't afford the books and don't have a computer at 
home." [...] There are only certain things we can do. Like, this cannot all land at our door.

Here, Amelia points out that, as faculty there is only so much that they are able to do in their role as teachers to address the non-academic reasons why students stop coming to class. The institution, via its authoring of the grant, seems to take the position that retention issues are solely academic, whereas Amelia contends that there are both academic and non-academic barriers to student success with which to contend. Through its approach to issues of student success and retention rates as solely academic, that can chalked up to a problem in the classroom, the institution fails to recognize that such problems may be caused by a combination of both academic and non-academic circumstances — as evidenced by its attempt to tackle such problems via solely academic means. As Amelia pointed out, these are not problems that can be solved by classroom policies alone.

Nonetheless, the English faculty on the grant committee are working within the constraints of the "only certain things we can do," as Amelia put it, to address these problems. One of the strategies the committee is piloting to help increase student retention in first-year writing classes at Rock Creek involves making course policies, such as late work policies, more flexible. Amelia explained that, "there are always the students who disappear for two or three weeks, but then they come back. And [...] if the syllabus, in writing, just says, 'I don't do late work, and, if you don't turn everything in, you get a zero for this part,' well, $[\ldots]$ who's going to come back, if you've already earned a zero and you think you're failing?" She explained that her course syllabus now has language indicating that her class is participating in the pilot program, and consequently provides some flexibility for students: 
So, my syllabus now says, "the college expectation is that papers are to be turned in on time, you will have those due dates a month in advance. This is the expectation. This, obviously, mirrors the professional world." [...] The next paragraph says, "If life happens, don't disappear. Don't assume worst case. Come find me. Wait outside the class, email me, call me, whatever you need to do. Let's, let's see." [...] And then it says, "and if life bites you again, don't disappear." Like, it has "don't disappear" in it like five times.

The inclusion of such language in course syllabi is part of the pilot program's multipronged approach, which also includes trying out more hybrid and online course offerings, as well as online modules covering basic course topics (such as thesis statements) for students who miss class.

At Rock Creek, then, the response to students' non-academic barriers to success, or the material conditions of their personal lives, seems to be largely individual (i.e., on the part of individual teachers) or departmental (e.g., the English division's strategies for increasing student retention in first-year writing classes through the means of the grant), but not explicitly sponsored nor supported by the institution, as the college has concerned itself more with numerical success rates. In other words, the institution, reflecting pressures from the state and KCTCS, seems to have a singular definition of success. Even with the college's authoring of the federal grant to help improve student success rates, there appear to be no institutional structures in place intended to address the nonacademic issues that, invariably, students and their faculty face. Instead, this kind of support seems to come primarily from individual faculty members. In contrast, Bradford State — seeming to mirror recent state legislation such as Tennessee Promise — takes a more holistic approach to student success. ${ }^{59}$ Ultimately, these two institutions ${ }^{60}$ seem to

\footnotetext{
${ }^{59}$ As discussed above.

${ }^{60}$ Bradford State and Rock Creek
} 
reflect differing state-level ideas about how to define student success, and the complex factors—academic and non-academic alike—involved.

\section{Conclusion}

The community college setting is a distinct academic workplace. Because of the community-serving mission characteristic of this institutional setting, individual colleges are unique, in that they tend to reflect the students and needs of the communities they serve (Vaughan, Community College Story). However, they are also shaped by larger forces, having historically and continually been influenced by economic conditions and outlooks at both the state and national levels (AACC; Vaughan, Community College Story; Cohen and Brawer). As such, the working lives of participants are dramatically shaped, not just by their individual institutions, but also by the broader context of statelevel politics and economics. At the same time, because of the open-admissions policy that also characterizes this setting, these faculty's working lives are also significantly impacted by the diverse range of students they teach (AACC; Vaughan, Community College Story), whose diverse needs often result in the creation of emotional labor for participants (Ostman). On the whole, such a context—a dynamic institutional setting that is, from a certain perspective, continually in flux - creates a unique institutional culture, shaped by a myriad of material conditions. However, though they might seem to be, these conditions are not prohibitive in the way our common cultural narratives about the community college setting might lead us to believe. On the contrary, these conditions, in shaping this institutional culture, ultimately lead to and foster the innovative scholarly 
lives of faculty, who enact a different model of scholarship, ${ }^{61}$ one that is intertwined - out of necessity, due to the material conditions of their workplaces - with other job responsibilities (teaching, professional development, and service).

${ }^{61}$ This model is discussed in the following two chapters. 


\section{CHAPTER THREE}

\section{TWO-YEAR COLLEGE WRITING FACULTY AS SCHOLARS: CLASSROOM}

\section{EDITION}

“Just as I'm listening, I keep thinking that, the hole is so huge. Like it's such a chasm, and I really just wanted it to be everything. I want it to fix all of the holes, like, bridge all of it. And it can't and so I'm trying to make peace with, just like, putting those timbers down, so more people can help build the bridge. [...] But it's exciting. I mean, right? Like, almost half of all undergraduate students are at community colleges and people don't talk about it, unless they say the words 'retention' or 'first-generation.' [...] And don't even get me started on people who think community college and go, 'Oh, like all the students who have troubles.' I'm like, hello, SCHOLARS. Schol-ars.”

- Amelia

At the time of her interview, Amelia was in her twelfth year of working full-time at Rock Creek Community and Technical College. She was also completing her dissertation, for which she conducted interviews with community college faculty and students in the Northeast. It is these interviews to which she refers in the quote above. Her interest in the project was initially spurred by the minimal representation two-year colleges have in scholarship in Women's and Gender Studies, the discipline in which she is getting her $\mathrm{PhD}$. In my interview with her, we bonded over this overlap in our research interests and motivations, and Amelia continued by describing how upset she gets when she hears people assert these kinds of commonly-held and misinformed ideas about community college students. 
In their oft-cited volume, The American Community College, Cohen and Brawer assert another commonly-held idea about community colleges - that community college teachers are neither scholars nor researchers. They write, "although it is possible to generalize in only the grossest way when one is describing 300,000 people, demographically the community college faculty differ from instructors in other types of schools. [...] Their primary responsibility is to teach; they rarely conduct research or scholarly inquiry" (84). Cohen and Brawer-authors of what is described as "the nearest thing to a comprehensive work on the community college" (Frye 3) - thus sum up a prevalent attitude about two-year colleges: that they are teaching enterprises, and no more. This idea is commonly understood and accepted, in large part due to the also widely-circulated idea that the practice of teaching is distinct from research and scholarship. Andelora, for example, opens his 2005 article with the statement, "As faculty in two-year and open-admissions colleges, we occupy a somewhat tenuous position in the stratified world of higher education," in part, "because of the institutional culture of twoyear colleges, which historically has cast faculty as teachers, not researchers or scholars" ("Teacher/Scholar" 307).

Like Amelia, who argues that her students are scholars, I argue that she and the other faculty I interviewed are also scholars. Their scholarly identities are not readily recognizable, however, because they engage in an alternate model of scholarship, one that differs from academia's traditionally-understood model, which is premised on the value and reward system of the four-year research university. As discussed in Chapters One and Four, in this dissertation, I understand scholarship to be inquiry work that results in the discovery and circulation of new knowledge. My conception of a scholar is 
someone who engages in such practices - someone who inquires into an issue or problem by asking questions and engaging in research, formal or informal; whose inquiry leads to new knowledge; and who then shares that knowledge, in a variety of forms-e.g., by enacting what they have learned through their inquiry and applying it to practices such as teaching, activism, or departmental or institutional policies; by circulating it within departmental, institutional, local, or regional professional circles; by publishing written texts, research articles or otherwise. I acknowledge that research and scholarship are understood to have certain characteristics, in order to be defined as such—for example, as Shulman notes, scholarship must be peer-reviewed and circulated, towards the end of making and contributing new knowledge to a discipline ("Course Anatomy" 5). Furthermore, adherence to these characteristics is one of the challenges facing the scholarship of teaching and learning, because teaching is not easily translated into a written form that can be peer-reviewed and circulated (Shulman, "Course Anatomy"; Kern et al.; Minter and Goodburn). While there are other concerns when it comes to what makes one's work "valid" scholarship, such as the steps involved in the research process (Shulman, "Course Anatomy"; Kern et al.), my focus is on the "product" of the inquiry and knowledge-making processes of community college writing faculty, specifically examining how and where their more informal scholarly work is applied, shared, and circulated: in the classroom (this chapter) and other sites outside of the classroom, where that work is defined as "professional development" or "service," not "scholarship" or "research" (Chapter Four). My secondary focus is on how those sites, and the work that participants engage in at those sites, are inextricably linked with participants' teaching, 
inquiry, and knowledge-making, influencing the questions they ask and, thus, shaping the research that they do.

Though they are marked — and frequently mark themselves — as "teachers," the faculty I interviewed are also scholars, and the lines between practice and inquiry are not as clear-cut as institutional structures at large might suggest. In the cases of Amelia, Audrey, Donna, Henry, Lois, Ruby, and Sally, the various aspects of their jobs are closely intertwined, with their roles as teachers infusing their research and professional development, so that it is often difficult to distinguish between their teaching and classroom practices, their inquiry and research, and their professional development and service. In this chapter, I focus on the scholarly inquiry that impacts their teaching, recognizing that these two threads are also closely related to their professional development. In Chapter Four, I shift my attention to professional development and service as another type of scholarly inquiry - again, with the recognition that it, too, has a similarly reciprocal relationship with their classroom practices. Together, these two chapters set forth an alternate model of scholarship, characterized by the following:

1) Professional spaces institutionally understood as sites of teaching and professional development and service, but leveraged as sites of inquiry and circulation of new knowledge.

2) Complex and overlapping relationships between faculty's different position responsibilities (e.g., teaching, professional development and service), and between their inquiry practices and circulation of new knowledge.

3) Highly collaborative relationships between colleagues and between faculty and students. 
4) Largely local applications of faculty's discovered knowledge, at the classroom, departmental or divisional, institutional, or regional levels.

This model of scholarship is fostered by the institutional cultures ${ }^{62}$ in which participants work, which have distinct values and rewards systems (Choseed 21).

In examining participants' scholarly practices, I interrogate the cultural narrative of the two-year college faculty member as teacher, at the expense of the designations of "researcher" or "scholar" (Andelora, "Teacher/Scholar" 307), arguing that the two-year college faculty I interviewed for this study are, indeed, scholars, but that those endeavors are not always recognized as such because of they enact an alternative model of scholarship, which is closely associated with the practice of teaching (this chapter) —and professional development and service (Chapter Four). As a result of two-year college faculty being marked primarily as "teacher," the kinds of scholarly work that take place within participants' institutions are likewise marked as "teaching." Of course, much of the scholarly work these faculty describe does, eventually, relate back to the classroom or to their students; it is undeniable that two-year college faculty are, primarily, teachers (Madden, "Crossing Borders"; Albert; Ostman; Carpenter; Choseed)—and, given the community college mission and history, this fact is wholly unsurprising (Vaughan, Community College Story; Frye; $A A C C$ ). However, positions such as Cohen and Brawer's suggest that two-year college faculty's teaching necessarily comes at the expense of their scholarly identities, and so many of their scholarly contributions are often not recognized as such. As a result, their scholarly contributions-i.e., the new knowledge they discover, enact, and circulate - remains largely unrecognized by the

${ }^{62}$ Described in Chapter Two. 
discipline of Composition Studies. Consequently, there is effectively a rift in the body of Composition Studies knowledge, one that falls along institutional lines. McCulloch reminds us that "the principal role of an academic is to produce, shape and distribute knowledge"; as an academic discipline, Composition Studies is in the enterprise of knowledge-production. Recognition of the alternate ways in which faculty in different institutional settings are also scholars engaged in such an enterprise is, I believe, one key step to mending that rift.

\section{Chapter Overview}

This chapter focuses on the classroom practices of two-year college faculty, presenting those practices as examples of scholarly teaching (Shulman, "From Minsk to Pinsk"). Because my argument rests on the idea that academic disciplines are social communities (Hyland), and that, within those disciplines, cultural narratives accrue over time (Bruner), ${ }^{63} \mathrm{I}$ begin with a short overview of the separation of practice from inquiry. Drawing on North's conception of "Practitioners" as distinct from "Scholars" and "Researchers," I contend that the institutional structures that tend to separate teaching from scholarship have contributed to the trope of the two-year college faculty as teacher, not scholar. In the next section, because I understand the disciplinary scholarship within our journals to serve as one vehicle by which such narratives are circulated - thereby both reflecting disciplinary values as well as contributing to their maintenance (Goggin; Hyland) ${ }^{64}$ - I show how the narrative of two-year college faculty as teacher is manifested in some of the prominent journals in Composition Studies. Following this discussion of journal data, I describe how this narrative - and that of practice as separate from

\footnotetext{
${ }^{63}$ As discussed in Chapter One.

${ }^{64}$ As discussed in Chapter One.
} 
inquiry — plays out in the attitudes and self-perceptions of most of the faculty I interviewed. Finally, I discuss the scholarly teaching in which my participants engage.

\section{Practice vs. Inquiry: An Overview}

The relationship between research and scholarship, on the one hand, and teaching, on the other, is fraught, so that the two are often perceived as divorced from one another (Boyer; North; Cohen and Brawer; Shulman, "Visions of the Possible"). North's conception of the creation of new knowledge in Composition, given the discipline's history, aligns with Boyer's telling of the history of higher education in the United States. According to Boyer, the mid-twentieth century saw an expansion of "the mission of American higher education" and subsequently larger student enrollments in universities and colleges (12; see also Goggin; Frye; Connors). However, the continued narrowing of "standards used to measure academic prestige" was in conflict with that expansionspecifically, "the research mission, [...] appropriate for some institutions," cast "a shadow over the entire higher learning enterprise," and soon came to be "the yardstick by which all institutions would be measured" (Boyer 12, emphasis in original). Consequently, Boyer argues, "at the very time America's higher education institutions were becoming more open and inclusive, the culture of the professoriate was becoming more hierarchical and restrictive," ultimately resulting in a system of higher education dominated by "a single model of scholarship" $(12-13 ; 55)$. This tension is particularly apparent in Composition Studies, a discipline that, from some scholars' perspectives, was

relegated to the margins of English departments during its formative period because of its emphasis on the teaching of writing, at the expense of more "scholarly" pursuits 
(Strickland; Miller; Connors; Brereton). It is important to point out that I am not suggesting that Composition Studies does not value teaching, nor am I suggesting that a wide range of scholarship is not actively pursued and celebrated (Gebhardt, "Evolving Approaches"; Gere; Minter and Goodburn; Schilb). Such commitments are evidenced by the countless publications and individuals who have shaped the discipline, and are facts to which my own experiences as a student attest. I am, however, suggesting that these commitments have, at times in our short history, been at odds with institutional structures of modern higher education that prioritize empirical research, and that see teaching and research as separate pursuits (Boyer; Frye; Gebhardt, "Scholarship and Teaching"; Connors; Brereton; Ray; Shulman, "Visions of the Possible").

North's The Making of Knowledge in Composition delineates the compounding of such attitudes toward teaching and pedagogy within Composition Studies. North argues that "the birth of modern Composition, capital C" in 1963 was marked by the "need to replace practice as the field's dominant mode of inquiry" (15). In the 1960s, North explains, "practitioner knowledge" had "to be supplanted," as called for in a report ${ }^{65}$ which North deems "the charter of modern Composition" (16-17). Furthermore, per North's interpretation of the document, "the authority of an emerging Composition [is derived] from inquiry_'research'-modeled [...] on research in the sciences," at the expense of "practical knowledge, the stuff of teachers' rooms, how-to-articles, textbooks, and the like, [which] doesn't count as research" (North 17). Writing from his perspective in the late 1980s, North contends that, since the mid-1960s drastically changed the face of Composition, we are "largely unaccustomed to entertaining the notion of practice as a

${ }^{65}$ Research in Written Composition, written by the NCTE Executive Council in 1962. 
mode of inquiry at all, as involving a series of steps that result in a contribution to a field of knowledge," and, under the new paradigm of disciplinary knowledge established in the 1960s, it is well understood that "Scholars and especially Researchers make knowledge; Practitioners apply it" (North 21, emphasis in original). The relegation of practice to a less-than-scholarly pursuit, then, was a reaction to the then-tenuous position of Composition and Rhetoric as an academic discipline within American higher education. ${ }^{66}$

The maintenance of the split between scholarship, research, and practice—and the hierarchy in which these pursuits are organized—has had its lasting effects. As discussed in the literature review in Chapter One, two-year colleges have been impacted by a legacy that has left its seemingly indelible impression that this kind of institutional setting is second-rate, in part because of its mission and prioritizing of teaching over research (Frye; Cohen and Brawer; Reynolds, "Two-Year-College Teachers”; Andelora, "The Teacher/Scholar"; Kroll and Alford; Choseed; Powers-Stubbs and Sommers). Very broadly ${ }^{67}$ the alignment of two-year colleges with teaching - the teaching of "underprepared" students, no less—and of universities with research has been a contributing factor to the popular trope of TYCs as places devoid of scholarly activities, resulting in a binary that privileges four-year research universities (Choseed). As I understand it, this binary tends to aligns scholarship with research and theory, in contrast with practice and teaching - reflecting the values and rewards system of most fourresearch universities, established by the typical tenure process at such institutions (Boyer, Scholarship Reconsidered 12, 15; Glassick et al. 7-8).

\footnotetext{
${ }^{66}$ As also discussed in the literature review in Chapter One.

${ }^{67}$ This history of - and the relationships between - two-year colleges and universities are much more complex than presented here, as described more fully in the literature review in Chapter One.
} 
Like Andelora, Reynolds points out that because of the institutional background of two-year colleges, TYC faculty consequently "belong to that large body of practitioners who have contributed to what Stephen North has called lore, the knowledge that emanates from classrooms across the county and from teacher practice, much of which never gets written down but which circulates widely through practice and talk and, consequently, becomes knowledge" (“Two-Year College Teachers" 5). Per North's terms, practice, the realm of the teacher, becomes inquiry—but not scholarship —only when it contributes to lore (33). Lore is, as Reynolds explains, the medium by which the new knowledge that might be produced through practice is circulated amongst other Practitioners (North 33; Reynolds, "Two-Year College Teachers" 5). Reynolds further points out that such lore-in North's terms - is rarely written down ("Two-Year College Teachers" 5). In a discipline whose very understanding of scholarship is premised on the written product that is so often used to circulate the new knowledge discovered through research (Kirsch and Sullivan; S. Miller, "Writing Theory : : Theory Writing"), it is unsurprising that lore is rarely considered scholarship. North explains that "the various forms of Practitioner publication" range from "the very informal," such as hallway conversations, to formal conference presentations, and argues that "writing is, by definition, the medium least amenable to representing the results of Practitioner inquiry," going so far as to claim that when Practitioners write about their inquiry, "they look more and more like bad Scholars or inadequate Researchers" (North 51-55). Practice is thus divorced from scholarship. This idea is reflected by others, such as Weimer, who explains that the general understanding amongst university faculty is that "writing about pedagogy isn't regarded as legitimate scholarship" (44). It is my position that two-year college 
faculty are still working within this paradigm, one that has been perpetuated, in part, by disciplinary scholarship, as evidenced by trends in the institutional affiliations of contributors to some of the prominent journals in Composition Studies. Moreover, the interviews I conducted suggest that, though participants do not always describe their work as such, they are, indeed, engaged in rich scholarly activity — further illustrating the enactment of this paradigm.

\section{Two-Year College Faculty: Teacher, Not Scholar}

In his 2005 article on the professional identities of two-year college English faculty, Andelora writes:

For all intents and purposes, two-year college English faculty have established a strong national identity within the field of rhetoric and composition. However, while the growth of the national organization [TYCA], a successful journal [TETYC], and strong representation on national committees all indicate considerable success in forming a national presence within the discipline, a look at who actually contributes to the rhet/comp journals complicates the story. Twoyear college English faculty have never had a particularly strong presence in the journals that make up our discipline. (312; emphasis added)

Given the overview of the relationship between practice and inquiry outlined in the section above, and the shape that history has taken in the institutional hierarchy of postsecondary education, I contend that the "tenuous" position of two-year college faculty that Andelora also describes ("Teacher/Scholar" 307) has been perpetuated, in part, by trends in the institutional affiliations of contributors in scholarly journal publications in Composition Studies. These trends, as I discuss in this section, both evidence this hierarchy, as well as contribute to the cultural narratives surrounding two- 
year college faculty in the discipline (Bruner; Hyland; Goggin). ${ }^{68}$ Furthermore, these narratives are apparent in the attitudes and self-perceptions described by interview participants.

\section{Trends in Institutional Affiliations of Journal Contributors}

As described in detail in Chapter One, in order to better understand the trends in Composition Studies journals related to two-year colleges, I conducted keyword searches in six journals (below). From those searches, I identified contributions from two-year college-affiliated authors. Because of the drastic differences between the search results (discussed below), I have placed these journals into two categories:

1) Four-Year Journals, or journals with contributors predominantly from four-year institutions:

- College Composition and Communication (CCC),

- College English (CE),

- Computers and Composition (CandC),

- Journal of Basic Writing $(J B W)$, and

- WPA: Writing Program Administration (WPA)

2) Two-Year Journals, or journals with contributors predominantly from two-year institutions:

- $\quad$ Teaching English in the Two-Year College (TETYC)

In this section, I refer to the categories listed above in my discussion of the search results. Furthermore, like Hassel, whose 2013 study of the journal, Teaching English in the TwoYear College, focused specifically on research articles, and because of the high academic

\footnotetext{
${ }^{68}$ I more fully explain my conception of the relationship between journals, disciplinarity, and cultural narratives in Chapter One.
} 
value placed on traditional research articles as a product of scholarship, my analysis of journal data in this section focuses on research articles with at least one two-year college author.

From the journal data that I collected, I found that, on average, less than one article with a two-year college-affiliated author is published annually in each of the journals in the Four-Year group $(C C C, C E$, Cand $C, J B W$, and $W P A) \cdot{ }^{69}$ Keyword searches in journals from the Four-Year group yielded a total of 384 results from the five journals; of those results, only $66^{70}$ are authored by at least one two-year college-affiliated contributor. ${ }^{71}$ Roughly half of those 66 pieces-36, or $54.5 \%$ - are articles. ${ }^{72}$ Because I collected data from a total of ten different years $(1995,2000,2005$, and 2010-2016), this means that, on average, only 3.6 articles (single-authored and co-authored articles) with at least one two-year college-affiliated author are published each year across these five journals collectively, or an average of less than one article with a two-year college author in each. Again, this number includes co-authored articles, over $70 \%$ of which include university-affiliated authors. ${ }^{73}$ Perhaps unsurprisingly, these results contrast with findings from Teaching English in the Two-Year College, the only journal in the Two-Year

\footnotetext{
${ }^{69}$ See Table 4 for a breakdown of results by journal.

${ }^{70}$ The vast majority of search results that included the keywords searched, but did not have a TYC-affiliated author, were from the front or back matter of the journals.

${ }^{71}$ Affiliation at the time of writing, as indicated in the journal.

${ }^{72}$ The other 30 pieces are in the following categories: Review, Letter from Conference Chair, Plenary Talk, From the Editor, In Memoriam, Poem, Position Statement, Response, Comment, Open Letter, Discussion Forum, and Symposium.

${ }^{73}$ See Tables 7, 8, and 9 in Appendix C for a breakdown of single-authored and coauthored articles by journal.
} 
Journal group, as seen in Table 4. In the data collected from the same ten years of TETYC, ${ }^{74}$ I found a total of 281 TYC-authored contributions, 111 of which are articles. ${ }^{75}$

While these numbers are certainly telling, the most eye-opening data from the journals comes in the form of the annual percentage of journal articles that have at least one two-year college-affiliated author. After calculating the average number of articles with a two-year college author published every year within each journal (Table 4), I then calculated the average number of articles published annually by each journal during each year I collected data from $(1995,2000,2010-2016)$. From these two averages, I found the average percentage of articles with at least one two-year college author that are published annually in each journal. The results of these calculations can be seen in Table 4, and are illustrated in Figure 1.

Table 4: Articles with Two-Year College (TYC) Authors

\begin{tabular}{|l|c|c|c|c|}
\hline Journal & $\begin{array}{c}\text { Total \# Articles } \\
\text { w/ TYC Author } \\
\text { (years searched) }\end{array}$ & $\begin{array}{c}\text { Average \# } \\
\text { Articles } \\
\text { Published/Year* }\end{array}$ & $\begin{array}{c}\text { Average \# } \\
\text { Articles/Year } \\
\text { with TYC Author }\end{array}$ & $\begin{array}{c}\text { Average \% } \\
\text { Articles/Year } \\
\text { with TYC Author }\end{array}$ \\
\hline$W P A$ & 3 & 10.30 & 0.30 & $2.91 \%$ \\
\hline$C E$ & 6 & 21.90 & 0.60 & $2.74 \%$ \\
\hline$J B W$ & 8 & 9.55 & $0.88^{* *}$ & $9.21 \%$ \\
\hline$C C C$ & 9 & 16.80 & 0.90 & $5.36 \%$ \\
\hline CandC & 10 & 27.20 & 1.00 & $3.68 \%$ \\
\hline$T E T Y C$ & 111 & 17.60 & 11.10 & $63.07 \%$ \\
\hline
\end{tabular}

*Based on total number of articles published for each year searched: 1995 (1996 for TETYC), 2000, 2005, 2010-2016 (2010-2015 for JBW).

** Journal data for 2016 issues of JBW unavailable at the time of data collection; average based on nine years of issues, instead of ten.

\footnotetext{
${ }^{74}$ Except for issues from 1995, which were unavailable at the time of data collection, so I searched issues of TETYC from 1996, instead.

${ }^{75}$ The other 170 pieces are in the following categories: Report, White Paper, Review, From the Editor, Poem, Commentary, General Information, Speech, Response, Instructional Note, contributions to the "What Works for Me" section, and Inquiry Piece (series started by current TETYC editor Holly Hassel in 2013).
} 


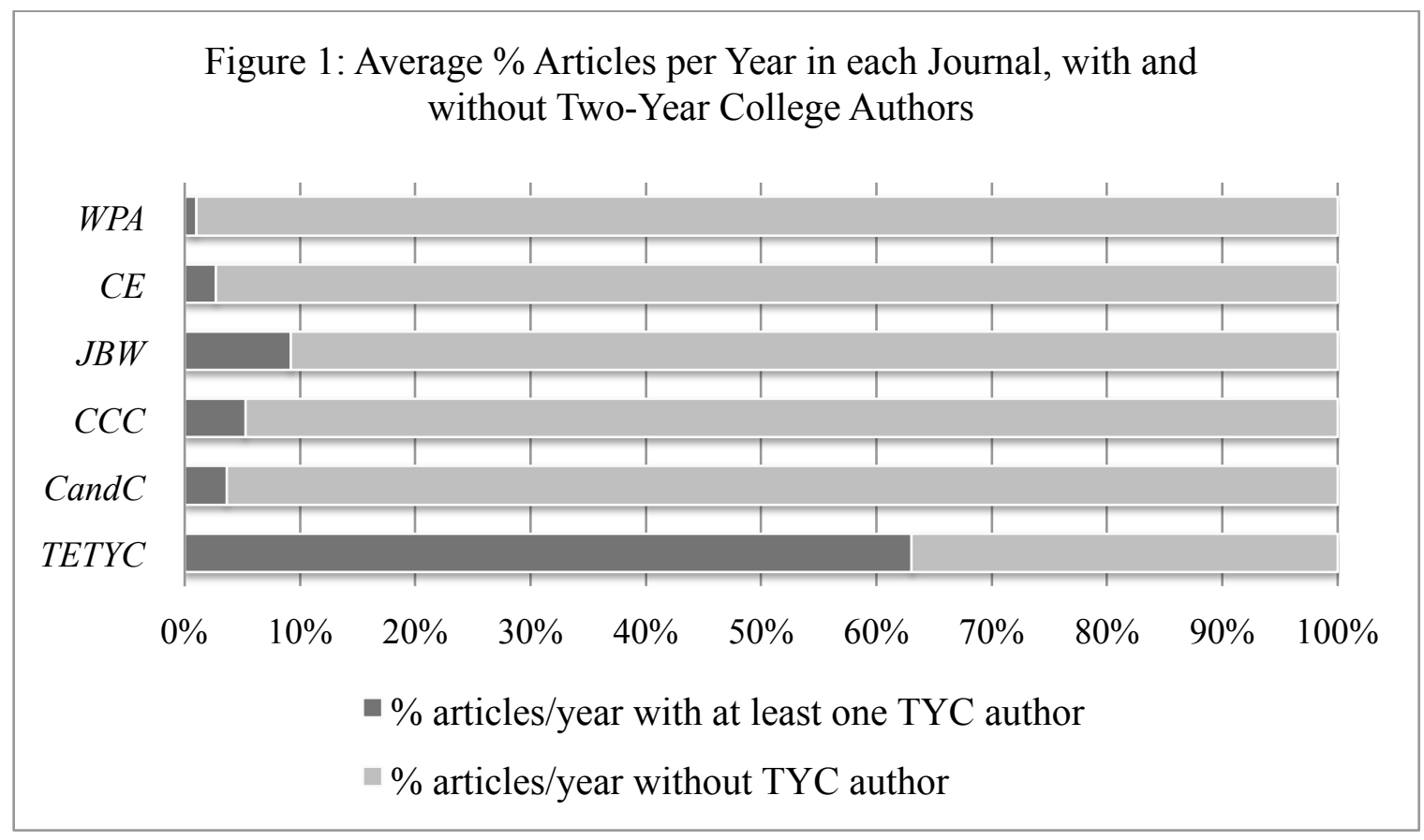

As Table 4 and Figure 1 show, on average, fewer than 10\% of the articles published annually are authored by a two-year college-affiliate in each of the journals that comprise the Four-Year Journal group ( $W P A, C E, J B W, C C C$, and $C a n d C$ ). For three of those journals ( $W P A, C E$, and $C a n d C$ ), that number is less than $5 \%$, illustrative of what Kroll and Alford describe as "the comparative invisibility of two-year college faculty in academia" (60). These numbers are striking, given that, according to the American Association of Community Colleges, nearly half of all undergraduate students are enrolled in two-year colleges, and that the majority of the English courses taught in twoyear colleges are composition courses (Ostman). In fact, TETYC alone comes closest to representing the reality of the institutional affiliations of those who teach college writing courses. Overall, these findings attest to - and clearly illustrate - what others have already argued: that much of our disciplinary scholarship is, and has been, authored primarily by faculty affiliated with four-year institutions (Amorose; Goggin), and that the 
presence of two-year college faculty is minimal in the vast majority of that scholarship ${ }^{76}$ (Raines "Teaching Writing"; Raines "Is There a Writing Program"; Tinberg "Seeing Ourselves"; Nist and Raines "Writing in the Margins"; Nist and Raines "Two-Year Colleges"; Holladay; Alford; Sommers “Two-Year College English Faculty”; Reynolds “Two-Year-College Teachers”; Andelora “Teacher/Scholar”; Ostman; Hassel; Toth; TYCA “Guidelines”).

Of course, there are certainly a number of possible reasons why there may be so few publications from two-year college faculty in these journals. For example, perhaps fewer than $3 \%$ of the articles in WPA during the years I searched have two-year college authors because so few two-year colleges have a distinct and institutionally-recognized writing program (Ostman; Taylor). However, such programs are often "embedded" in the curriculum (Gladstein and Regaignon 96), and it is important to note that the work of writing program administration does take place in two-year college, recognized or not (Ostman). Because most TYC English departments predominantly teach developmental or first-year composition or other kinds of writing courses, whole departments tend to function as writing programs in many ways, and so the work of writing program administration is often woven in to the job of the department chair or other administrative roles (Ostman; Holmsten; Calhoon-Dillahunt; Klausman, “Mapping the Terrain”; Klausman, "Toward a Definition"; Raines, "Is There a Writing Program”; Kroll and Alford). Furthermore, as this dissertation argues, the institutional culture of the typical community college is another likely reason for so few publications by two-year college

\footnotetext{
${ }^{76}$ As discussed in Chapter One.
} 
faculty, as it fosters an alternate form of scholarship, by valuing and rewarding "products" of inquiry distinct from the traditional research article.

Hyland sees published academic writing as a "collective social practice"; scholarly journals, as one iteration of that practice, function as "the most concrete, public and accessible realization of these practices," and, consequently, "[influence] how members relate to one another, and [determine] who will be regarded as members, who will gain success, and what will count as knowledge" (Disciplinary Discourse 1; 5). Working within this framework of academic discourse, and given Goggin's understanding of the disciplinary role of journal scholarship ${ }^{77}$ — that journals "[shape] the discipline even as they are shaped by it" (xvi) — this journal data reveals one way by which the narrative of the TYC faculty as teacher, not scholar, is manifested: by impacting the very shape of the conversations that take place within scholarly journals published in Composition Studies. The effect of so few articles by two-year college authors being published in $C C C, C E$, Cand $C, J B W$, and $W P A$ is that two-year college faculty have a very limited representation in those journals; though they do have a presence in the journals, that presence is minimal on the pages containing research articles. It is notable that two-year college faculty are mentioned frequently in the journals in the Four-Year group (to which the total number of 384 search results yielded in my keyword searches attests), and yet the vast majority of those results dwell on pages in the front and back matter of the journals - e.g., advertisements and lists of committee or editorial board members. It is also striking that only approximately half of the 66 pieces written by a two-year college author are articles, as the other half includes book

\footnotetext{
${ }^{77}$ Also discussed in Chapter One.
} 
reviews, plenary talks, "in memoriam" pieces, open letters, responses, comments, and at least one poem. I do not wish here to discount these other types of pieces, as they are, indeed, valuable contributions to disciplinary conversations. However, such pieces are not usually considered "scholarly" in the same way that a research article is. Overall, the shape of disciplinary journal scholarship, as drawn by the institutional affiliation of its contributors, likely influences the value system of what is counted or valued as scholarship, per the institutional hierarchies of four-year research universities, which dominate.

In other words, what is largely valued in research universities tends to be what is valued in the discipline at large; it is the university system that dictates the valuing of scholarship across the discipline (Goggin), and, indeed, academia (Boyer; Shulman, "Visions of the Possible"). Goggin, specifically, notes that "[the discipline of Rhetoric and Composition] has been anchored increasingly within one kind institution"- the fouryear research university (161-166). Furthermore, because the five journals in the FourYear group are prominent in Composition Studies, and are thus vehicles for much of the circulation and exchange of disciplinary ideas and knowledge, trends in article authorship affiliation in these journals, as well as the marked presence of two-year college contributors in parts of the journals that are not research-focused, likely contribute to the idea of two-year colleges as places where little scholarly work takes place-because that work is not fully represented in journals such as College English or CCC. Disciplinary members from other institutions are thus less likely to be exposed to the scholarly endeavors and contributions of two-year college faculty; this contributes to - and helps 
maintain - the narrative that these faculty are solely teachers, at the expense of also being scholars.

Ultimately, the stark difference between two-year college affiliated authors in the Four-Year and Two-Year Journal groups illustrates the apparent disciplinary split between the two types of institutions, perhaps also illustrating documented tensions between four-year universities and two-year colleges (Fearing 185; see also: Choseed; Schwalm; Nist and Raines; Trainor and Godley; Powers-Stubbs and Sommers). Hyland suggests that disciplinary "members" participation in academic discourses contributes to [...] disciplinary cohesion," and that, "although they work day to day in local institutions, members have a sense of being part of a discipline," so that "one often has more to do with people one meets occasionally at conferences $[\ldots]$ than with those on the next floor of the same building" (Disciplinary Identities 43; 25). In contrast, the faculty I interviewed work both within and outside of disciplinary lines, teaching courses and working with colleagues in other disciplines, as well as presenting at conferences outside of Composition Studies. The primary affiliation with which they identify seems to be institutional, rather than disciplinary, aligning with Toth's findings in her 2014 study of two-year college faculty membership in professional organizations, as well as the idea of the two-year college as interdisciplinary and TYC English faculty as generalists who are necessarily adaptable (Ostman; Reynolds, “Two-Year-College Teachers”; Starr). Drawing on Hyland's understanding of the important role of academic discourse (such as that circulated via published journal scholarship) in disciplinary cohesion, I suggest that the shape of our own discipline's apparent institutional split in recent journal scholarship serves to also illustrate the established scholarship-teaching binary that persists in 
academia (Choseed; Ray), and consequently perpetuates the narrative of the two-year college faculty as teacher, not scholar.

\section{Attitudes and Self-Perceptions of Interview Participants}

The narrative of the two-year college faculty as teacher, at the expense of scholar, is apparent in the interviews I conducted. From these interviews, I found that, though participants leverage their classrooms and professional development and service efforts as spaces in which they also engage in scholarly activity, these sites tend to remain unacknowledged as sites of scholarship_-by common understandings in academia at large; by participants' institutions, which see them as sites of teaching and professional development; and, often, by participants themselves, as I also found that participants seem to have internalized the cultural narrative perpetuated by disciplinary scholarship that identifies these faculty as teachers, at the expense of also being scholars, and that, consequently, they tend to align themselves with "practice," not "scholarship" or "theory."

In this section, I describe how this narrative - and that of practice as separate from inquiry - plays out in the attitudes and self-perceptions of these faculty. First, in order to establish the narrative, I discuss how some participants embody the teacher narrative when describing their jobs. I then examine the ways in which some participants apparently devalue the writing that they produce, as well as understand "writing for work" as necessarily "publishing research articles," suggesting that this conflation of "writing" with "research"—alongside the devaluing of their own writing — further exemplifies the narrative of practice as separate from inquiry embedded in disciplinary and institutional structures. Before describing how the idea of two-year college faculty as 
teacher, not scholar, is manifested in the interviews, it is important to note that I am not contesting the idea that teaching is the primary role of two-year college faculty, as is made very clear by existing literature and participants alike. Rather, my goal in this section is to examine how the idea that teaching is distinct from scholarship is manifested in the lived professional experiences described by participants, in order to argue in the next section that, though it often goes unrecognized as such, their teaching is scholarly work.

\section{TYC Faculty as Teacher}

As noted, I am not seeking to contest that teaching is the general institutional focus of two-year colleges — as described in Chapter Two, for all of the faculty I interviewed, teaching is the aspect of the job that takes up the majority of their time. For example, per their contracts as full-time community college faculty, Donna, Henry, Sally, and Amelia devote $80 \%$ of their time to teaching. While they also engage in many other professional activities beyond teaching - again, as discussed in Chapter Two - teaching is the ultimate focus of their work, a finding that aligns with existing scholarship on twoyear colleges (Vaughan, Community College Story; Cohen and Brawer; Ostman). Indeed, this focus is why some of the individuals I interviewed were initially drawn to working in a community college. Henry, for example, said that when he first started his full-time job at Mountain Hill, he thought, 'Oh great! I really just want to teach,'” explaining that he “wasn't all that keen on doing research and publication, [and] being subject to the ‘publish-or-perish' imperative." Though his attitudes toward research have since changed, ${ }^{78}$ this statement, an expression of Henry's perception of community college

\footnotetext{
${ }^{78}$ As discussed in more detail below.
} 
work as a newcomer to the institution, ${ }^{79}$ succinctly captures narratives surrounding twoyear colleges, teaching, and research often embedded in cultural understandings and attitudes.

Similarly, Audrey decided to pursue a community college career because of the focus on teaching, based on her own previous experiences as a community college student, experiences that stood in contrast to those she had in the university classroom. As discussed in Chapter Two, Audrey is a former part-time community college student who took several general education courses for transfer credit while working on her Bachelor's degree at a four-year research university—like many other community college students who attend part-time or for transfer credit $(A A C C)$. Audrey explained that, after a troubling classroom experience with a professor at the university, she immediately dropped that professor's class, and later took its equivalent at a nearby community college. There, she said, "I realized that my professors were very different, they were very student-focused. [...] I just loved my teachers." In contrast to her university professors, Audrey's professors at the community college “didn't seem focused on their research; they were focused on teaching." Her professors' focus on their students—in addition to the diversity of her classmates, as described in Chapter Two-ultimately shaped Audrey's career path. It was there, she reflected, that she decided, "'I want to teach at a community college." Throughout her interview, Audrey repeatedly noted the impact of her experience as a student in a community college, citing both her interactions with her classmates and the impact of her teachers as the reasons she now teaches and

\footnotetext{
${ }^{79}$ In his interview, Henry noted that, prior to working at Mountain Hill, his only postsecondary teaching experience was at a four-year research university, and he often drew comparisons between the two institutional settings.
} 
tutors part-time at Bradford State, and is seeking a full-time position there. Audrey, then, decided to pursue a career in a two-year college because of the focus on students, a focus that is a reason that many individuals choose to begin or continue to work in this institutional setting (Choseed; Albert; Starr).

For most of the other faculty I interviewed, like Ruby and Donna, the distinguishing characteristic of community colleges as teaching-focused is a prominent factor in the general job satisfaction they describe, ${ }^{80}$ one that, for many, makes this institutional setting a preferred workplace over a four-year college or university setting (Choseed). For example, when I asked why she decided to work in a community college, Ruby - who has worked in both high schools and community colleges over the course of her career-explained, "I really think the well-kept secret is with the community college classroom." She continued:

The community classroom setting is so ideal. Because you have the freedom that you don't have in K-12 education, and you don't have some of the expectations and pressures in the four-year college.

Ruby further described teaching and being in the classroom as "great" and "a lot of fun," and, when explaining a typical week of work, she summed up her description with the conclusion that, yes, “things add up, but, generally_I mean, I can't complain. Generally, I teach my classes, and I grade papers. That's the real focus. And meet with students. That's the focus of my job."

This focus on students and teaching is also prominent in Donna's interview. Like other interviewees, Donna's research is intertwined with her teaching and professional

\footnotetext{
${ }^{80}$ Though participants may not all be entirely positive about the institutional structures and material conditions within which they work, they all describe enjoying their jobs as teachers.
} 
development, and is largely fueled by her obvious desire to improve her teaching for the sake of her students. Consequently, Donna's students have a profound impact on her, and, as is the case for all participants, a primary reason why she works in a community college. For example, Donna stated, "community college students are very different than university students. [...] That is why I teach at a community college." The differences she sees between university and community college students, combined with an institutionwide emphasis on student success are, as Donna makes clear, the reason she works at Rock Creek. She prefers community college work to her university experiences because of the focus on students that she and Ruby (and others) describe.

Donna made other, similar observations about the differences between working in a four-year setting and working in a two-year setting, such as the difference between students at each ${ }^{81}$ In fact, similarly to Audrey, Donna began teaching at Rock Creek fulltime because of these very differences. She explained that, when she was in graduate school working on her $\mathrm{PhD}$, "obviously, the need to publish was there," and described the competitive environment of the department that ensued. It was this kind of environment that contributed to her decision to quit her doctoral program early and work full-time at Rock Creek, where she had previously been working part-time as an adjunct. In contrast to the university where she was a graduate student, Donna said, at the community college, "there's no competition against each other in that way. [...] Our entire mission is student success, and we're focused on students, and so it's not about who can get published and who can do this and who can do that. [...] We're not competing against

${ }^{81}$ Differences that are also noted by Henry, Sally, Audrey, and Lois. 
each other." Donna thus attributes her collegial work environment with the college's mission of student success.

As an example of the ways in which this relationship between a student-focused institution and minimal competition between colleagues, Donna described the tenure process at Rock Creek. The process of getting tenure at the community college is still "a pretty rigorous promotion process," similar to "what it would be at a university," but, because of the college's focus on teaching, Donna sees two important differences:

1) publications are not required, but do count as "bonus," and

2) at the community college, "we're only competing with ourselves." According to Donna, this second difference is a product of the institutional structures of universities and community colleges. As Donna explained to me, at Rock Creek, "there's not a certain number [of people] that can get [tenure]. If you do what you are supposed to do and you can prove it, document it, and you shine in whatever way, according to which promotion you're going for, you get it." Interestingly, Donna's description of the tenure process at Rock Creek is similar to the process at most four-year institutions. What she sees as the absence of competition with colleagues for things like tenure is, according to Donna, due to the student-focused mission of the two-year college. Consequently, Donna views this focus as positive, in that it promotes a more collegial work environment for her and her colleagues - one that is similar to those described by other interviewees. However, some scholars argue that an overwhelming emphasis on this focus contributes to the maintenance of the idea that community colleges are devoid of scholarly activity (Choseed; Vaughan, "Scholarship and Teaching")—-despite strong evidence to the contrary. 
While she regularly conducts research related to her teaching and has a notable publication history, ${ }^{82}$ Donna was also very open about her decision to not write for publication at this point in her career-having been teaching at Rock Creek for roughly twenty years - a decision that stems from the college's mission of student success and the subsequent focus of her job on teaching. For example, she explained that, since the time she served as department head, when she did publish various types of writing, such as newsletters and articles, she "hasn't sent out anything that wasn't solicited." The reason for this, as she put it, is that "I just haven't felt the need to. [...] At one point, I wanted to be a dean, or this, or that, and — not now. I'm just going to teach my classes." However, as I discuss at length below, Donna's teaching exemplifies the ideals of the scholarship of teaching and learning (Boyer; Shulman) and scholarly teaching (Shulman, "From Minsk to Pinsk"). As such, what she describes as "just" teaching also includes the research she conducts in order to improve her and her colleagues' teaching methods. This is true for all of the other participants. Ultimately, their discussions of their teaching, research, and publication practices exemplify some of ways in which the teacher narrative simultaneously embodies the concurrent narrative that separates teaching from scholarship, and practice from inquiry and theory (North; Powers-Stubbs and Sommers; Choseed; Ray).

Embodying the Scholarship-Practice Binary

It is clear that there is a perceived split between two- and four-year institutions, a split that seems to be "based primarily on the prestige attached to research versus the devalued position of teaching" in both Composition Studies, specifically, and in

\footnotetext{
${ }^{82}$ Both of which are discussed in more detail below.
} 
academia, overall (Powers-Stubbs and Sommers 29). Or, as Choseed puts, "there is a split between theory and practice, a binary which still needs to be deconstructed" (21) — or, indeed, as Ray explains, the "low status" of teachers is partially due to "a false dichotomy between teaching and research" (Ray 49). As described above, this binary tends to align scholarship with research and theory, in contrast with practice and teaching. This binary is present across all interviews, and the devaluation to which Powers-Stubbs and Sommers refer often moves beyond teaching. It is frequently present, either explicitly or implicitly, in participants' descriptions of various aspects of their work, descriptions that embody the binary Choseed describes.

A brief but clear example of this binary played out early in my interview with Sally, after I asked her about the typical size of an English class at Rock Creek. While explaining that she recently learned that class sizes vary from campus to campus, determined by the buildings residing on each, Sally interjected her description with the following remark:

[...] the desired [class] size, which I believe is recommended by, you know, people who study this thing [laughing], like you, probably.

Here, Sally refers to me - a researcher from a university who is interviewing her — as the kind of person who probably studies the things that make their way into disciplinary recommendations about best practices for teaching, guidelines that impact the administrative decisions she must make, such as the maximum number of students that should be enrolled in a college writing class, and ultimately have the potential to shape the classroom practices of her and her colleagues. In short, in this brief moment during our conversation, Sally has aligned me — as someone who "[studies] this thing"—with "research" and "theory," while aligning herself with "practice" (Choseed; Ray). It is 
within this binary - that privileges the university/research/theory side over the community college/teaching/practice side - that participants seem to place themselves (and those who work in four-year settings), as evidenced by the ways in which they frequently seem to devalue their work.

This devaluing was often apparent when participants spoke about the kinds of writing they do for work, a topic I asked everyone about. A clear example of this happened later in Sally's interview, when she described the different kinds of writing she has published. While she identified this writing as scholarship, ${ }^{83}$ she consistently devalued it while describing it to me. When I asked her what kinds of writing she has done for work, Sally answered, "I've had a couple little things published, [but] nothing great" (emphasis added). She elaborated, explaining how she "wrote an essay about teaching [detective fiction] online" for an edited collection:

So I wrote that essay, and it was published there [in the edited collection]. I don't know who would buy something like that, but anyway, it got published. [...] I bought it because my essay was in it, but, you know. (emphasis added)

Sally wrote the essay in question based on her own experiences teaching detective fiction online; though we did not go into all of the details about her experience writing this essay, it seems to be an example of the scholarship of teaching, as Sally's pedagogy, here, has gone into circulation via this edited collection (Boyer; Shulman). However, Sally's apparent negative attitudes toward her own scholarship appear to embody the idea of such scholarship as "less than."

\footnotetext{
${ }^{83}$ Important here, too, is how Sally notes that it's been the administrative work-not teaching, as is the common idea - that has stood in the way of her writing, and that, once she's done with her administrative role after this year, she's looking forward to getting "back to some scholarship."
} 
Donna similarly undercut the value of the work she has done throughout her long and distinctly successful community college career. Donna did acknowledge her success, occasionally saying things such as, “And again, I don't know who this person is that's talking to you, because my entire career has not been like this. I don't know when the transfer happened," while describing how frequently she is solicited to publish or is invited to go to conferences. Immediately after such an acknowledgement, though, Donna added this disclaimer:

And again, we're talking really minor here, not like [...] getting invited to go to College English, you know. [...] In Kentucky, my name matters, not any place else. Those are two different worlds, and I don't live in that world.

Like many other interviewees, Donna frequently made such distinctions between regional publications and conferences, where she most often publishes and presents, and national publications and conferences - the latter (national) being the realm of the university professor, and the world in which, as she put it, she does not live. Nearly all participants made similar distinctions between regional and national venues for publications and presentations, even when simply describing these venues, almost always adding the qualifier of "regional" or "national." There was the apparent need, then, to qualify the "world" in which their scholarship circulates when discussing it with me, a researcher from a four-year university, if they even identified that work as scholarly at all. Additionally, most interviewees seemed to assign less value to the regional conference and publication circuit, in contrast to the national circuit.

One of the consequences of the university-dominated journal scholarship of the discipline is that it is this institution-type's value system that gets embedded in disciplinary attitudes toward and understandings of scholarship, a value system that is, 
indeed, prevalent throughout academia at large (Boyer; Shulman; Amorose). As Ray points out, "classroom experience is institutionally devalued and discounted as a form of knowledge making" in this value system (50). This hierarchy seems implicit in participants' apparent devaluing of their non-teaching work, as well as their decisions to make distinctions between "regional" and "national" venues. It was also often apparent when some participants discussed the kinds of writing they do for work. When I asked interviewees about their writing practices, several of their responses seemed to conflate "writing for work" with "scholarly writing" or "research articles" - types of writing that are generally also understood to be highly valued by the standards of a four-year research university—reflecting our discipline's understanding that writing is integral to scholarship (Kirsch and Sullivan; S. Miller, "Writing Theory : : Theory Writing"). For example, Sally's initial response to my question about writing for work was:

Well, I don't do as much of my own writing as I thought I would in this profession, being a writing teacher. [...] So I've written papers for presentations at conferences. I've had a couple little things published. [...] But haven't done much of that in recent years, because the administrative stuff kind of got in the way. But I do believe in that, and I value it, and I think, you know, I need to be doing more of it. That's one reason why, after seven years in administration, I will be happy to kind of get away from that a little bit, so that I can get back to some scholarship, you know.

Likewise, Audrey's initial response to the same question also focused on scholarly writing:

Writing for work. Mm, no. Thought about it, but I haven't. [...] When I first started adjuncting, I wanted to do a research project with some colleagues from grad school. But, as an adjunct, you don't have access to data.

By immediately bringing up conference presentations and publications (Sally) and research projects (Audrey), Audrey's and Sally's responses seem to embody an understanding of "writing for work" as necessarily "scholarly writing"-at least when 
that question is coming from an individual from a research university, who necessarily represents that kind of scholarship, given the context of the interview. In contrast, other participants (e.g., Henry, Donna) responded to this question with detailed descriptions of other kinds of writing related to their jobs, such as emails, letters of recommendation, lesson plans, assignment sheets, worksheets, and comments on student papers.

Lois's responses to my questions about her writing practices seemed to make similar assumptions about writing. I asked her specifically about any writing she does for publication, and, in her response, she seemed to interpret "writing for publication" as a particular kind of scholarship, one that is necessarily based on empirical research, such as that which North describes (17). After she described being asked to write some articles for newsletters, ${ }^{84}$ she added, "but those aren't really in any way scholarly, because they're $[\ldots]$ all about practicality" - they include "a little bit of research in there as to why it works, but the focus is on the practicality of it." Lois's response thus highlights the tensions that exist between practice and scholarship, explicitly illustrating the binary that Choseed and Ray name, that sees practice as not scholarly. What is clear from this selection of examples from interviews with Sally, Donna, Audrey, and Lois, is that, at least to some extent, what tends to be valued and rewarded at four-year universities is the scholarship-practice binary, and this paradigm of academia seems to also be embedded in participants' attitudes toward certain aspects of their community college work.

\section{Scholarly Teaching}

\footnotetext{
${ }^{84}$ Amelia, too, described the writing she used to do for work, before her $\mathrm{PhD}$ - because her dissertation is now the primary "work" writing that she does - as "very [...] short pieces, like, would talk to people and write stuff for newsletters and things like that [...] that kind of, like, stop'n'go, little teeny tiny things, not published at all."
} 
Having established that the dominant cultural narrative in academia sees teaching as distinct from scholarship, as established by the value system of the four-year research university—which dominates prominent disciplinary journal scholarship — and having then examined the ways by which the scholarship-practice binary is manifested in participants' attitudes toward their own work, in this section, I argue that this binary is an insufficient lens through which to view the scholarly work of participants, because their part of their scholarly work is teaching (or, in North's terms, practice). Consequently, their scholarly work often goes unrecognized as such. This section opens with a discussion of scholarly teaching and the scholarship of teaching and learning, which is followed by select examples of the kinds of teaching practices and inquiry in which participants engage.

\section{Scholarly Teaching and the Two-Year College}

Participants' teaching exemplifies what Shulman calls scholarly teaching, a classification of teaching related to the scholarship of teaching and learning, or SOTL (“From Minsk to Pinsk”). Since Boyer's seminal work, Scholarship Reconsidered-in

which he calls for "the meaning of scholarship [to be] creatively reconsidered" (13) — was published in 1990, a rich interdisciplinary conversation around SOTL has thrived (Hatch; Kreber; McKinney; Becker and Andrews; Hutchings; Shulman, “Taking Learning Seriously"; Shulman, "From Minsk to Pinsk"; Shulman, "Visions of the Possible"; Glassick et al; Tinberg et al; Minter and Goodburn; Ray). As such, there are a number of nuanced, and sometimes conflicting, definitions of what SOTL entails (Kreber 1); as a starting point, McKinney offers a basic and general definition, describing SOTL as "systematic reflection on teaching and learning made public"” (Illinois State University 
qtd. in McKinney, "Introduction" 1). These characteristics of being systematic and made public - with the goal of engaging in the enterprise of scholarly exchange, as it is described by Shulman - are key to SOTL. Shulman notes that such exchange is the necessary distinction between "scholarly teaching" and "a scholarship of teaching" ("From Minsk to Pinsk" 2, emphasis in original). The former (scholarly teaching), Shulman explains, "is teaching that is well grounded in the sources and resources appropriate to the field" and "reflects a thoughtful selection and integration of ideas and examples" as well as "well-designed strategies of course design, development, transmission, interaction and assessment" (Shulman, "From Minsk to Pinsk" 2). It is only "when our work as teachers becomes public, peer-reviewed and critiqued, and exchanged with other members of our professional communities so they, in turn, can build on our work," Shulman argues, that a scholarship of teaching is developed—because "these are the qualities of all scholarship" ("From Minsk to Pinsk" 2). I understand the key distinction between scholarly teaching and SOTL or teacher research to be the enterprise of "going public" (Hatch 3) and engaging in the kind of scholarly exchange Shulman outlines, and it is from this perspective that I assert that participants engage in scholarly teaching. Their teaching, as they describe it, is clearly grounded in resources, and relies on well-designed strategies and careful consideration (Shulman, "From Minsk to Pinsk").

There is, however, a long line of scholarship — beginning around the early 1990s, when Boyer published Scholarship Reconsidered — that argues for community college faculty to push beyond scholarly teaching and engage in formalized SOTL (Andelora, “Teacher/Scholar"). For example, in his 1994 essay, "Scholarship and Teaching," Vaughan argues that the association of two-year college faculty solely with teaching 
needs to be revised, and that community colleges must work to present a more nuancedand complete - image of the work that is done in two-year institutions, one that includes both the teaching and scholarship that take place in such institutions. Vaughan's reasons include his contentions that (1) two-year college faculty are both teachers and scholars, and by not claiming research as part of their professional domain, they are "distorting" the true nature of their work, and (2) for two-year colleges to continue to portray themselves as teaching institutions whose faculty do not conduct research is for them to maintain the imagined binary between teaching and research ("Scholarship and Teaching”212-213). Vaughan concludes that community colleges

simply must begin to place more emphasis on what it means to work in an institution of higher education - for an institution of higher education with an institutional mission devoid of scholarship is a contradiction in terms. [...] To achieve its mission as a teaching institution, the community college must make scholarship one of its top priorities, for one cannot remain an outstanding teacher without a commitment to scholarship. ("Scholarship and Teaching" 220)

Such arguments are made by other prominent community college scholars throughout the 1990s, such as Tinberg, and into the early 2000s. In a 2004 article, Sommers argues that many two-year college English faculty "are already engaged in [the scholarship of teaching and learning], although often in informal ways" (15). Sommers further contends that "Teaching English in the Two-Year College contributors and readers"-most of whom teach in two-year colleges ${ }^{85}$ —are already participants in [a] newly emerging community of scholars," described by Barbara Cambridge as " faculty who pose, study, and begin to answer intriguing questions about their teaching"' (Cambridge, qtd. in Sommers 15). Sommers' claim, that the TETYC community is one whose members are

\footnotetext{
${ }^{85}$ TETYC focuses on the teaching of first- and second-year college composition, and invites contributions from both two- and four-year institutions.
} 
already practitioners of what he describes as informal SOTL — and that I understand to be scholarly teaching, per Shulman's terms - is one in a long line of similar arguments.

Since the mid-1990s, two-year college teacher-scholars have argued for the importance of and the need for more TYC faculty to engage in formal SOTL, citing the fact that such faculty are already engaged in scholarly teaching practices (e.g., Tinberg, "Seeing Ourselves Differently [1993]; Vaughan, "Scholarship and Teaching" [1994]; Madden, "A Job at a 'Real' College" [1995]; Sommers, "Two-Year College English Faculty” [2004]; Reynolds, "Two-Year-College Teachers as Knowledge Makers" [2005]; Hassel, "Research Gaps" [2013]). These authors would all agree that many two-year college faculty, such as my participants, engage in scholarly teaching (per Shulman's terms), but that much of their scholarly teaching is not formal SOTL, per se, as their scholarly teaching does not always make it into scholarly circulation - that is, it is not always made "public, peer-reviewed and critiqued, and exchanged with other members of [...] professional communities" toward the end of building on that scholarship (Shulman, "From Minsk to Pinsk" 2). Instead, it is often applied directly back to their classroom practices.

This thread is persistent in two-year college English scholarship; as Andelora points out, "there has been an ongoing invitation to two year-college faculty to join the professional conversations" ("Teacher/Scholar" 312). It could be argued that two-year college faculty within Composition Studies are not heeding calls for engaging in formalized SOTL, as Shulman defines it. Perhaps this is, in part, a consequence of what Ray calls a false dichotomy between—or, in Choseed's terms, the binary of—-practice and inquiry, as the inquiry in which participants engage usually impacts their teaching, 
and their teaching is often a form of inquiry (Ray). Vaughan persuasively argues for community college faculty to engage more fully in scholarship, and to cease public celebration of this particular institutional space as being only about teaching, and the other scholars listed above, who uphold the line of disciplinary dialogue that urges community college faculty to engage in more formalized scholarship, are similarly convincing ("Scholarship and Teaching"). They all make important arguments. However, those arguments seem to rest upon a research university standard of a particular brand of scholarship, in that they urge community college faculty to engage in formalized classroom research that results in written publications about that research (e.g., Hassel, "Research Gaps"), ultimately falling in line with "the faculty reward system" of the fouryear research university (Boyer 1) that arguably has contributed to some of the negative attitudes toward the two-year college setting. In the framework of such a reward system, "when it comes to making judgments about professional performance, [teaching, research, and service] are rarely assigned equal merit” (Boyer 15). As participants make clear, though, the relationship between their practice and inquiry is reciprocal and, in a sense, organic - inquiry is a key aspect of their teaching, and vice versa. What is needed, then, is a more nuanced framework by which to understand the scholarly and practical work that goes on in community colleges (Boyer 16), akin to Choseed's call for "the field of composition $[\ldots]$ to reconceptualize its view of the work of teaching and learning in the classroom generally and the two-year college classroom specifically" (29). It is from this perspective that I assert an alternate model of scholarship, as enacted by participants, and fostered by the institutional cultures in which they work.

\section{Practice and Inquiry}


Choseed argues that "focusing on teaching allows, even forces, a person to collapse the false binary between theory and practice" (22). The collapse of this binary was readily apparent in the conversations I had with participants, though they did not always describe it as such. Though they clearly work within the paradigm of knowledgecreation outlined by North and further explained by scholars such as Ray and Choseedand thus seemed to understand their experiences through that lens-all participants described the ways in which they continually seek to improve their teaching and better address student needs through inquiry. Furthermore, much of their teaching is intertwined with various kinds of inquiry, from finding ways to adapt in order to meet the needs of different student populations, directly soliciting feedback from students and adjusting their practices accordingly, or engaging in practices that more closely match conceptions of formal research—namely, inquiry that, in North's terms, "[involves] a series of steps" (21). Regardless of the shape it takes in their teaching, Amelia, Audrey, Donna, Henry, Lois, Ruby, and Sally clearly take seriously the community college commitment to students, and illustrate that the identity of "teacher" does not always come at the expense of "scholar."

\section{Dynamic Teaching}

Overall, participants' teaching practices enact dynamic teaching practices

(Boyer). Boyer describes teaching as

a dynamic endeavor involving all the analogies, metaphors, and images that build bridges between the teacher's understanding and the student's learning. Pedagogical procedures must be carefully planned, [and] continuously examined. $[\ldots]$ Further, good teaching means that faculty, as scholars, are also learners. (2324) 
This description closely matches participants' teaching practices. A common theme across these faculty's descriptions of their teaching is the crucial impact of their students, and the ways in which these teachers continually work within the material constraints of their institutional settings ${ }^{86}$ to adapt and improve their classroom practices to more sufficiently meet student needs - in other words, practices that seem to fit Boyer's description of "dynamic" teaching. This thread is also apparent in existing literature on teaching in the two-year college (Starr; Choseed; Ostman), and, while not illustrative of more formal Composition classroom research (e.g., as described by Anderson 278-9), per se, does exemplify the kind of creativity, adaptability, and responsiveness participants bring to their teaching, despite the many other demands on their time.

For example, as discussed in Chapter Two, the material conditions of community college students' lives play a prominent role in participants' workloads, often manifesting as emotional labor. Henry described how these material conditions have influenced him to change his course policies and curriculum. He explained that, at community colleges, "it's more difficult for teachers to have firm policies sometimes, because they're dealing with students in more extraordinary situations than they are in four-year schools," elaborating that his first-year composition curriculum has changed since he taught at a university, becoming more streamlined. The changes Henry made—e.g., assigning fewer and longer papers, giving students more time between major assignments, altering methods for giving feedback on those assignments - were some of his direct responses to the needs of his community college students (as well as to the material constraints of his position at a two-year college), and took place over the course of multiple semesters.

${ }^{86}$ Discussed in Chapter Two. 
Henry, as do other participants, continually strives to find ways to respond accordingly to different and emerging student needs. For example, in the semester I interviewed him, Henry was in the process of further improving his methods of providing feedback to students, in response both to previous semesters' experiences and a particular class he was teaching, all of the students in which were also enrolled in a special professional program. While he was trying to refine a new method of delivering his feedback to students - through individual conferences - Henry was simultaneously figuring out how to most effectively provide feedback to the cohort of students who had different scheduling demands because of the special professional program in which they were enrolled. Henry thus exemplifies the kind of continual responsiveness to changing student needs that all participants seem to possess.

Donna's students similarly shape her teaching practices. For example, from student feedback she directly solicited from students the previous semester, Donna learned that they wanted more feedback on their work. She explained that, in response:

This semester, I'm doing a kind of split. So I don't handwrite on any papers. I actually do all my grading in Blackboard. So for their first major assignment [...] I just gave them the note kind of comment. For the second major assignment, I downloaded all of their papers, and used the comment function in Word, and did it like I would have back in the old days, where we wrote all over it, that kind of thing, and gave it to them that way. And then told them that next time, they're going tell me which way they want it, and the caveat is that, for me to do that [use the comment function in Word], it takes longer. So do they want their papers back faster, or, do they want that kind of feedback? And that's what they have to decide. And they're going to vote on it as a class.

Because of her previous students' responses to her teaching methods, this semester, Donna is testing out different methods of providing feedback on their papers, ultimately giving students the choice of which kind of feedback they want. This is a direct response to her students' expressed needs. Notable, too, is that the student feedback she references 
was her own questionnaire that she administered to find out "what worked and what didn't work," not a general teaching evaluation administered by the institution, indicating that Donna sought this kind of feedback from her students specifically in order to further improve her teaching. This is one example of the classroom inquiry in which she frequently engages. Donna-like Henry—is continuing to adapt her teaching to better meet current student needs, even after nearly twenty years of teaching. Also like Henry, Donna exemplifies the kind of teacher all participants seem to be: creative, responsive, and adaptable, individuals who obviously care deeply about their students and thus continually (re-)examine their teaching in order to further improve. This responsiveness is exemplified by: the amount of time Henry puts in to creating new courses and trying out different methods of teaching and giving feedback; Sally's excitement to try out a new writing assignment she learned about at the most recent TYCA-SE conference; Lois's description of how interdisciplinary presentations on pedagogy have opened her eyes to new methods to teach content in her own classes; Audrey's frequent incorporation of new and relevant texts into her lesson plans as a response to current events unfolding as the semester progresses; Ruby's planned "intervention" for her upcoming classes to encourage student involvement on campus; and Amelia's work on a federal grant program to address student retention issues. These are all examples of dynamic teaching (Boyer), as I understand it. Admittedly, these brief examples might also serve to support the narrative of the two-year college faculty as teacher. However, as discussed in the next section, that narrative is incomplete, for it tends to put the "teacher" identity at odds with that of "scholar," so that two-year college faculty are often seen are teachers at the expense of also engaging in inquiry. 


\section{Dynamic Teaching as Inquiry}

Inquiry as it relates to practice, such as the above example of Donna eliciting direct feedback from students, is important to the teaching practices of participants, nearly all of whom brought up research ideas, projects they are interested in completing and that are all connected to their students in some way. Audrey, for example, when discussing the research on service learning that she conducted and recently presented at NCTE, mentioned that she has another project she would like to do, one related to writing centers and student success. ${ }^{87}$ Henry also has several ideas for various research projects centered on students and their success, given that he has access to "a lot of data, not just from our college, but across the system" that he would like to study and analyze. In addition to being creative and responsive teachers - or perhaps because they are such teachers - Amelia, Audrey, Donna, Henry, Lois, Ruby, and Sally ${ }^{88}$ all engage in inquiry to some degree. Be it informing themselves about new teaching strategies and best practices through reading or attending conferences, or conducting a "full-blown" study, they are all active in seeking new ways to improve classroom practices.

Overall, participants describe a largely reciprocal relationship between three aspects of their jobs: (1) teaching, (2) research, and (3) professional development and service. Since this chapter focuses on the classroom, I selected the following examples because they are skewed toward teaching, whereas in the following chapter, the examples I discuss are more illustrative of professional development. However, all of these

\footnotetext{
${ }^{87}$ However, though the data exists, Audrey is unable to conduct this study because of her position as an adjunct, which restricts her access to this and other such institutional data. ${ }^{88}$ I discuss Ruby and Sally in more depth in Chapter Four, as their inquiry is more related to professional development and service.
} 
examples contain elements of participants' teaching, research, and professional development and service. I note this for two reasons:

1) To acknowledge that some of these examples contain elements of participants' professional development and service, and that, though not all participants are described in this section, all participants do engage in inquiry ${ }^{89}$ and

2) To point out that this further illustrates what Choseed describes, that teaching allows for the collapse of a false binary.

It is the collapse of this binary that I hope to illustrate through my descriptions of some of the classroom-related research in which participants engage, focusing specifically on Amelia and Donna.

Amelia

As discussed in Chapter Two, Amelia is very heavily involved in a recent federal grant program focusing on student success at Rock Creek, under which the college is redesigning the courses with the highest enrollment across the disciplines. Amelia is chairing the committee that is redesigning —or, as she put it, revising — the first-year writing course in order to increase student success and retention in the course. She described how she "went into it like a little qualitative study," and that she and two other members of the committee invited every person who had taught first-year writing (across all five of college's campuses) the previous semester to be interviewed. In addition to what they learned from the interviews about how individual instructors had taught the course and what was successful in their classes, Amelia and her committee also "looked at some internal data" that no one at the college had yet attached to student success.

${ }^{89}$ As noted, this discussion is continued in the following chapter. 
Specifically, the committee looked at students' last dates of attendance, seeking to find trends in first-year writing courses to see if there were certain points in the semester where they were "losing" students. Amelia and her team were surprised to find that the department was "losing everybody at Week Five, and then the last week of the semester." Because of this finding, Amelia said,

We went back, and said, okay, if we're "losing" people — so the people who fail or the people who withdraw-why are we losing them? [...] So we looked at last date of attendance, the interviews, and then pulled rosters of all the students who had earned failing grades or had withdrawn, and sent it back to each instructor and said, "Here's a list of five of the most common reasons. Do you know what happened to this person?" And we knew. Which told us a lot. That we know what's happening with our students, that we are engaged.

Based on their triangulation of the data they collected from various sources, the grant committee for the first-year writing course revision is now piloting different strategies this semester to help improve student success and retention in first-year writing at Rock Creek. These strategies include a program designed to help better meet the needs of students who might miss class due to the material conditions of their lives, such as those described in Chapter Two. This program comprises online modules for students who miss certain topics covered in class due to absences, and more flexible late work and attendance policies, similar to what Henry described in his interview. Consequently, the research Amelia and the grant committee have conducted has resulted in the direct application of their findings to the classroom practices of both Amelia and her colleagues who are piloting the program, and, eventually, will impact teachers and students across the college-wide department. Amelia's example further highlights just how important the breakdown of the "scholar-teacher" binary is. The student-focused community college culture seems to foster an environment where teachers are engaged with their students, as 
noted in Amelia's quote above. This kind of engagement-wherein the teachers interviewed and later surveyed know the reasons why individual students failed or withdrew from their classes - profoundly contributes to the research that Amelia and her colleagues conduct. Teaching and research here are intimately connected, and, as a result, will likely lead to positive department-wide curricular and policy changes via the strategies currently being piloted.

\section{Donna}

Some participants, like Amelia, engage in collaborative research that is institutionally-sponsored. Others engage in various kinds of research related to their teaching that is largely independent, or at least begins that way. Donna, like Amelia (who has made changes to her classroom policies per the pilot program), shapes her teaching in response to her research, either by being "in the journals researching something," as she put it, or "conducting a full-blown [...] empirical study."

Donna described changing some of her classroom practices in response to her research, explaining a project ${ }^{90}$ she undertook for her classes that began with research she did on retention at community colleges. Specifically, Donna said,

Some of it was empirical studies of our classes and things like that, and some of it was, you know, more, "I'm going to go hit the books" kind of research. [...] I did a kind of best practices study. [...] Then I led a series of professional development workshops for our entire college, on these things you can do [...], you know, hands-on kind of things.

Additionally, an important piece of this research project was Donna's own classroom. She described the success rate in her online English class as "pathetic," and explained that if her students" success rates were "going to become an issue," she knew that "before

\footnotetext{
${ }^{90}$ This is an example of only one of Donna's research projects; she described several others during her interview.
} 
I helped anybody fix theirs, I needed to fix my own," referring to the professional development workshops she led. In response to this, and to help "fix" her success rates, Donna explained,

I looked at online learning and retention, and all of it kept referring to these adult learning theories. And so I studied adult learning theories, spent an entire summer doing it $[\ldots]$ and came up with these best practices from, you know, having studied all this. And then applied them to my class in the fall, and my success rate went up fifty percentage points.

My understanding of the project Donna described is that it followed this progression:

1) Donna conducted research on community college retention, including empirical studies of classes at Rock Creek and reading scholarship about student retention.

2) Based on best practices learned from research, Donna led a series of professional development workshops for faculty across entire college.

3) Donna then recognized that success rates in her own classes needed improvement, and so turned her attention to scholarship about online learning and retention.

4) That research led Donna to adult learning theories, which she spent an entire summer studying.

5) Donna then applied that research (adult learning theories) to her own classes.

6) As a result of this application, the student success rate in Donna's online class went up by fifty percentage points.

Donna's inquiry and her teaching, as well as professional development (facilitating workshops for faculty across the college) are thus combined, and hard to clearly separate out from each other. Furthermore, the "product" of her inquiry is not a written publication, but direct application specifically to her classes, as well circulation of this new knowledge about how to successfully enact such classroom strategies amongst 
faculty at her college, through the workshops that she led. Donna began with some initial, independent research that included reading published scholarship, then eventually applied that research to her classroom practices, and, finally, noted marked improvements as a result. Again, as in the example of the grant program Amelia is working on, the threads of research and teaching are interwoven.

Not only is such inquiry important to her role as a teacher, it is important to Donna personally. When discussing research projects like the one described above, Donna told me that she likes "to always have a research project going on," and explained:

Those are the kinds of things that if I didn't do, I would hate my job. [...] I would say, at least once a month, I am in the journals researching something, or I would lose my mind. [...] Conducting a full-blown [...] empirical study, I probably do that once a year.

While Donna also made clear that publishing and presenting at conferences are not things that are important to her at this point in her career, research is—it contributes to her teaching, and significantly adds to her job satisfaction. Furthermore, research for Donna is not tied to generally accepted understandings of "scholarship," that see research as ultimately resulting in a publication, but is, in fact, necessarily related to her practice. All of Donna's research projects, both those she has already completed or is in the process of completing, and those she plans to do, have something to do with teaching. While this is unsurprising, given the community college emphasis on teaching, it is also important to note, once again, that the practice of teaching is not divorced from the realm of scholarship. However, as illustrated by the work of Amelia and Donna, this research is less likely to result in written, published scholarship, and results, instead, in direct application to teaching practices-likely given what tends to be institutionally rewarded in community colleges, where publications are "bonus" items on annual evaluations. 
Consequently, this research likely goes largely unrecognized outside of the local contexts in which participants work because the accepted mode of knowledge creation and exchange is written publication, per the pervasive values of four-year research universities.

\section{Conclusion}

Boyer notes that, "according to the dominant view, to be a scholar is to be a researcher - and publication is the primary yardstick by which scholarly productivity is measured" (2); this has resulted in a "restricted view of scholarship" (15). Such a view contributes to the maintenance of the commonly understood narrative that two-year college faculty are teachers. As established, however, this narrative comes at the expense of TYC faculty being seen also as scholars, because that scholarship is largely intertwined with their teaching, and the dominant framework within academia tends to see teaching as distinct from research and scholarship (Boyer; North; Choseed; Ray; Shulman, "Visions of the Possible"). For my participants, this narrative is sorely incomplete, as their teaching is often also a form of inquiry that, consequently, goes largely unrecognized as such. This is due, in part, to the persistence of the ideas that practice is distinct from research and scholarship, and that practice is incompatible with inquiry, as inquiry necessarily "[involves] a series of steps that result in a contribution to a field of knowledge," and because the knowledge produced by practice (lore) rarely "gets written down" (North 21; 5). However, this perspective raises important questions about what is valued —or even recognized—as scholarship, who is deemed "scholar," and what is considered a "valid" contribution to a field of knowledge. While participants do 
not always convey their findings via written publications, which are typically understood as the medium by which new knowledge is contributed to the discipline, these faculty do enact and circulate those findings, often at the local level.

At stake, then, is the presumably vast body of new disciplinary knowledge and innovative teaching practices that remains unrecognized, as participants' scholarly inquiries seem to more often end with practical application or enactment of new knowledge ${ }^{91}$ than a research article. Henry, who was excited to focus solely on teaching and to not have to worry about research when he first began working at Mountain Hill, told me that his attitude toward research has changed in the four years he has been at the community college, explaining that he is now "thinking twice about that [initial attitude]." He is thinking twice, he said, "because it's hard to keep up, and I feel detached, in some ways. [...] I think I have more experience now to see how research can make a difference, even at the college classroom level." Henry then elaborated:

I think I've had enough experiences being a full-time faculty member to really value [classroom] research, not just for myself, [...] but as something that can have material worth to my colleagues. Like I said, looking at the data across the system, about students in English classes, and how well they do, and if that correlates with the number of classes they have, the amount of time they have someone working on, looking at their writing, that could have value to the decisions being made at the curriculum level right now.

Henry echoes Hatch's argument that teaching at all education levels, from K-12 to postsecondary, needs to be made "public," so that teachers - the ones doing the teaching - are also involved in the decision-making process about policies and curriculum that impact their teaching (3). ${ }^{91}$ And, as will be discussed in the next chapter, conference presentations or sharing with
colleagues through other professional development opportunities, such as workshops. 
As such, I contest that if the work of two-year college writing teachers is recognized and more adequately valued as the scholarly work that it is, then we - as a discipline — can better engage in interinstitutional dialogues about our teaching and research practices, and thus expand our shared body of disciplinary knowledge. As Boyer argues, "theory surely leads to practice. But practice also leads to theory. And teaching, at its best, shapes both research and practice"; it is from this perspective that "a more comprehensive, more dynamic understanding can be considered, one in which the rigid categories of teaching, research, and service are broadened and more flexibly defined" (16). A shift towards a more dynamic and comprehensive framework-such as that which Boyer describes - by which to understand a wider range of scholarship would allow for the work of individuals such as my participants to be recognized and valued by the discipline at large. Additionally, it would likely loosen the rigid narratives about institutional settings within which participants work, which seem to shape how they, as two-year college faculty, understand and value both their work and the work that takes place in four-year settings. Finally, such a framework would open the doors for more interinstitutional dialogues between two- and four-year settings. Such dialogues might begin at the local level, where writing faculty in different institutional settings in a community or region likely work with similar student bodies and policy issues, and would rely on the recognition of alternate models of scholarship, particularly from those who, themselves, enact it. While it is true that two-year colleges and four-year institutions are distinct academic contexts, with differing student needs and institutional structures, the composition classroom nonetheless exists in both, and it is this unifying factor that propels the disciplinary need for stronger dialogues about the scholarship and teaching 
that takes place in the full range of postsecondary institutions ${ }^{92}$ in which the work of Composition Studies takes place. As such, in this dissertation, I offer an alternate model of scholarship by which to recognize and understand new disciplinary knowledge that is not restricted to traditional conceptions of scholarship. This model—and, more importantly, the recognition of the wide range of disciplinary knowledge with which I am concerned - is important to the kind of disciplinary cohesion that is imperative for our participation in public dialogues that ultimately shape the work that we do. As AdlerKassner and Wardle argue,

[...] our field knows a lot about its subject of study. We know much about how writers write and learn to write, and how best to assess writing. Yet we continue to lose the battle over discussions of writing to stakeholders who have money, power, and influence but little related expertise. If we want to actively and positively impact the lives of writers and writing teachers, we must do a better job of clearly stating what our field knows and helping others understand how to use that knowledge [...]. (7)

92 I do not wish to exclude other types of institutions; as Amorose, who is concerned with small liberal arts colleges (SLACs) argues, we all "stand to gain any time the [...] record on [our] work expands to reflect the diversity" of that work, "since with this diversity comes a multiplicity of new options for doing our work well" (93-94; see also Gladstein and Regaignon). 


\title{
CHAPTER FOUR
}

TWO-YEAR COLLEGE WRITING FACULTY AS SCHOLARS: OUTSIDE THE

\author{
CLASSROOM
}

"I've got a research project that I want to do. [...] A couple, actually. But I think-I think I'm realizing I need to make it more than just me. I need to get other people involved with it, [do] collaborative stuff, be sure that it gets done, for one. Because if it's just me, other responsibilities are going to eclipse that."

$$
- \text { Henry }
$$

"The amount of stuff that students deal with, that has a significant impact on their academic success. [...] Yeah, I underestimated that. [...] I knew to expect some. But I had no idea I would have to deal with, or be presented with, the things they present me with. [...] And I've handled it by wanting to learn more, which is why I became a part of [the Student Advocacy Project $\left.{ }^{93}\right] . "$

$$
- \text { Audrey }
$$

"I'm also in a [faculty reading] group. [...] So, gosh. That's the other thing I do with my time!"

$$
-R u b y
$$

"My first thought [at the beginning of the interview] was, 'oh my gosh, I don't do any professional development!' But, you know, after talking about this, I do.”

$-R u b y$

Over the course of my conversation with her, Ruby's perception of her full-time position at Bradford State Community College shifted. At first, her descriptions of her

${ }^{93}$ Pseudonym. 
job responsibilities revolved around teaching, and she frequently mentioned that she did little else outside of being a teacher at Bradford State. By the end of the interview, though, Ruby, had surprised herself with the realization that she is actively involved in various professional development opportunities, such as faculty reading groups, for which she also engages in research. However, these aspects of her professional identity are often subsumed by her identity as a teacher, as they are inextricably linked to her teaching and her students. As this and the previous chapter explores, these tight connections between inquiry, teaching, and professional development and service exist for other participants, as well—such as Audrey, who is an adjunct at Bradford State and involved in some of the same reading groups as Ruby. Crucial to each of these areas of work are these faculty's relationships with colleagues, as Henry describes. Taken together, the brief excerpts above from Ruby's, Audrey's, and Henry's interviews offer a snapshot of the scholarly practices in which they and other community college faculty engage, reflecting a model of scholarship that is fostered by the institutional culture in which they work.

This model rests on the sites where faculty both engage in and share the results of their scholarly activity, sites that, despite being integral to participants' scholarship, are largely unacknowledged as such — by common understandings of these sites in academia at large, by participants' institutions, and often by participants themselves. In Chapter Three, I examined the first of three sites where some community college writing faculty engage in inquiry and circulate or apply the results of that inquiry: the classroom. This chapter now shifts to sites of inquiry and knowledge-making outside of the classroom, focusing specifically on two sites that are institutionally understood as professional 
development: conferences and faculty reading groups. These sites are an important part of participants' inquiry processes, as they influence the questions that they ask. These are also sites where they articulate, circulate, apply, and exchange the products of those processes. In other words, as explained below, participants' inquiry processes are recursively linked with these sites of circulation; the knowledge articulated at these sites is not necessarily the "end" products of their research, and is often influenced by the scholarly exchange occurring at the sites themselves. In fact, I found that participants' teaching, as described in Chapter Three, is intertwined with their professional development and service, key job responsibilities of their positions as community college writing teachers. Though scholarship is not explicitly named as part of those job responsibilities, these responsibilities - teaching and professional development and service - double as sites where participants both engage in the process of scholarly activity and circulate the products of their inquiry. Consequently, they tend to remain unacknowledged as sites of scholarship (by common understandings of these sites in academia at large, by participants' institutions, and often by participants themselves). Furthermore, these three strands (teaching, professional development and service, and research) are linked by a recursive relationship between the different facets of participants' work, ${ }^{94}$ with their students ultimately at the core. For example, Ruby's and Sally's revisions of their teaching methods stem, in large part, from the work they do that falls under the category of professional development, such as attending and presenting at conferences; Amelia presents with her students at conferences, leveraging conferences as

\footnotetext{
${ }^{94}$ Reflective of Boyer's model of scholarship, which sees scholarship as dynamic and having a recursive relationship with other kinds of academic work-e.g., as described in Scholarship Reconsidered (16).
} 
sites of professional development for both her and them; and Audrey and Ruby belong to a college-wide reading group that doubles as activism for Bradford State students.

Across these and the other examples this chapter explores, participants engage in inquiry and locally apply or enact the knowledge they discover. As such, this and the previous chapter set forth a model of inquiry and knowledge-making that offers an expanded framework by which to understand how new knowledge is created and circulated by teacher-scholars whose work takes place outside of four-year research universities, where the institutional model of research dominates understandings of what counts as "Scholarship" in academia at large (Boyer, Scholarship Reconsidered 2;

Glassick et al. 7; Juergensmeyer 61-62; Rice 31; Jaschik; Schon 28; Gebhardt, "Evolving Approaches" 9-10; Schilb 27). In advancing an alternate model of inquiry and knowledge-making, I acknowledge that there are certain established characteristics of the work that the academy generally defines and accepts as scholarship, such as the steps involved in the research process and the need for peer-review and circulation (Shulman, “Course Anatomy"; Kern et al.; Minter and Goodburn). ${ }^{95}$ However, I maintain that these characteristics are premised on the values espoused by the typical tenure process at the four-year research university, which tends to see teaching, research, and scholarship as separate endeavors that are unequally rewarded (Boyer, Scholarship Reconsidered 12, 15; Glassick et al. 7-8). Furthermore, I understand the cornerstone of scholarship to be inquiry work that results in the creation of new knowledge. Because of the institutional culture where participants work ${ }^{96}$ — which differs greatly from that of the four-year

\footnotetext{
95 As described in Chapter Three.

${ }^{96}$ Discussed in Chapter Two.
} 
research university ${ }^{97}$ - their scholarly activity (inquiry resulting in new knowledge) looks different from the processes and products commonly understood and accepted to be "scholarship." In other words, the community college fosters a different model of scholarship, as exhibited by participants' descriptions of their professional lives. Integral to this model are those professional spaces that are more commonly understood to be sites of teaching and professional development and service, but which participants leverage as sites of scholarly activity, as well. Overall, this alternate model of scholarship relies on the spaces where that work takes place, spaces that are designated by their institutions - and commonly understood - as places where other kinds of academic work (teaching and professional development and service) takes place. At these sites, participants engage in scholarly activity, but are rewarded by their colleges for "teaching" or "professional development and service." Consequently, it is altogether unsurprising that their scholarly activity and that of other faculty in similar institutional settings infrequently appears in major journal publications, as these are the venues by which the products of the traditional model of scholarship are more often circulated. ${ }^{98}$

Another integral part of this model is the importance of collaborative networks, as a key factor influencing these faculty members' work is their relationships with their colleagues, within and outside of their colleges. For example, for Audrey, like most other participants, it is her colleagues from whom she hears about places to submit her writing - a fellow teacher and tutor on Bradford State's East Campus, she explained, who knew about a writing project of Audrey's, informed Audrey of an upcoming deadline for

\footnotetext{
${ }^{97}$ For example, as described in great detail by Ostman in Writing Program Administration and the Community College.

${ }^{98}$ As described in Chapter Three.
} 
submissions to a literary journal of creative nonfiction. "“I thought about what you're writing [...] have you seen this?,"” Audrey told me her colleague had said. Not only did this colleague encourage Audrey to submit her writing to the journal, but she also was familiar enough with Audrey's work to bring the publication opportunity up unprompted (i.e., Audrey did not ask her colleague if she knew of any places where she might publish her current writing project). This relationship exemplifies the kinds of relationships many of these faculty have established with their colleagues, and the roles those colleagues play in their professional development efforts. These relationships result in various kinds of collaborations, such as presenting together at conferences (e.g., Ruby) and working together on special grant-funded projects (e.g., Amelia). For some faculty, these relationships also form scholarly networks through which participants learn about new scholarship to read (e.g., Henry, Audrey, Donna) or places to submit their writing (e.g., Audrey).

\section{Chapter Overview}

I begin this chapter by first describing what constitutes professional development and service for community college writing faculty, based on participants' descriptions of their job responsibilities. Next, I discuss the prominent role participants' conference attendance plays in the recursive relationship between their professional development, scholarly inquiry, and teaching. Then, I shift attention to another site of professional development and service, faculty reading groups, and examine the role participants' engagement in such groups plays in their conceptions of their professional identities, utilizing the conception of the teacher-scholar-activist (Jensen and Toth; Toth and Jensen; Toth et al., "Distinct”; Toth et al., "Dubious"; Hassel et al. "TYCA White Paper"; 
Griffiths, "Professional Autonomy”; Sullivan, "Teacher-Scholar-Activist”; Andelora, "Teacher/Scholar") as a framework by which to understand those identities.

\section{Explanation of Terms: Professional Development and Service}

As outlined in Chapter Two, the job responsibilities of community college writing faculty include much more than just teaching, though the cultural narratives surrounding this institutional setting might suggest that little else happens there besides that. In this chapter, I examine the ways in which the teacher-scholars I interviewed engage in inquiry and knowledge-making activities outside of the classroom, in spaces that are designated by their institutions as sites of professional development and service. Consequently, in my discussion, I frequently refer to these activities as professional development and service. This is in keeping with participants' descriptions of their work, and how their work is categorized per the terms of their contracts. While this chapter focuses specifically on conferences and faculty reading groups, the full extent of participants' professional development and service reaches far beyond the specific activities on which I focus. In this section, then, I describe the range of activities that participants described as professional development and service. Given the variety of this work, I do not wish to imply a limited range, and do wish to honor the full extent of this area of participants' work. Furthermore, I acknowledge that these activities are not drastically different from the kinds of work that would be counted as professional development and service at other types of institutions (Blalock; Kinzy and Minter; Marshall; Schneider); what is distinct about this work for my participants is the integral role these activities play in their research and scholarly endeavors. 
For these faculty, professional development ranges from attending faculty development workshops and orientations on campus to attending conferences or writing for publication. Because their institutions allow for such a range of work to be counted as professional development, participants are able to include scholarly activities under this category in their annual work plans, though scholarship is not explicitly required. Early in his interview, Henry described what counts as professional development at Mountain Hill Community and Technical College while recounting the responsibilities of his position as a full-time English instructor. "Professional development," he said, "can be anything from on-campus professional development, going to conferences, doing publications, even giving talks," adding that he has "given some talks on [his] dissertation findings to adjuncts and full-time faculty [at Mountain Hill]." He further explained that professional development "can be within the school system" or outside of it; for example, when he attended the Conference on College Composition and Communication, he was able to include that on his performance agreement as professional development.

The range of work that counts as professional development at other participants' home institutions is similarly wide, and their descriptions of their professional development included: facilitating or attending workshops—online or face-to-face, on campus or sponsored by their college or system; leading or participating in book clubs and reading groups; and staying up-to-date on current research and best practices for teaching through their individual reading habits. ${ }^{99}$ Audrey noted, for example, that, of the four types of work that faculty at Bradford State Community College are expected to

\footnotetext{
${ }^{99}$ The latter is particularly important to Lois's job at Valley Way University; Lois expressed how lucky she feels to have a boss who understands how important it is for her "to keep my professional development up," and so provides her ample time for professional development.
} 
engage in, "one chunk $[\ldots]$ is personal professional development, which is where any kind of research or anything might come in, or creative writing. [...] So if you're trying to actively get published, that counts as that chunk." ${ }^{100}$ A variety of publication types, including both scholarly and creative $\mathrm{e}^{101}$ endeavors, count as professional development at Bradford State. In other words, while "research" may not be one of the "chunks" for which Bradford State faculty are held accountable as one of their position responsibilities, if they do engage in research, it is counted as "professional development." Similarly, Henry noted that going to a conference - either presenting or simply attending - also counts as professional development. While conference-going is not explicitly a formal responsibility from the college, it is, for some, an implicit institutional expectation voiced by departmental supervisors or colleagues (as discussed below). Overall, "professional development," an important aspect of participants' jobs, is a wide-ranging and varied category of responsibilities for participants. Furthermore, there is no apparent valuation of different "levels" of professional development; the different kinds of professional development that participants mentioned seem to carry equal weight. Subsequently, they are enabled to pursue their individual professional interests, though they are limited by the material constraints imposed by their institutions (i.e., time and money, as discussed in Chapter Two).

Professional service, like professional development, also accounts for a portion of participants' job responsibilities, and is similarly varied. For most, like Henry and Lois,

\footnotetext{
${ }^{100}$ However, Audrey was also quick to add, "the majority of my time as an adjunct is definitely the teaching/academic side. Because I don't get paid for anything else right now."

${ }^{101}$ Audrey is not the only one who writes creatively-Donna and Henry also mentioned that they do, too.
} 
this constitutes internal service. Internal service typically includes serving on college- or system-level committees, such as Henry's role as faculty secretary (for faculty meetings), as well as his roles on system-level committees, one of which is focused on how the state community and technical college system will meet their "new digital literacy definition," and another that works on assessment of general education courses. Internal service might also take the form of serving as faculty advisors for student organizations at their colleges, such as Ruby's role as a faculty soccer advisor at Bradford State, or Amelia's involvement in two unnamed student organizations at Rock Creek. Other participants, like Lois, Donna, Sally, and Amelia, engage in external service, such as serving on committees or in leadership roles in professional organizations outside of their college or system, at both the regional and national levels, and across a range of academic disciplines. ${ }^{102}$ External service might also take the form of service to the community. For example, Audrey explained that faculty at Bradford State are also responsible for community service that, "oftentimes [is] through a function of the college," such as doing Habitat for Humanity builds.

Though these faculty must work within the material constraints imposed by their institutions, it is also because of the culture of their institutions — evidenced explicitly through formal paperwork such as annual work plans, and implicitly through what is encouraged by their colleagues - that they simultaneously have the freedom to engage in a wide range of scholarly activity, thus leveraging professional development and service opportunities as spaces where they also carve out their unique identities as teacherscholars. Ultimately, the lines between these two categories of professional activities

\footnotetext{
${ }^{102}$ While participants are all English faculty, some choose to also participate in other disciplines.
} 
(development and service) and their inquiry and knowledge-making often get blurred, so that these different kinds of work inform one another. Participants perform a wide range of professional development and service work, and this range, paired with the notable absence of a hierarchy that dictates how different activities are "counted" or valued in specific categories of professional responsibility, ultimately allows for the kind of integrated scholarship in which participants engage (Choseed 21-22). In other words, it is precisely this wide range of what can be categorized as professional service and development that allows for participants' robust scholarly activity, which reflects Boyer's model of scholarship and departs from the rigid delineations between research, teaching, and service espoused by the tenure guidelines at most four-year institutions (Scholarship Reconsidered; "Scholarship of Engagement”).

\section{Site One: Conferences}

Conferences are sites that participants and their institutions designate as "professional development," but these sites are also integral to these faculty's inquiry and knowledge-making processes, thus contributing to their scholarly identities, as well. Just as their classrooms both influence their inquiry and serve as sites of articulation of the knowledge they produce or discover (Chapter Three), participants described a similarly recursive intellectual relationship between conferences and their inquiry. Furthermore, while conferences are recognized as conventional venues of scholarship in academia at large, for most participants, they are more important than publications as sites of circulation, scholarly exchange, and collaboration, which is a departure from traditional academic norms. 
This section begins with an overview of participants' conference attendance, including conferences they have attended and their motivations for participating in conferences. Next, I discuss the ways in which conferences serve as sites of professional enrichment, and their relationship with participants' teaching, research, and service. Finally, this section ends with a discussion of the implications of this relationship.

\section{Conference Attendance: Where, Why, and How}

Participants described active involvement in a range of conferences, though, due to institutional financial restraints, they are limited in the number of conferences they are able to go to, as well as restricted in terms of location-i.e., they tended to describe more active involvement in regional conferences than in national conferences. Tables 5 and 6 provide a breakdown of the venues participants named ${ }^{103}$ during their interviews as examples of conferences they have presented at or attended. As shown in Tables 5 and 6 , participants have gone to a variety of conferences at the state, regional, national, and even international levels, and within and outside of the discipline (for the purposes of the discussion in this section, English Studies in general). In fact, some participants have chosen not to be involved in English conferences in recent years. For example, though they did not state specific reasons for their preferences, Lois and Amelia both noted that they choose to go to conferences outside of English studies. As seen in Tables 5 and 6 ,

${ }^{103}$ The conferences listed in Tables 5 and 6 are not exhaustive, as they only include the conferences explicitly named by participants as those they have recently attended or presented at. In some cases, participants did not give names for all of the conferences they described (e.g., Donna, who mentioned a number of other conferences in passing which she has also participated in). Nor do these tables include those conferences that participants said they hoped or intended to attend (e.g., Audrey listed several conferences she would like to go to, when she has sufficient financial support). However, this table is included here in order to give the reader a general sense of the different kinds of conferences participants have attended in recent years. 
Lois currently prefers interdisciplinary conferences to English conferences, and explained, "I just stopped going to English stuff. I used to go to English stuff. I just don't anymore." Similarly, Amelia, who teaches courses in English, Humanities, and Women's Studies at Rock Creek Community and Technical College, told me that, of the different disciplines in which she teaches, she chooses to go to Women's Studies Conferences:

Because we really don't have a lot of professional development dollars, and most of us pay for things out of pocket, to be honest, I tend to spend more of my time at Women's Studies conferences. But also because [I take students to] regional Women's Studies conferences [...] if I'm presenting. [...] Nine students in three semesters have presented at regional conferences, so they've gotten a paper and a conference presentation under their belt before they graduate, so that's my focus. So when I use those travel expenses, that's what I try to do.

Because of the limited amount of financial support ${ }^{104}$ she gets from the college for presenting at conferences, Amelia, like other faculty, is also limited in the number of conferences she can choose to present at or attend, and so primarily attends conferences outside of English Studies. Furthermore, as discussed later in this section, Amelia also leverages conferences as an opportunity not only for her own professional development, but that of her students, as well. Other participants - those who are not in the unique positions that Lois and Amelia are in (i.e., Lois's full-time university job in faculty development and Amelia's focus on Women's Studies likely stemming, in part, from the Ph.D. in Women's Studies that she is currently working on) — similarly have attended and presented at other conferences that fall outside of the purview of English studies (Table 6). The range of conferences my participants have attended in recent years echoes Toth's finding from her 2014 study that her participants-full-time community college English

${ }^{104}$ Discussed more thoroughly in Chapter Two. 
faculty—were professionally engaged "in an array of disciplines," including English studies, education, and interdisciplinary organizations (347).

Table 5: Conferences Recently Attended or Presented At, English Studies

\begin{tabular}{|c|c|c|c|c|c|c|c|}
\hline & Amelia & Audrey & Donna & Henry & Lois & Ruby & Sally \\
\hline $\begin{array}{c}\text { Conference on } \\
\text { College } \\
\text { Composition and } \\
\text { Communication*** }\end{array}$ & & & & & & & $\mathrm{X}$ \\
\hline $\begin{array}{c}\text { National Council of } \\
\text { Teachers of } \\
\text { English*** }\end{array}$ & & $\mathrm{X}$ & & & & & \\
\hline $\begin{array}{c}\text { Two-Year College } \\
\text { English } \\
\text { Association- } \\
\text { Kentucky* }\end{array}$ & $\mathrm{X}$ & & $\mathrm{X}$ & $\mathrm{X}$ & & & $\mathrm{X}$ \\
\hline $\begin{array}{c}\text { Two-Year College } \\
\text { English } \\
\text { Association- } \\
\text { Tennessee* }\end{array}$ & & $\mathrm{X}$ & & & & & \\
\hline $\begin{array}{c}\text { Two-Year College } \\
\text { English }\end{array}$ & $\mathrm{X}$ & & $\mathrm{X}$ & & & $\mathrm{X}$ & $\mathrm{X}$ \\
$\begin{array}{c}\text { Association- } \\
\text { Southeast** }\end{array}$ & & & & & & $\mathrm{X}$ & \\
\hline
\end{tabular}

*State; **Regional; ***National

Table 6: Conferences Recently Attended or Presented At, Outside of English Studies

\begin{tabular}{|c|l|l|l|l|c|c|c|}
\hline & Amelia & Audrey & Donna & Henry & Lois $^{\mathbf{1 0 5}}$ & Ruby & Sally \\
\hline $\begin{array}{c}\text { The Assessment } \\
\text { Institute**** }\end{array}$ & & & & & $\mathrm{X}$ & & \\
\hline $\begin{array}{c}\text { Community } \\
\text { College Humanities } \\
\text { Association*** }\end{array}$ & & & $\mathrm{X}$ & & & & $\mathrm{X}$ \\
\hline $\begin{array}{c}\text { Drexel Assessment } \\
\text { Conference** }\end{array}$ & & & & & $\mathrm{X}$ & & \\
\hline $\begin{array}{c}\text { Innovate } \\
\text { Conference*** }\end{array}$ & & & & & $\mathrm{X}$ & & \\
\hline International Forum & & & & & & \\
\hline
\end{tabular}

${ }^{105}$ The conferences Lois attends are for her job at the university, as part of that position requires her to travel to conferences and that is where her financial support for conference-going comes from. However, I am including them here because I am not in the position to decide what does or does not impact her teaching at the community college, particularly since she expressed that she sees her jobs at the two different institutions as informing each other. 


\begin{tabular}{|c|c|c|c|c|c|}
\hline $\begin{array}{l}\text { for Women in } \\
\text { eLearning } * * * *\end{array}$ & & & & & \\
\hline $\begin{array}{c}\text { Kentucky } \\
\text { Association of } \\
\text { Developmental } \\
\text { Education* }\end{array}$ & & $\mathrm{X}$ & & & \\
\hline $\begin{array}{l}\text { Kentucky Success } \\
\text { Summit* }\end{array}$ & & & $\mathrm{X}$ & & \\
\hline $\begin{array}{l}\text { Magna Teaching } \\
\text { with Technology } \\
\text { Conference*** }\end{array}$ & & & $\mathrm{X}$ & & \\
\hline $\begin{array}{c}\text { National } \\
\text { Association of } \\
\text { Developmental } \\
\text { Education*** }\end{array}$ & & & & $\mathrm{X}$ & \\
\hline $\begin{array}{l}\text { National Women's } \\
\text { Studies Association } \\
\text { Conference*** }\end{array}$ & $\mathrm{X}$ & & & & \\
\hline $\begin{array}{l}\text { Online Learning } \\
\text { Consortium } \\
\text { Accelerate*** }\end{array}$ & & & $X$ & & \\
\hline Pedagogicon* & & & $\mathrm{X}$ & & \\
\hline $\begin{array}{l}\text { POD Network } \\
\text { Conference*** }\end{array}$ & & & $\mathrm{X}$ & & \\
\hline $\begin{array}{l}\text { Popular Culture } \\
\text { Association*** }\end{array}$ & & & & & $X$ \\
\hline $\begin{array}{c}\text { QM (Quality } \\
\text { Matters) Connect } \\
\text { Conference*** }\end{array}$ & & & $\mathrm{X}$ & & \\
\hline $\begin{array}{c}\text { Southern } \\
\text { Association of } \\
\text { Colleges and } \\
\text { Schools } \\
\text { Conference** }\end{array}$ & & $\mathrm{X}$ & & & \\
\hline $\begin{array}{c}\text { Southeast Women's } \\
\text { Studies } \\
\text { Conference** }\end{array}$ & $\mathrm{X}$ & & & & \\
\hline $\begin{array}{l}\text { Tennessee } \\
\text { Association for } \\
\text { Student Success } \\
\text { and Retention* }\end{array}$ & & & & $\mathrm{X}$ & \\
\hline $\begin{array}{c}\text { United States } \\
\text { Distance Learning } \\
\text { Association*** }\end{array}$ & & & $\mathrm{X}$ & & \\
\hline $\begin{array}{c}\text { WICHE } \\
\text { Cooperative for }\end{array}$ & & & $X$ & & \\
\hline
\end{tabular}




\begin{tabular}{|c|l|l|l|l|l|l|l|}
\hline $\begin{array}{c}\text { Educational } \\
\text { Technologies } \\
\text { (WCET)*** }\end{array}$ & & & & & & & \\
\hline $\begin{array}{c}\text { Women's and } \\
\text { Gender Studies } \\
\text { Conference** }\end{array}$ & $\mathrm{X}$ & & & & & & \\
\hline
\end{tabular}

*State; **Regional; ***National; ****International

Most participants make choices similar to the ones Lois and Amelia have made, as they-like many faculty across two- and four-year institutions alike-must work within the material constraints of their positions as community college faculty, some of whom recently faced a drastic downsizing of the financial support provided by their college for conference travel. As discussed in Chapter Two, participants' involvement in conferences is largely determined by the amount of financial support they receive from their college to attend — which varies depending on participants' rank and college, and ranges from those who receive no funding (e.g., Audrey); to those who receive enough funding to travel to and present at one or two conferences each year, but who might also supplement that funding by covering a portion of the associated costs themselves (e.g., Sally and Amelia); to those whose requests for conference travel funding have always been fulfilled, whether they are presenting or not (e.g., Ruby). While most participants have attended or presented at national conferences, they more frequently participate in state or regional conferences, largely due to the cost of attending national conferences. For example, Sally said of the Conference on College Composition and Communication, or CCCC: “But I've never been to-well, I went to four Cs [CCCC] one time. It's so expensive. I just can't pull off four Cs very often." In contrast, Sally has attended the regional Two-Year College English Association-Southeast (TYCA-SE) Conference every year for the last decade. 
Similarly, when I asked Henry about the kinds of conferences he usually goes to, he mentioned CCCC, as well as "in-state Kentucky conferences, and if the school, if the system had, like, a professional development workshop or something.” Henry quickly made clear, though, that his most recent experience attending CCCC was possible because the conference was within driving distance that year, and he traveled with a group of colleagues. He elaborated that, "I know people [at Mountain Hill] are very, very interested [in going to conferences], and they get a lot out of it, it's just, you know [...] money, money, money." Like Sally, Henry and his colleagues are thus constrained by the limitations of available institutional resources to attend or present at national conferences. This raises the importance of the local and regional conferences they more frequently attend, which they leverage as both professional development opportunities and sites integral to their inquiry processes. Consequently, the scholarly activity in which they engage at the conferences they do attend tends to get overlooked by faculty at four-year research universities, where national conferences are more highly valued than those at the state or regional level and are thus the norm.

Perhaps because of this commonly-understood hierarchy of conference prestige, all of the faculty with whom I spoke qualified conferences as being at the state, regional, or national levels when they described them to me, a researcher from a four-year university. Indeed, Henry, who recently earned his Ph.D., indicated a clear preference for national conferences when comparing these venues to the state or regional conferences that are more accessible to him. He stated that, though "the [state] system [of community colleges] does provide a lot of professional development opportunities, [...] it's nothing like going to a national conference of composition teachers," such as CCCC, indicating 
his clear preference for the national conferences that he is not often able to attend. Henry's attitude here is reminiscent of Andelora's claim that, "because the community college culture has traditionally emphasized the role of faculty member as teacher and devalued the role of faculty member as scholar, it's not uncommon for faculty who spend their careers teaching in a two-year college to feel a growing sense of estrangement from their discipline" ("Teacher/Scholar" 309). However, Henry was the only participant who expressed such a preference for national conferences and subsequent feelings of disconnection from the discipline to which he primarily subscribes.

In contrast to Henry, Sally noted that her involvement in the regional TYCA-SE is important to her, in part, specifically because it is where she learns about "issues facing community colleges [in the region], and there's always a person there from national TYCA, so we get a national perspective as well. So I feel like it increases my awareness." Sally's description exemplifies one of the original reasons for the creation of regional TYCA organizations and conferences; as Andelora describes in his comprehensive history of the founding of the organization, regional organizations have "made it possible to preserve the regional structure [of community colleges] while at the same time provide a clear link between each regional group and the national organization" ("TYCA and the Struggle for a National Voice" 138). Conferences are thus avenues by which some faculty stay informed and engaged in their disciplines, as others have similarly shown (Toth, "Unmeasured Engagement"; Laster and Fatherree). It seems, then, that the structure of TYCA has lived up to its original intent of preserving a link between regional and national groups. By sending a representative from the national organization to each regional conference, this structure keeps community college faculty abreast of the 
national organization, and thus the larger discipline, as Sally described. However, this structure does not keep the discipline abreast of the work of community college faculty who primarily attend the regional conferences.

Despite the difficulties some participants face in attending conferences (due to the constraints of their colleges' available financial support), they are all dedicated to active conference participation. The sense of connection that Sally feels as a result of her participation in TYCA-SE is one reason for such dedication. Another primary reason lies in participants' colleagues, who contribute to a departmental culture in which conference involvement is highly encouraged, and thus play important roles in participants' motivation to attend conferences. When I asked participants where they usually found out or heard about professional development opportunities such as conferences, they all mentioned colleagues, current or former, in their responses. Sally, whose professional identity is closely linked to TYCA-SE, explained that she was unaware of the organization until a colleague told her about it. "When I first started here," she said, "I [...] didn't know about TYCA-SE, and it was a colleague [who told me about it]." She explained, "it was $[\ldots]$ an older colleague of mine, who came to me and to somebody else who was relatively new [here]. [...] She came to us $[\ldots]$ and said, ' $[\ldots]$ You all need to go to this conference next year, because you need to work on this, this is good for your notebook,' you know, toward tenure and everything." This kind of informal mentoring seems to be the norm in Sally's department, where, she explained, "mostly, it's colleagues who say, 'oh, this is a good conference, you should go,' or 'I'm going here, do you want to come with me?,' that kind of thing." According to Sally, it is this "word of mouth" method by which a lot of the information about conferences is circulated among 
her colleagues, as is motivation to attend, a common way that professional development opportunities are encouraged in two-year college writing programs or English departments (Ostman 131-133). Though some individuals do not have an apparent interest in going to the conferences their colleagues recommend, overall, Sally's department seems to have a strong culture of encouraging and fostering such professional development opportunities.

Audrey, an adjunct at Bradford State, has similarly been encouraged and supported by her full-time colleagues to attend conferences, despite the lack of financial support she receives from the college to do so. She described how some of her colleagues recently enabled her to attend the state Two-Year College English Association-Tennessee (TYCAT) Conference: “So, some of my colleagues were actually like, 'hey, you know you can go for free. We're all going, you can ride with us.' [...] And, they got to get their hotel room paid for because they're full-time, and so they invited me to come, so I could go, totally for free. And all the meals were included, too." Not only did her colleagues inform Audrey that, as an adjunct, she was able to attend the conference for free (TYCAT provides free conference registration, which includes meals, to adjunct faculty), they also provided her the means to attend — namely, transportation and a place to stay—both encouraging her to attend the conference, as well as materially supporting her attendance. This level of collegial support seems to be the norm across participants' departments or divisions. Henry, for example, described making travel arrangements, including a carpool, for colleagues who attended a recent conference. 
Distinct from other participants, whose primary motivation and support for conference involvement are their colleagues, Amelia named another reason that she is motivated to present at conferences—-her students. She explained:

Especially at the regional [conference], I try to present with students, so that we do a panel together [...]. And then, [...] I just got the acceptance today! [...] I submitted a roundtable with students from the community colleges I'm doing my dissertation on, and we're going to do a roundtable talking about activism on their campuses. [...] And I have three students from here who will go.

Over the course of three semesters, Amelia has presented with nine students at various conferences, "so they've gotten a paper and conference presentation under their belt before they graduate." Because this is a focus of hers, "when [she uses] those travel expenses [from her college]," she tries to take her students with her as co-presenters. Elsewhere in her interview, Amelia talked about the challenges she faces "trying to connect with students, and support them academically, and always trying to figure out that language that says, 'hey you are a budding scholar." Supporting her students is important to Amelia, and finding opportunities to encourage and reiterate their identities as scholars is a crucial part of her professional identity. By presenting with her students at conferences Amelia has found an opportunity for both her own professional development and theirs, while also reaching one of her goals as a teacher and resisting some of the negative stereotypes of community college students, that typecast them, as she put it, as “"all the students who have troubles." Furthermore, earlier on the day that we met for her interview, Amelia had found out that her proposal for an upcoming conference had been accepted; this proposal included not only three of her own students from Rock Creek, but some of the students from the community colleges where she was doing her dissertation work, who were participants in her research. The lines between Amelia's teaching 
(presenting with students), research (presenting with study participants from her dissertation research), and professional development (presenting at conferences) are thus blurred.

\section{Professional Enrichment and Connections to Teaching, Research, and Service}

Due to the institutional culture of their colleges, which is fostered by their colleagues, participants are — or have been ${ }^{106}$ - heavily engaged in conferences. These conferences — state, regional, and national; within and outside of the discipline — connect with multiple facets of participants' professional identities, influencing both their teaching and inquiry and knowledge-making processes. When participants talked about the ideas they have presented at conferences, many of them described topics related to teaching, further reifying the interrelationship between their scholarly activity and teaching (described in Chapter Three), as conferences are similarly sites integral to their scholarly activity. Henry noted that his most recent conference presentations were focused on some of his innovative classroom practices. ${ }^{107}$ Lois, who has presented on a variety of different subjects, in part due to the frequency of her attendance at a wide range of conferences for her university job, has also given presentations on pedagogical topics—or, as she puts it, "practical stuff”- - such as "what makes a successful first week in an online course." Similarly, Donna has presented on subjects related to her teaching; she recounted, for example, how a conference presentation grew out of a faculty development workshop about using SafeAssign, which she facilitated for English teachers at Rock Creek.

${ }^{106}$ As discussed in Chapter Two, participants who teach at community colleges in Kentucky recently faced a vast reduction in available resources, which has diminished their ability to attend conferences as frequently as they once were able.

107 Such as those discussed in Chapter Three. 
Conferences also serve as sites of scholarly collaboration for community college faculty. Much of the time, this collaboration takes the shape of more standard conference collaborations, such as presenting together on a panel. Ruby, for example, has presented a number of times with colleagues at conferences, such as the National Association of Developmental Education (NADE) Conference. These collaborative presentations have included "how [they] came up with the [new] co-requisite" developmental English class at Bradford State, a presentation with another colleague about reading, and, recently, a presentation about using themes in the first course in Bradford State's first-year composition course sequence.

Given that participants tend to present on topics related to their teaching, it is perhaps unsurprising that participants then find that teaching impacted, in turn, by the presentations they see at conferences. Participants described how beneficial and pedagogically enriching their conference participation is, whether they are presenting or simply attending others' presentations, as conferences are also sites of scholarly exchange with teacher-scholars outside of participants' home institutions and, in some cases, across disciplines. For example, Lois described how, when she attends interdisciplinary conferences - even sitting in the audience of presentations about teaching subject matter outside of English, such as math—she gets new ideas for teaching concepts in her writing classes. Similarly, Sally spoke at length about the pedagogical enrichment TYCA-SE provides. After she explained how important TYCA-SE is to her professional life, I asked her why this conference in particular held such a strong appeal for her. In response, Sally explained that the TYCA-SE conference positively impacts her as a teacher, because of all "the great ideas that you get. [... The majority [of the presentations], I truly learn 
something, and I learn something that I can use. Like I say, it's very hands-on stuff, you know, for the classroom." At another point during our conversation, Sally reiterated this idea, mentioning that TYCA-SE is "very hands-on, and usually there's something I can take back and actually apply to my own classes, either now" or in the future.

Sally's description of TYCA-SE closely aligns with one of Toth's 2014 findings about community college faculty's participation in and attitudes toward professional organizations such as their regional TYCA chapters (see also: Laster and Fatherree). Twelve of the full-time community college instructors Toth interviewed "preferred the 'practical' and 'hands-on' ethos of their regional TYCA — in fact, three specifically praised TYCA for always giving them something they could 'use in the classroom on Monday", (343). Toth further explains that "nearly every instructor could recall specific conference presentations or conversations with colleagues that had contributed to their teaching in some way" (343). Similarly, in my conversation with her, Sally described a presentation she had attended at the most recent TYCA-SE conference. The presentation was about assigning a multi-genre research project in a first-year writing course, and Sally, reflecting on it, said she thought that the idea was "fabulous," and had decided "to do something like that" for her own upcoming courses. Sally thus exemplifies how professional development, such as conference attendance, is often intertwined with teaching for these faculty.

Conferences are not just key sites for participants' own pedagogical enrichment, but also for that of their departments, as their conference participation sometimes leads to the circulation of new knowledge among local networks of colleagues, aligning with a delegate model of conference participation, "in which one or more faculty [...] attend a 
national or regional conference on behalf of the entire department" as a cost-saving measure (Toth "Unmeasured Engagement," 348). In her discussion of her previous work with accelerated learning programs, Donna described the rich and complex interrelation between individual inquiry done initially for her own professional development (and, subsequently, for colleagues in her department); the successful application of what she learned to her own teaching, which led to her offering her own professional development opportunities for faculty on campus (an act of service on her part); and her conference attendance on behalf of the college - then the (re)application of what she learned from those conferences back to the work she was doing at Rock Creek. Donna explained that, when her college "started having to fix our developmental education and accelerate it, they volunteered to send" her to conferences in Maryland and Colorado, ${ }^{108}$ to study accelerated learning programs in those states, so that she could implement what she learned in programs at Rock Creek. In her discussion of how and why this came about, Donna explained:

So because of that [success applying adult learning theories to her classes ${ }^{109}$ ], then I kind of became the poster child, right? And so, I then had to go around, do all these presentations about what I did, and how it worked, and what you should do $[\ldots]$. So, the next year, [...] I decided to then try to connect all of this to developmental students, those who don't test into college-level. [... Because ...] we offer developmental courses, pre-college classes, and we are being mandated $[\ldots]$ to make that process shorter.

As a result of her successful application of adult learning theories and best practices to her classes, ${ }^{110}$ Donna was asked by the college to offer workshops to other faculty at her college, so that they, too, could learn about and try those practices in their classes. An

${ }^{108}$ These are two of the conferences Donna mentioned during her interview, but did not name, so her attendance at these conferences is not reflected in Tables 5 and 6.

${ }^{109}$ Discussed in Chapter Three.

${ }^{110}$ Discussed in Chapter Three. 
additional result of her success was that she decided to "connect all of this to developmental students," because of system and college pressures to shorten the amount of time it takes developmental students to pass their pre-college-level courses and move into credit-bearing courses. Drawing on her own individual reading and research, she began a pilot Accelerated Learning Program (ALP) project with developmental students, based on the Baltimore Model, and, on behalf of the college, traveled to Baltimore, Maryland, to study the model in more depth, as well as to a conference in Colorado. "So I went to Baltimore and I studied their [...] ALP, Accelerated Learning Program[, and] went to, you know, a conference in Colorado, and all of these things, studied all of it, did all the research," Donna explained. Crucially, the college "volunteered" to send her to different conferences to conduct this research, essentially as a delegate on behalf of her college (Toth), who was simultaneously engaged in research and professional development and service. As a result of what she learned at these conferences, Donna then implemented a pilot program with twenty students who were not enrolled in classes she was teaching, each of whom she personally mentored, visiting them in class, emailing them, offering to tutor them, and extending help finding additional resources at the college. Donna then tracked this cohort's retention through the college's first-year writing sequence, and found that their retention rate in the first course in the sequence was higher than that of other developmental students, and that they passed the second course in the sequence at a higher rate than students who came out of the "regular" course.

The work that Donna did for this pilot ALP program at her college entailed her own inquiry, including reading and attending conferences; local application of that inquiry (i.e., implementation of the pilot program at her college); and professional 
development and service to the college (e.g., the workshops she facilitated and the students she worked with). Central to the work she put into this pilot program is the exchange of knowledge, with the two conferences she attended as key sites of that exchange. In addition to illustrating how Donna's service, research, and professional development are inextricably linked, her work on the ALP pilot program shows both the potential scholarly exchange that happens at conferences (e.g., learning about different approaches to Accelerated Learning Programs), and the potential impact of that exchange at the college-level, with Donna essentially acting as a delegate on behalf of her college (Toth). Furthermore, behind all of these components is the institutional culture of Rock Creek, which, with its emphasis on teaching and students, its capacious definitions of professional development and service, and the relationships that tend to form between colleagues, fosters this kind of teaching-scholarly work.

Conferences also serve as accessible sites of knowledge circulation, places where two-year college teacher-scholars share their own knowledge and expertise. For most participants, conferences are the primary sites of the articulation of the new knowledge they discover or produce when engaged in inquiry, similarly to how written scholarship (i.e., articles and books) functions as sites of knowledge articulation for faculty who teach in more research-oriented institutions. This is due, in part, to the institutional culture of participants' colleges, which is often nurtured through their relationships with their colleagues. Donna, for example, recounted how one of her conference presentations grew out of a faculty development workshop she facilitated for English teachers at Rock Creek. She explained, "I did this [...] English PD thing. [...] about [using] SafeAssign. [...] I was like, 'you don't use [SafeAssign] as a plagiarism checker, you use it as an 
instructional tool,' and I wrote this instruction page" with specific strategies for doing so. During the workshop, Donna said, the faculty in attendance encouraged her to present on her methods of using SafeAssign at TYCA. What initially began as an innovative classroom practice for Donna (her method of using SafeAssign) became a moment of professional development and service (facilitating a faculty development workshop at her college) that eventually morphed into a conference presentation, where she shared her knowledge of an innovative teaching practice, illustrating how conferences serve as venues of knowledge circulation - as well as one of the ways that these community college faculty are encouraged to blur the lines between their professional development, service, and teaching.

\section{Tensions}

This is also true for Henry, who offers a clear example of the ways participants work within — and leverage — the material constraints of their positions as community college faculty. Instead of producing written, peer-reviewed, published products from his dissertation findings, which is the next step in the process for many new PhDs in the first few years of their post-completion jobs (Graves), Henry, instead, has circulated his research findings by way of presentations to colleagues, both at his college and at conferences. However, his not having published out of his dissertation is troubling to Henry: when I asked him about his professional development, he opened his response with, "I still have yet to publish anything. And I feel so bad about that." Henry then explained that he has not "done any research or really gotten involved in conferences or anything like that for over a year now, in part because of the budget crunch," but, before this budget crunch, he was going to one or two conferences a year, a rate comparable to 
other participants, ${ }^{111}$ and most of the time he was presenting on his research at those conferences. Specifically, early on in his career, he "tried to get presentations out there, especially about [his] dissertation work," which, as I understand it, was about student writers, and had a pedagogical edge. When describing what professional development looks like for him at Mountain Hill, he also noted that "giving talks" at the college is one way to fulfill this position requirement, and mentioned, by way of example, that, in addition to presenting on his dissertation findings at conferences, he has given talks on those findings to faculty at his college. Though Henry feels bad about not having published any written scholarship, he has utilized his research findings in a way that is not only common for two-year college faculty, but also valued in this institutional setting. While conference presentations are a conventional and recognized venue of scholarship across institutions of higher education, they are distinctly important as a key site of the circulation of the scholarly activities of community college faculty, for whom research is not an explicit job responsibility.

As a recent graduate from a doctoral program, ${ }^{112}$ Henry's attitude towards his own work seems to match a conception of scholarly activity that values written scholarship over other forms of scholarly products (e.g., as Boyer explains in Scholarship Reconsidered). Despite the connections between their inquiry and professional development and service, participants tended not to describe conferences as sites connected to their scholarly work. Instead, conferences were more often brought up

\footnotetext{
${ }^{111}$ Except for Lois, who attends between seven and ten conferences each year as part of her full-time job at Valley Way University.

${ }^{112}$ At the time of his interview, Henry was in his fourth year at Mountain Hill, where he was hired while finishing his dissertation.
} 
strictly as examples of professional development. This is understandable, because this is how conference-going is categorized by their colleges.

Furthermore, some participants, such as Lois, explicitly described the conferences they attend as not related to scholarship. For instance, Lois noted that a conference she was recently invited to was "a pedagogy conference," elaborating that, by "pedagogy," she meant, "it's not about the research. I mean, there are some research presentations there, but it's all about practical applications." In other words, pedagogy, for Lois, is disconnected from research. Similarly, when discussing a regional conference with which she had been involved, Lois described it as "a chance for [presenters] to showcase to each other, and it was almost always practical stuff, very little research presented, just because there's not that research expectation at the community college level." Per these descriptions, Lois thus separates "pedagogy" and "practice" from "research" and "scholarship," in much the same way Choseed describes (21).

This understanding of practice as being distinct from research came up a few more times during Lois's interview. When discussing the kinds of writing that she does for work, Lois mentioned that she had recently been asked to write articles for The Teaching Professor newsletter and blog:

I'm presenting for them in June, and, they contacted me and wanted me to turn my presentation into an article for one of their newsletters. And then once I drafted that out $[\ldots]$ and sent it to them, there were a couple of the ideas that I had in that article, they're like, "well we want you to write articles on this, too." But those aren't really in any way scholarly. Because [...] Teaching Professor is all about practicality. [...] [I have] a little bit of the research in there as to why it works, but the focus is on the practicality of it.

Lois, then, seems to understand teaching —including articles and conference presentations about teaching — as distinct from research, because of the focus on 
practicality, thereby separating practice from research and scholarship, similarly to North. Interestingly, however, at other moments during her interview, Lois's conception of the close relationship between "practice" and "research" surfaced. When discussing an upcoming conference presentation, Lois mentioned the research that she planned to include in that presentation, and added, "I think that might be why I get accepted to most places I write to, is because I include $[\ldots]$ the research behind it, $[\ldots]$ how do you take that and put it into practical action in your classes." Taken together, Lois's comments highlight a tension between her ideas of what constitutes research and how research relates to classroom practice that is apparent throughout her interview. While she clearly sees a relationship between research and practice, Lois does not seem to see products of inquiry about teaching (e.g., written pieces and conference presentations) as scholarly, because of their focus on practice. ${ }^{113}$

\section{Discussion}

Whether giving presentations on subjects more easily identifiable as "research," such as Henry's dissertation project, or presenting on topics related to their teaching, conferences provide participants accessible means of sharing their knowledge with the wider field. By presenting at conferences, participants are working within the parameters of their positions as community college faculty. Their position responsibilities, per the terms of the colleges that employ them, do not explicitly call for research or publication. They do, however, require professional development and service, broadly defined, thus

\footnotetext{
${ }^{113}$ I do not mean to suggest here that writing a blog post or newsletter is as time-intensive or rigorous a process as writing a research article; I use these examples from Lois's interview to point out the clear distinction she makes between "research" and "practice," which, as I understand it, is based on the topic of these products - not the forms that they take.
} 
allowing participants to leverage conference participation as both scholarly and professional development opportunities.

As such, participants are actively engaged in a range of scholarly activities, and produce different scholarly "products" from those activities - less frequently a written article, and more frequently a conference presentation, a workshop, a substantial revision to their own or their college's curriculum, as these are the ways in which scholarship is valued by — and valuable to - their institutional settings. Enabled by their institution's capacious definitions of what can count as "professional development and service" (e.g., in their annual work plans or progress reviews), participants are engaged in rich scholarly activity. This work is tied primarily to students (e.g., through research focused on the classroom), likely due to the institutional focus of community colleges on teaching. Because the education of students is the central focus of most community college mission statements (Vaughan, Community College Story; Frye; $A A C C$ ), the primary professional identity of community college faculty tends to be that of "teacher" (Madden, "Crossing Borders"; Albert; Ostman; Carpenter; Choseed). Consequently, with their scholarly activity tied largely to teaching, or practice (often understood to be distinct from research and scholarship, as Lois pointed out), and with that activity taking place in spaces marked by their institutions as professional development and service (e.g., conferences), it is unsurprising that it is not wholly acknowledged, because it is subsumed by other identifying markers_—“teaching," "practice," "professional development," "service." Additionally, because conference presentations are key products of their inquiry — acting, in a sense, as their versions of "publications"-it is unsurprising that little of this work 
makes its way into Composition Studies journals. ${ }^{114}$ Finally, because these community college faculty tend to present more frequently at state or regional conferences (again, working within their college's capacious categories of professional responsibilities, which do not seem to value national conferences more highly than local conferences), their work is further divided from the wider discipline.

\section{Site Two: Faculty Reading Groups}

The institutional settings in which participants work foster collaborative relationships among colleagues. Just as they are key to motivating and encouraging conference involvement, colleagues also play important roles in participants' reading practices. All participants mentioned their colleagues - either at their colleges or fellow community college faculty in their state or region — as one of the ways they hear about new things to read for their professional enrichment. These recommendations often happen informally, through the means of "hallway conversations" (Ostman 133), but also through more formalized faculty reading groups. As such, nearly all of the faculty I interviewed actively participate in both formal and informal reading groups. Henry, Ruby, and Audrey are currently engaged in established reading groups with colleagues at their colleges - Ruby, in particular, has been involved with a number of different reading groups, both face-to-face and online. ${ }^{115}$ Additionally, Lois leads a faculty reading group at Valley Way University, ${ }^{116}$ and, though Audrey and Amelia did not name any formal

\footnotetext{
${ }^{114}$ As discussed in Chapter Three.

115 Ruby described these groups as both "reading groups" and "faculty inquiry groups."

116 That there are a few such opportunities for faculty development at Forest Lake Community and Technical College is a concern of Lois's, one that I discuss more fully at the end of this section.
} 
reading groups to which they belong, they described the networks of colleagues with whom they connect online, ${ }^{117}$ such as Facebook friends, who serve as "curators of great things to read," according to Audrey. ${ }^{118}$ These networks, Audrey and Amelia said, are one of the key places where they learn about things to read for their professional development, such as recent scholarly articles; these networks also foster discussion about those readings, essentially serving as informal reading groups.

Reading groups, then, are common professional development opportunities, likely encouraged by an institutional culture that promotes such collegial relationships. Like conferences, the reading groups on which this section focuses (those in which Ruby and Audrey are involved) similarly serve as key sites in the inquiry and knowledge-making processes of participants. However, unlike conferences, these reading groups are not established venues for the circulation and exchange of inquiry and knowledge, and, instead, are more commonly understood strictly as sites of professional development. Furthermore, just as participants leverage conferences as sites of scholarly activity, some participants similarly leverage reading groups as sites of both scholarly activity and activism. Those sites identified by both participants and their institutions as "reading groups," then—which are thus designated "professional development and/or service"— are additionally mechanisms for both inquiry and activism. In this section, I focus

\footnotetext{
${ }^{117}$ As discussed in Chapter Two.

${ }^{118}$ Such online networks of colleagues are also important to Donna; however, while she did describe how big of a role connecting with colleagues online plays in her professional development, she did not go into detail about the things they discuss, only that she does not always know how or where to count these activities, though they are connected to her job. As such, I do not typify these online connections as informal reading groups, as I do for Audrey and Amelia, who explicitly discussed these connections in relation to the things they read for work.
} 
specifically on Ruby and Audrey, for whom involvement in faculty reading groups is particularly important, and has led to activism on behalf of their students.

In my discussion of this "hidden" site of scholarship, ${ }^{119}$ I utilize the emerging concept of the community college teacher-scholar-activist (Jensen and Toth; Toth and Jensen; Toth et al., "Distinct”; Toth et al., "Dubious"; Hassel et al. "TYCA White Paper"; Griffiths, "Professional Autonomy”; Sullivan, “Teacher-Scholar-Activist”; Andelora, "Teacher/Scholar") as a model by which to understand Ruby's and Audrey's professional identities. In their opening of the 2017 "Responses to the TYCA Guidelines for Preparing Teachers of English in the Two-Year College," Toth and Jensen explain this emerging model of professional identity for two-year college faculty:

Some two-year college faculty are [...] rallying under a new banner: teacherscholar-activism, a conception of professional identity that foregrounds faculty members' responsibility to be public intellectuals and agents of change [...]. This identity challenges faculty to think beyond the classroom to engage in meaningful change on behalf of their students and profession. ("Responses to the TYCA Guidelines" 31, emphasis in original)

Writing in 2015, Sullivan offers a similar explanation of the teacher-scholar-activist model:

[Two-year college English teachers] are heirs to a robust activist tradition. I would like us to consider adding a third item-activist - to that important phrase teacher-scholar. I suggest that we deliberately frame our professional identity, in part, as activists - accepting and embracing the revolutionary and inescapably political nature of our work. This activism might, in fact, require some front-line, in-your-face political work as we seek to create positive change in our communities and on our campuses. ("Teacher-Scholar-Activist" 327-8, emphasis in original).

${ }^{119}$ As noted in the opening of this chapter, I understand the cornerstone of scholarship to be inquiry work that results in the creation, discovery, and/or application of new knowledge. 
As Sullivan and Toth and Jensen make clear, this recent movement within two-year college English relies on the idea that these three areas - scholarship, teaching, and activism - work in conjunction and complement one another, more clearly capturing the multi-faceted work in which many two-year college English teachers engage. In my use of this model to explain Audrey's and Ruby's professional identities, I suggest that, though the work they do with their reading groups closely aligns with the teacherscholar-activist framework, each seems to orient herself towards only aspects of this professional identity. Specifically, based on the way they each talked about their involvement in reading groups, Ruby orients herself towards the identity of "teacher," while Audrey explicitly identifies herself as an activist—and neither described their work as scholarly.

Ruby and Audrey are both involved in the same faculty group at Bradford State, the Student Advocacy Project. Though designated as a "reading group," this group comprises faculty who have joined together under the cause of finding ways to better meet student needs, and is thus a site of both research and activism, as well as professional development for the faculty involved. As such, it is much more than just a professional development opportunity for its members. I describe it as such, however, because Audrey and Ruby brought it up as an example of reading groups they belong to, and because this is how the institution defines it. The Student Advocacy Project, though, is a unique site — marked officially by Bradford State as "professional development and service" for its members, it is equal parts student-centered, research-focused, and actionoriented, embodying the ideals of the teacher-scholar-activist model of professional identity. It is also a site that relies on the strong relationships and collaborative attitudes 
of Bradford State faculty, and that has emerged as a result of the culture of this particular institutional setting. Interestingly, in their descriptions of the Student Advocacy Project, Ruby more often referred to it as a reading group, while Audrey more often referred to it as an activist group, reflecting their primary professional identity orientations.

The Student Advocacy Project began as a single reading group, but has grown so that each campus in the Bradford State system has its own group. Though each is autonomous, these campus groups are united by a common cause (meeting student needs) and a common book, which changes from semester to semester. Ruby explained to me the interesting history of the Student Advocacy Project, which has seen shifts in focus since its inception:

It was begun by someone in the English Department. Originally, it was a group about poverty. [The founder of the group] had done some of her own personal research about bridges out of poverty. [...] Her reading group's been going on for, a couple years now. [...] And I was part of some of her earlier groups that were about poverty. And then, we all kind of realized [...] it's not just students in poverty who need this boost and this sense of belonging. You're going to find that across the spectrum. [...] [And now it's] about connecting students to all the resources on campus. [...] It involves these reading groups. [...] It began as just a reading group, and then it turned into this. [...] And now, from this, there are different reading groups [laughs]. We're all reading the same thing, this semester, but there are different groups because of the different meeting places and different meeting times.

Audrey similarly recounted the origins of this reading group:

One of my colleagues did a study on [Bradford State] students, and figured out that $60 \%$ of our students [struggle with food and housing insecurity]. So [the Student Advocacy Project is] trying to get faculty to understand poverty and how that affects the classroom, academic and non-academic barriers to success, and how we can acknowledge those. [...] It started at [North Campus] with, like, this recognition of $[\ldots]$ poverty. [...] And then we started studying it, and then it's like, okay, what can we actually do as an institution? [...] So how do we remove the non-academic barriers to success? [...] It's like a reading group, based at each site campus. And they kind of are autonomous. It's self-selecting, people who want to be a part [of it], do, and then they make action items to go try to get. So it's like, "What can we do? We're aware, how do we make other people aware?" 
The Student Advocacy Project first began a few years ago, after one of their Bradford State colleagues conducted some research about student poverty. Per Ruby's telling, this research was on "bridges out of poverty," and Audrey added that it was also a study of the poverty rates of students at Bradford State. Based on her research, the founder of the Student Advocacy Project formed a reading group on Bradford State's main campus, North Campus. Since the creation of that initial reading group, the faculty involved have begun to take action, implementing initiatives aimed at alleviating barriers to student success at the college. These actions, as I understand it, differ from campus to campus.

What began with one individual's research has since evolved into a collaborative, multi-campus organization, one that Audrey described as "grassroots." The Student Advocacy Project is both a reading group and an activist group. Beyond providing professional development for faculty, the Student Advocacy Project also is actionoriented, as Audrey described, and has a clear impact on other aspects of participants' professional lives, unequivocally blurring the lines between their professional development, research, and teaching - embodying an institutional space in which its members are called upon to be teachers, scholars, and activists. As Audrey explained it, the Student Advocacy Project is

A group of people who want to help and want to learn more about our students' needs and trying to meet [those needs] at an institutional level. And then also teaching practices. Like, one of the reading groups, the book was [...] focused on self care of the professor, like, being aware of all this stuff, so that you can be compassionate towards your students. Like, self-practices to keep you being open and compassionate to students. 
The reading done in The Student Advocacy Project, then, spans a range of topics, from institutional change to teaching practices to self-care, all with a focus on better meeting the needs of the students who attend Bradford State.

The Student Advocacy Project first came up during my conversation with Ruby when I asked her about the kinds of reading she does for work. Her initial answer was that she reads articles when she wants "to try to think of doing a particular intervention" for students in her classes, explicitly linking a form of professional development (reading) to her teaching. By way of example, she went on to explain that, during the semester I interviewed her, the Student Advocacy Project group was reading Paul Tough's book, Helping Children Succeed, applying it to the community college setting, and so the members of her campus group were "all in the process [...] of gathering up some research articles to justify an intervention [...] to try." This intervention was centered around Tough's argument about how important a sense of belonging is to student success. Ruby explained the connection between Tough's argument and the reading group's original emphasis on combatting the issues that arise for students as a result of poverty, noting that, "students have to have some intangible qualities, or [...] develop skills that are not just academic. [...] It's also kind of wrapped up in poverty, that children in poverty tend to have fewer [...] other types of resources, like knowing college behaviors, and knowing people in college, and using them as a bridge." From there, she continued, the group "looked at many ways that we [teachers] could actually be that person, to instill college behaviors [...] and be a mentor for [students]."

Toward the end of establishing a model of what it takes to succeed academically for students who might otherwise have no such model, the intervention Ruby planned 
was to ask students to complete written reflections at the beginning, middle, and end of the semester about their college experiences, asking them if they have done certain things that are expected behaviors of college students - e.g., visiting a professor during office hours, attending a campus event, visiting the Writing Center. Ruby's intervention was also informed by her reading of Vincent Tinto's research about academic and social belonging, as well as a recent article, which "said that a lot of the community college students aren't that interested in the social belonging. They have their own lives outside of school. And so they said that if you blend the academic and the social, that's the way to hit the sweet spot for [community college students'] retention and their sense of belonging." "That's why," Ruby continued, "I wanted these exercises, these assignments, to force [students] to do something to promote belonging." She concluded that she and her colleagues in her campus chapter of the Student Advocacy Project are "going to formalize" their interventions, and that they plan "to ask institutional research to pull out those students - the students in our classes - to see if they do have a higher level of persistence.”

Ruby's participation in the Student Advocacy Project complicates traditional conceptions of —and boundaries between—professional development, research, teaching, and activism. Because of her involvement in this group, Ruby is both implementing changes in her classroom and conducting her own further research, both for her particular planned intervention (i.e., the research she has done to justify her intervention, such as the Tinto model and applications of that model to the community college setting) and the formalized, collaborative research of the reading group itself (i.e., tracking the students in the classes in which the interventions are being implemented, to see if there is an impact 
on their retention and thus measure the impact of those interventions). These veins of research exemplify two key characteristics of the nature of inquiry in a community college setting, as my participants described it. First, Ruby's own personal research of best practices, and her adaptation and application of those strategies to her classroom, highlight the student-focused mission of the institutional setting ${ }^{120}$ (Vaughan, Community College Story; Frye; $A A C C$ ) and faculty's tendency towards the identity of "teacher" (Madden, "Crossing Borders”; Albert; Ostman; Carpenter; Choseed). Second, the formalized research that members of the Student Advocacy Project have planned reflects the value placed on collegial relationships and collaborative work within the setting - not only are individuals working together on the same research project, they are also working across disciplines (the Student Advocacy Project is an interdisciplinary group) as well as across college units (e.g., by working with the institutional research office). Notable in Ruby's discussion of her work is that, though she referred to the research articles she and other reading group members "gathered," and mentioned that they were going to ask Bradford State's institutional research office to track the students, at no point, did she typify the work surrounding these interventions as "research" or as "scholarly." In fact, her discussion of this entire project was prompted by my question, "Is there any reading that you tend to do for work?," suggesting that she considers these activities as such, and perhaps nothing more.

In contrast to Ruby, Audrey's description of her involvement in the Student Advocacy Project centers on the activism of the group. While the reading and research that Ruby engages in is tied predominantly to her classroom, Audrey's efforts focus more

${ }^{120}$ Also discussed in Chapters Two and Three. 
on what happens in students' lives outside of the classroom. For example, in her campus chapter of the Student Advocacy Project, Audrey explained that they began by asking, “"what are some clear action items we can do?"” The action items they came up with included advocating for "more accessible formats of [the] common book" and working with the textbook selection committee to ensure sufficient rental options for students, and "fighting" to get free WiFi hotspots installed on campus, to address students' limited access to WiFi, which is "a huge barrier for a lot of students." Audrey is also "on the advisory council for [a] campus garden and food pantry," which "winds up being a little bit of support work for that $[\ldots]$ a couple meetings a semester, [and] if [there's] any research [she does] sometimes, it's [...] related to that.” She explained:

So, [the] campus garden. Originally, it was like, "we want to put food in the cafeteria." And that shifted. And it was like, "we need to have a food pantry." And all that has happened within the context of these [Student Advocacy] groups, and the research of, "let's shift this; how in the world can we do a food pantry here, create a way of doing it, create a system? How can we get food out to students confidentially?" Like, "how are we going to do this?" And so all that's happened as a result of that [the work of the Student Advocacy Project].

Just as Ruby's work on the Student Advocacy Project is applied directly to her teaching, Audrey describes how her group similarly applies the results of such inquiry to direct action items across campus, in an attempt to improve the conditions of students' lives outside of the classroom. ${ }^{121}$

In sum, Ruby and Audrey offer concrete examples of the complex, recursive relationship between their and other faculty's professional development, teaching, inquiry, and activism —all under the guise of "professional development and service."

${ }^{121}$ This focus on students' lives outside of the classroom is also emphasized in Chapter Two, in my discussion of how participants such as Amelia and Henry have worked to implement classroom policies that take into consideration these nonacademic barriers to success. 
Ruby's professional development (i.e., involvement in the Student Advocacy Project) has led to research (i.e., gathering and reading articles) that directly impacts her teaching (i.e., her planned classroom intervention), the results of which will be collected, collaboratively, in order to understand the impact of her and her colleagues' interventions (i.e., asking institutional research office to track students), presumably to then tweak and make further changes in the research, professional development, and teaching of the faculty involved the Student Advocacy Project. Similarly, Audrey's professional development has led to research that shapes her and others' activism on campus, the results of which are felt by the students and faculty whose lives they impact.

\section{Conclusion}

This chapter focuses on the ways in which participants engage in inquiry at sites institutionally marked otherwise, advancing the alternate model of inquiry and knowledge-making enacted by participants. This model offers an alternate means by which to recognize and understand how new knowledge is encountered, created, and circulated by teacher-scholars whose work does not match the traditional model of scholarship, which tends to see research, teaching, and faculty development and/or service as areas of professional responsibility that are distinct from one another, with research — and, subsequently, publication—-being most highly valued, per the terms of tenure guidelines at most four-year research universities (Boyer, Scholarship Reconsidered 12, 15; Glassick et al. 7-8; North; Choseed; Ray). Given these commonly accepted standards, the scholarship of faculty in such four-year institutions tends to dominate the pages of major disciplinary journal publications, as I argue in Chapter 
Three. The specific institutional values of four-year research universities thus fundamentally shape Composition Studies scholarship, as these publications are key to disciplinary advancement (Goggin; Hyland).

However, two-year colleges - which, according to the American Association of Community Colleges, account for the education of nearly half of undergraduates in the United States - do not adhere to the institutional and disciplinary values of the four-year research university. Research is not valued in the same way (e.g., Vaughan, "Scholarship and Teaching"), nor are written publications. Instead, the institutional settings in which participants work allow for faculty to carve out their own unique professional identities as teacher-scholars, ultimately fostering a different model of scholarship—which, as noted, I understand broadly to be inquiry work that results in the creation and circulation of new knowledge. Participants engage in such inquiry work at sites that are marked by their institutions (per the terms of their contracts and annual work plans) as sites of other kinds of professional activities: the classroom, designated for teaching (Chapter Three), and conferences and readings groups (this chapter), understood to be spaces for professional development and service. Participants, however, leverage these as sites where they also engage in and/or circulate their scholarly activity, ultimately resulting in a complex relationship between these sites and their inquiry. The dynamic and recursive nature of these professional activities reflects the model of scholarship which Boyer urges the academy toward in Scholarship Reassessed, in which he argues for "a more comprehensive, more dynamic understanding of scholarship, $[\ldots]$ one in which the rigid categories of teaching, research, and service are broadened and more flexibly defined" (16). The institutional culture of community colleges fosters such a breakdown of the 
rigid delineations between these categories of academic work that have been established by traditional conceptions of what it means to be a faculty member in a four-year research university. As a result, community college faculty engage in rich scholarly endeavors that, though they are not easily nor often recognized as such, contribute to the advancement of both knowledge and practice at the local college (or regional) level. Though there is a long line of scholarship urging two-year college faculty to engage in and publish more formalized research, ${ }^{122}$ I contend that such a position perpetuates the hierarchy of institutions - and, thus, institutional values - that places more value on the work that goes on in four-year research universities by failing to fully recognize the rich and complex scholarly lives that two-year college faculty already lead, for which written publications may not be the best application of or product by which to "deliver" the new knowledge they encounter.

${ }^{122}$ Discussed in Chapter Three. 


\section{CHAPTER FIVE}

\section{CONCLUSION: TOWARDS MENDING THE CONVERSATION}

“'It's crucial, I think, for two-year college faculty to work with four-year college and university faculty in the discipline. We make up half of the field ... It just feels like it's incumbent on us to be part of this." (343)

- Christie Toth, "Unmeasured Engagement: Two-Year College English Faculty and Disciplinary Professional Organizations"

Since I first turned my attention to researching two-year colleges, the movement for tuition-free community college programs, or promise programs, has expanded remarkably (College Promise Campaign). As of January 2018, just three years after Tennessee became the first state to implement a state-level promise program, legislation for similar programs has been passed in fifteen other states, and over two-hundred programs have been created at the local level (Lierman). These programs take numerous forms and have requirements that vary from city to city and state by state (Powell; Smith, "Tuition-Free"), but the idea behind these initiatives remains the same: there is a strong push to increase students' access to higher education via tuition-free two-year college programs nationwide. As such programs continue to take hold, increases in two-year college 
student enrollments, which already account for nearly half ${ }^{123}$ of the nation's undergraduate population, are incredibly likely; one conceivable result of this trend is that student populations at institutions of higher education will continue to push against the imagined standard of the "traditional" college student.

As two-year degree-granting institutions, ${ }^{124}$ community colleges tend to emphasize general education courses, such as first-year writing. Because of this emphasis, the majority of the English courses offered at a community college tend to be first-year writing courses; furthermore, the work we typically understand to be writing program administration is often embedded in English departments or divisions, though it may not always be explicitly named or identified as such (Ostman). Consequently, a significant portion of the work of Composition Studies already takes place in the twoyear college setting, whether visible or not. However, as the journal analysis component of my study, ${ }^{125}$ shows, this reality is at extreme odds with the face of the discipline as it is reflected in major Composition Studies journals. In the current economic and political climate, as the landscape of higher education holds the potential for a dramatic shift towards the two-year college, those of us whose work and expertise fall under the banner of Composition Studies can no longer afford to move forward as a disjointed discipline that privileges the values of the four-year research university and so understands academic work through the singular lens of this particular institutional setting. Such a perspective perpetuates a commonly-understood hierarchy within academia, one that fails

${ }^{123}$ As stated in Chapter One, according to the AACC, forty-five percent of the nation's undergraduate students attend a community college.

${ }^{124}$ This is true in most cases; however, some community colleges are beginning to offer four-year degrees, as well $(A A C C)$.

${ }^{125}$ Discussed in Chapter Three. 
to sufficiently recognize the reality of alternate models of scholarly work and pays a disservice to the array of institutional settings in which the work of Composition Studies is enacted, the faculty who work in those settings, and, ultimately, the students enrolled in those institutions. Whatever type of postsecondary institutional setting we find ourselves working in, we should find the mismatch between lived reality and the patterns engrained in our written scholarship to be troubling, and we must ask ourselves what important perspectives we are consequently missing out on.

\section{Recognizing Alternate Forms of Scholarship}

Community colleges are a distinct academic workplace. While the faculty I interviewed have professional responsibilities similar to those of faculty in other kinds of institutions (e.g., teaching, professional development, service), as Chapter Two shows, the breakdown of participants' job responsibilities is significantly different than it is for many faculty beyond the two-year college. Additionally, two-year college faculty face a myriad of material working conditions that constrain their work, and such conditions reflect larger economic and political conditions (Chapter Two). Again, such conditions are not unique to the two-year college setting; what is unique is the subsequent shape of the institutional culture, and the resulting impact of that culture on the professional lives of faculty. Furthermore, though these working conditions (faculty workload and material constraints) match some of the cultural narratives about the community college settingsuch as the heavy teaching load - these conditions are not always prohibitive in the way cultural narratives about the community college setting might lead us to believe. In fact, as I show in Chapters Three and Four, these conditions lead to an institutional culture that 
fosters the innovative scholarly lives of some two-year college faculty, as they work within and leverage those conditions to carve out professional identities that challenge the trope of community college faculty as teachers, not scholars. For example, because of their institutions' capacious definitions of what counts as "professional development and service" on their annual performance reviews, these faculty are able to engage in scholarship (e.g., Amelia's work on her dissertation during the year I interviewed her counted towards her professional development).

My participants' scholarly activity — which I understand, in general, to be inquiry resulting in new knowledge that is then circulated—is distinct from the processes and products commonly understood and accepted to be "Scholarship." As a result of their institutional settings, these faculty enact a different model of the relationship between teaching, professional development and service, and scholarly activity, one that more closely aligns with Boyer's model of scholarship than the traditional model. In other words, the community colleges where my participants work foster a different model of scholarship. As Chapters Three and Four show, integral to this model are:

1) Those professional spaces that are more commonly understood to be sites of teaching and professional development and service—-but where participants also engage in inquiry and circulate their knowledge.

2) The complex and overlapping relationships between faculty's different position responsibilities (e.g., the blurring of the lines between teaching and research, as described in Chapter Three), as well as the recursive relationships between their inquiry practices and the circulation of the knowledge they uncover (e.g., the 
spaces in which they circulate their knowledge double as sites of inquiry and also impact that inquiry).

3) Highly collaborative relationships between colleagues (e.g., the faculty reading groups to which Audrey and Ruby belong), as well as between faculty and students (e.g., Amelia presenting with her students at conferences).

4) The largely local applications of participants' discovered knowledge (e.g., Donna's development of faculty workshops for her colleagues).

These characteristics are, in many ways, antithetical to an understanding of "Scholarship" that results in a single-authored written text, such as a journal article or book. In fact, as my study shows, the scholarly activity in which participants engage rarely yields a written text as the "product" of that activity. Instead, participants enact the knowledge they discover-in their classrooms, on their campuses, for and with their colleagues.

However, as I discuss in Chapters Three and Four, participants' scholarly activity tends to remain unrecognized as such by their institutions, academia at large, and, often, themselves. I believe this lack of recognition stems from the proliferation of the standards of the four-year research university. Because the value system of that setting is embedded in academia at large (e.g., Boyer), this system—which privileges a specific understanding of scholarly activity — shapes our own disciplinary attitudes toward and understandings of scholarship, so that what tends to be valued and rewarded at four-year research universities is "Scholarship," and is the perspective by which such work is identified. So, though community colleges are unique institutional settings — different from the typical four-year research university —when it comes to disciplinary views of what "counts" as scholarship, they are essentially held responsible for producing the same kinds of written 
scholarly products. This is evidenced, for example, by calls for two-year faculty to claim their legitimacy and engage in disciplinary conversations by publishing more written texts (e.g., Vaughan, "Scholarship and Teaching"; Tinberg). Furthermore, because scholarship, as it exists in the four-year research setting, is not easily identified in the two-year setting, a common assumption is that two-year college faculty are not scholars or researchers, and are teachers at the expense of also being scholars. This paradigm seems to also be embedded in my participants' attitudes toward their own work, which they did not often describe as "scholarly." If we-in Composition Studies, in academia at large - understand scholarship to result in the uncovering and sharing of new knowledge, but maintain a narrow understanding of the "legitimate" means by which that new knowledge can be shared (e.g., via written texts), then we are missing out on the scholarly contributions of a near-majority who teach in the name of our discipline, and our scholarly record is incomplete. As a result, their scholarly contributions are largely absent from the canon of disciplinary scholarship, and the narrative of two-year college faculty as "teacher, not scholar" is allowed to persist. However, by recognizing, as this study does, alternate models of scholarship, we enable ourselves to interrupt such narratives, and fully embrace the wide range of work done in the name of our discipline.

\section{“We Need to Get Out of Our Silos": Moving Forward, Together}

In his critique of the application of neo-liberal models to higher education, Greenwood describes the organizational structures of higher education as "Tayloristic," explaining the concept of Taylorism as

[A] system of production in which each product is broken down by an expert, into all of the operations needed to manufacture it. Each worker and workstation is a 
world unto itself where repetitive activities of a limited sort, [...] supposedly enhance productivity and quality. The problems of this authoritarian and hierarchical system are well known. It promotes a lack of communication among the component units, each treating the others as black boxes. [...] The research university model for $[\ldots]$ the United States $[\ldots]$ was based on diverse appropriations of the German university model. [...] [W] hile it linked the freedom to research and freedom to teach in a single institution, it was also based on a division of academic space into disciplines and departments. (116; emphasis added)

Greenwood describes the now-normed academic behaviors that maintain boundaries between disciplines as "dysfunctional" (117), and notes that such behaviors "receive strong support from the disciplinary associations, their journals, [and] academic promotion practices," together "reinforc[ing] a balkanized commodity production of academic work" (117-118). Though Greenwood's critique centers on disciplinary "silos" (119), a similar critique can be extended to the stratification of the institutional settings that comprise academia. This disciplinary structure that rests on the German research model of higher education transcends disciplines. It is how the very enterprise of higher education in America operates - the compartmentalization of different facets of academic and administrative work into a variety of units. This is, perhaps, one reason why the cultural narrative of two-year colleges as separate from ${ }^{126}$ - though their faculty teach similar subject matter and are, themselves, knowledgeable of disciplinary content—is so easily allowed to continue. Because of the organizational structures that make up higher education, it takes little effort to see academia as disjointed; we are, it seems, geared to understand it as such. So, just as Greenwood sees disciplinary silos, I similarly see institutional silos - in other words, I see academia similarly stratified into institutional

\footnotetext{
${ }^{126}$ To be clear, I am not suggesting that two-year colleges do not have unique characteristics, as I claim in the previous section and discuss in Chapters Two, Three, and Four; though their distinctiveness could be used as an argument in favor of their separation from other institutional settings, that is not the intent of my claim here.
} 
components. Faculty in these components tend to see themselves as separate from one another, as my study shows— - evidenced, for example, through the self-disassociation from the four-year research university setting continually mentioned by many of my participants (e.g., as described in Chapter Three).

This kind of institutional stratification is problematic for disciplinary unity. ${ }^{127}$ Amorose, writing about "the invisibility of small-school ${ }^{128}$ [Writing Program Administration, or WPA,] work" in the existing body of WPA literature within Composition Studies (91), compellingly argues that "all WPAs stand to gain any time the current excellent record on WPA work expands to reflect the diversity" of such work, "since with this diversity comes a multiplicity of new options for doing our work" (9394). According to Amorose, "disciplinary efforts to piece together who and what the WPA is $[\ldots]$ continually omit the material conditions of small-school WPAs, the nature of composition programs at small institutions, and the small-school contribution to the growing WPA culture" (91). Such an omission is ultimately "detrimental to small- and large-institution WPAs alike," as WPAs at small schools have been "under-served [...] by the discourse on WPA work," and their counterparts at large research universities have missed out on "ways to enlarge their vision of their work and strengthen their role within their institutions" (91). The underrepresentation of institutional settings beyond the fouryear university in our scholarship — whether it is, more specifically, the WPA canon, with

\footnotetext{
${ }^{127}$ While this claim may seem to be counter to my larger argument- - that the "siloing" of academia into separate components, institutionally or otherwise, is ultimately damaging to the enterprise as a whole- I am not calling for such unity at the expense of also establishing interdisciplinary relationships. Indeed, I believe that this unity is a necessary foundation for interdisciplinary and interinstitutional conversations alike.

${ }^{128}$ Amorose focuses primarily on small liberal arts colleges, or SLACs, another institutional setting with a quiet voice in disciplinary dialogues (see also: Gladstein and Regaignon).
} 
which Amorose is concerned, or other topics within Composition Studies discourse-is not just potentially damaging for those whose work is not represented, but also for those whose work remains in the spotlight of the dominant discourse, as they lose access to diverse perspectives and practices that could inform and benefit their own work. By minimally representing and engaging with the perspectives of faculty and students at various types of institutions, a canon of scholarship that betrays an imagined institutional norm essentially loses the full range of the diversity that is the reality of the discipline.

\section{Interinstitutional Dialogues}

In her 2014 study, Toth found that some of her participants, also two-year college instructors, "viewed [...] communication across institution types as important for both enhancing the professional recognition of two-year college faculty and for broadening the knowledge base of the discipline of composition" (343). Similarly, at its most basic, my argument is this: That faculty in different institutional settings have something to learn from one another about the work that they do. In the case of two-year colleges, specifically, composition faculty regularly work with diverse student bodies, and, despite having strong institutional commitments to both open access education and serving the needs of the local communities in which they reside (Vaughan, Community College Story 3-8) - making them postsecondary institutions with an overall mission that necessarily engages them with the community—community colleges are a virtually-untapped resource in disciplinary dialogues about student diversity, access, and communityengaged work. As such, I see the need for more interinstitutional dialogues about the work that we, the whole "we" of Composition Studies, do. 
These dialogues begin, I believe, with the recognition of alternate forms of scholarship. McCulloch reminds us that "the principal role of an academic is to produce, shape and distribute knowledge." Given this understanding of academia as the enterprise of knowledge-production, I believe that, foundational to interinstitutional dialogues is the capacity to see faculty in those other institutions as academics, as well. This necessitates the flexibility to step outside of the current paradigm of scholarship (the primary means of knowledge-creation and circulation), to recognize work that may not readily conform to common understandings of what scholarship looks like as possessing the potential to be a "valid" academic contribution. My study uncovered one such model by which we might begin to recognize different kinds of scholarly work. Interinstitutional dialogues, then, begin with the recognition of alternate models of scholarly activities - on both sides of the aisle. As I discuss in Chapters Three and Four, I found that participants in my study tended not to describe their own work as "scholarly," or even as "research." In fact, they seemed to minimize the importance of their work as they described it to me, a researcher from a four-year university. For these faculty, and others like them who also work in community colleges, to engage in interinstitutional dialogues, it would be necessary to own the significance and the complexities of the work that they do (Griffiths). As Griffiths argues, "so long as writing instructors at two-year colleges limit the influence of their own pedagogical knowledge to their courses, they will struggle to assert their professional authority. [...] Such a position will likely continue to limit the status and autonomy of writing instructors who teach at two-year colleges" (63).

Similarly, the onus for more disciplinary conversation between institutional settings must also fall on both sides of the aisle, and, I believe, can begin at the local 
level. While conferences are a key site of disciplinary exchange (Toth, "Unmeasured Engagement"; Hyland, Disciplinary Identities), my study suggests that, though they may occasionally attend them, community college faculty tend not frequent the larger, national conferences that are the typical conference circuit for the four-year university faculty member (as I discuss in Chapter Four). As such, while interinstitutional dialogues may certainly happen at conferences, more local conversations-e.g., between a community college English department and the first-year writing program at a nearby university, where some of their students may eventually transfer —are likely more feasible. From each other, such programs could learn, for example, new approaches to working with similar student bodies, as well as work to align their writing curricula. Another potential area of common ground between institutions is the material: funding issues and increasing reliance on contingent labor, for example. Not only might these shared issues allow for identification between institutions, but faculty in each could engage in dialogue about the ways in which they are addressing and working around those issues.

Like Boyer, I "believe the time has come to move beyond the tired old 'teaching versus research' debate and give the $[\ldots]$ term 'scholarship' a broader, more capacious meaning, one that brings legitimacy to the full scope of academic work," for, as he reminds us, "the work of the scholar also means [...] looking for connections, building bridges between theory and practice, and communicating one's knowledge effectively" (Scholarship Reconsidered 16). Ultimately, I maintain that we need to more fully recognize the variety of advances made in our disciplinary knowledge, in order to move forward — as a discipline — as well as to learn from each other. As Lois passionately 
argued during her interview, "we have a lot more [...] to learn from each other than people think we do. And we need to stop siloing ourselves. And we all hear that, that's the big buzzword, 'we need to get out of our silos.' But it's true. We need to get out of our silos." 


\section{REFERENCES}

“2015 Fact Sheet.” American Association of Community Colleges, www.aacc.nche.edu/research-trends/fast-facts/. Accessed 25 April 2015.

Adler-Kassner, Linda and Elizabeth Wardle. "Naming What We Know: The Project of This Book." Naming What We Know: Threshold Concepts of Writing Studies, edited by Linda Adler-Kassner and Elizabeth Wardle, Utah State University Press, 2015, pp. 1-11.

Albert, Janice M. "I Am Not the Look in Your Eyes." Two-Year College English: Essays for a New Century, edited by Mark Reynolds, National Council of Teachers of English, 1994, pp. 9-15.

Alford, Barry. "Introduction." The Politics of Writing in the Two-Year College, edited by Barry Alford and Keith Kroll, Boynton/Cook, 2001, pp. v-viii.

American Association of Community Colleges. www.aacc.nche.edu/. Accessed 5 November 2015.

Amorose, Thomas. "WPA Work at the Small College or University: Re-Imagining Power and Making the Small School Visible." WPA: Writing Program Administration, vol. 23 , no. 3 , 2000 , pp. $85-103$.

Andelora, Jeff. "The Professionalization of Two-Year College English Faculty: 19501990." Teaching English in the Two Year College, vol. 35, no. 1, 2007, pp. 6-19. 
---. “The Teacher/Scholar: Reconstructing Our Professional Identity in Two-Year Colleges." Teaching English in the Two Year College, vol. 32, no. 3, 2005, pp. 307-322.

Anderson, Kathryn and Dana C. Jack. "Learning to Listen: Interview Techniques and Analyses." Women's Words: The Feminist Practice of Oral History, edited by Sherna Berger Gluck and Daphne Patai, Routledge, 1991, pp. 11-26.

Anderson, Paul V. "Ethics, Institutional Review Boards, and the Involvement of Human Participants in Composition Research." Ethics and Representation in Qualitative Studies of Literacy, edited by Peter Mortensen and Gesa E. Kirsch, NCTE, 1996, pp. 260-285.

Barnett, Ronald. Imagining the University. Routledge, 2013.

Bartholomae, David. "Inventing the University." The Norton Book of Composition Studies, edited by Susan Miller, Norton, 2009, pp. 605-630.

Becker, William W. and Moya L. Andrews, editors. The Scholarship of Teaching and Learning in Higher Education: Contributions of Research Universities. Indiana University Press, 2004.

Bidwell, Allie. "Obama's Community College Plan Builds on State Efforts." U.S. News \& World Report, 9 January 2015, www.usnews.com/news/articles/2015/01/09/president-obama-announces-planfor-tuition-free-community-college. Accessed 13 September 2016.

"Bill Haslam, 49th Governor of Tennessee." TN State Government: Office of the Governor, www.tn.gov/governor/about-bill-haslam.html. Accessed 22 March 2018. 
Bizzell, Patricia. "What Happens When Basic Writers Come to College?” College Composition and Communication, vol. 37, no. 3, 1986, pp. 294-301.

Blalock, Glenn. "Faculty Development in English Studies: An Overview of Resources and a Suggested Sequence.” Pedagogy, vol. 8, no. 3, 2008, pp. 555-586.

Bousquet, Marc, Tony Scott, and Leo Parascondola, editors. Tenured Bosses and Disposable Teachers: Writing Instruction in the Managed University. Southern Illinois University Press, 2004.

Bousquet, Marc. How the University Works: Higher Education and the Low-Wage Nation. New York University Press, 2008.

Boyer, Ernest L. Scholarship Reconsidered: Priorities of the Professoriate. The Carnegie Foundation for the Advancement of Teaching, 1990.

Brereton, John C. "Introduction." The Origins of Composition Studies in the American College, edited by John C. Brereton, University of Pittsburgh Press, 1995, Pittsburgh Series in Composition, Literacy, and Culture, David Bartholomae and Jean Ferguson Carr.

Bruner, Jerome. Acts of Meaning. Harvard University Press, 1990.

---. "The Narrative Construction of Reality.” Critical Inquiry, vol. 18, no. 1, 1991, pp. 121.

"By-Laws of the Two-Year College English Association and the Regional Associations." Two-Year College English Association, 2012, http://cccc.ncte.org/tyca. Accessed 5 November 2015. 
Calhoon-Dillahunt, Carolyn. "Writing Programs without Administrators: Frameworks for Successful Writing Programs in the Two-Year College." WPA: Writing Program Administration, vol. 35, no. 1, 2011, pp. 118-134.

Carolyn Calhoon-Dillahunt, Darin L. Jensen, Sarah Z. Johnson, Howard Tinberg, and Christie Toth. "TYCA Guidelines for Preparing Teachers of English in the TwoYear College." National Council of Teachers of English, www.ncte.org/library/NCTEFiles/Groups/TYCA/GuidelinesPrep2YCEngFac_RE VISED.pdf. Accessed 16 August 2017.

Carpenter, Lissette. "Teaching in the Community College: A Possible Road to Be Taken.” ADE Bulletin, vol. 111, 1995, pp. 20-22.

Chiseri-Strater, Elizabeth. "Turning in Upon Ourselves: Positionality, Subjectivity, and Reflexivity in Case Study and Ethnographic Research.” Ethics and Representation in Qualitative Studies of Literacy, edited by Peter Mortensen and Gesa Kirsch, NCTE, 1996, pp. 115-133.

Choseed, Malkiel. "Moving up in the World: A Career at a Two-Year College." Rewriting Success in Rhetoric and Composition Careers, edited by Donna LeCourt, Amy Goodburn, and Carrie Leverenz, Parlor Press, 2013, pp. 18-31.

Cohen, Arthur M. and Florence B. Brawer. The American Community College. 5th edition, Jossey-Bass, 2008.

College Promise Campaign. College Promise, 2016, collegepromise.org/. Accessed 26 March 2018. 
Connors, Robert. Composition-Rhetoric: Backgrounds, Theory, and Pedagogy. University of Pittsburgh Press, 1997. Pittsburgh Series in Composition, Literacy, and Culture, David Bartholomae and Jean Ferguson.

---. "Composition History and Disciplinarity." History, Reflection, and Narrative: The Professionalization of Composition, 1963-1983, edited by Beth Boehm, Mary Rosner, and Debra Journet, Ablex Publishing Corporation, 1999, pp. 3-21. Perspectives on Writing: Theory, Research, Practice, Kathleen Blake Yancey and Brian Huot.

---. "Rhetoric in the Modern University: The Creation of an Underclass." The Politics of Writing Instruction: Postsecondary, edited by Richard Bullock and John Trimbur, Boynton/Cook Publishers, 1991, pp. 55-84.

Coogan, David. "Service Learning and Social Change: The Case for Materialist Rhetoric." College Composition and Communication, vol. 57, no. 4, 2006, pp. 667-693.

Daniel, James Rushing. "Freshman Composition as a Precariat Enterprise." College English, vol. 80, no. 1, 2017, pp. 63-85.

“Drive to 55 Alliance." Drive to 55 Alliance, driveto55.org/. Accessed 23 March 2018. Erlin, Matt and Lynne Tatlock. "Introduction: 'Distant Reading' and the Historiography of Nineteenth-Century German Literature.” Distant Readings: Topologies of German Culture in the Long Nineteenth Century, edited by Matt Erlin and Lynne Tatlock, Camden House, 2014, pp. 1-25. 
"Fast Facts from Our Fact Sheet." American Association of Community Colleges, www.aacc.nche.edu/AboutCC/Pages/fastfactsfactsheet.aspx. Accessed 3 September 2016 .

Fearing, Bertie E. "Renewed Vitality in the Twenty-First Century: The Partnership between Two-Year College and University English Departments." Two-Year College English: Essays for a New Century, edited by Mark Reynolds, National Council of Teachers of English, 1994.

"FORUM: Issues About Part-Time and Contingent Faculty." Conference on College Composition and Communication, www.ncte.org/cccc/forum. Accessed 2 September 2016.

Friedrich, Patricia. "Assessing the Needs of Linguistically Diverse First-Year Students: Bringing Together and Telling Apart International ESL, Resident ESL, and Monolingual Basic Writers.” WPA: Writing Program Administration, vol. 30, no. $1-2,2006$, pp. 15-35.

Frye, John H. The Vision of the Public Junior College, 1900-1940: Professional Goals and Popular Aspirations. Greenwood Press, 1992.

Gang, Duane W. "Eyes on Tennessee as It Begins Free Community College Plan.” The Tennessean, 16 April 2014, www.tennessean.com/story/news/education/2014/04/16/tennessee-lawmakersapprove-free-community-college-plan/7772245/. Accessed 2 May 2016.

Gebhardt, Richard C. "Evolving Approaches to Scholarship, Promotion, and Tenure in Composition Studies." Academic Advancement in Composition Studies: 
Scholarship, Publication, Promotion, Tenure, edited by Richard C. Gebhardt and Barbara Genelle Smith Gebhardt, Lawrence Erlbaum Associates, 1997, pp. 1-19. ---. "Scholarship and Teaching: Motives and Strategies for Writing Articles in Composition Studies." Publishing in Rhetoric and Composition, edited by Gary A. Olson and Todd W. Taylor, State University of New York Press, 1997, pp. 3546.

George, Diana, editor. Kitchen Cooks, Plate Twirlers, and Troubadours: Writing Program Administrators Tell Their Stories. Boynton/Cook, 1999.

Gere, Anne Ruggles. "Preface," Composition, Pedagogy, and the Scholarship of Teaching, edited by Deborah Minter and Amy M. Goodburn, Heinemann, 2002, pp. xi-xiii.

Gillam, Alice. "Collaboration, Ethics, and the Emotional Labor of WPAs." A Way to Move: Rhetorics of Emotion and Composition Studies, edited by Dale and Laura R. Micciche Jacobs, Boynton/Cook, 2003, pp. 113-123.

Gilligan, Carol. "Introduction: The Listening Guide Method of Psychological Inquiry." Qualitative Psychology, vol. 2, no. 1, 2015, pp. 69-77.

Gilligan, Carol and Jessica Eddy. "Listening as a Path to Psychological Discovery: An Introduction to the Listening Guide." Perspectives on Medical Education, vol. 6, 2017, pp. $76-81$.

Gladstein, Jill M. and Dara Rossman Regaignon. Writing Program Administration at Small Liberal Arts Colleges. Parlor Press, 2012.

Glassick, Charles E., Mary Taylor Huber, and Gene Maeroff. Scholarship Assessed: Evaluation of the Professoriate. Jossey-Bass, Inc., 1997. 
Goggin, Maureen Daly. Authoring a Discipline: Scholarly Journals and the Post-World War Ii Emergence of Rhetoric and Composition. Laurence Erlbaum Associates, 2000.

Grabill, Jeffery T. "Community-Based Research and the Importance of a Research Stance." Writing Studies Research in Practice: Methods and Methodologies, edited by Lee Nickoson and Mary P. Sheridan, Southern Illinois University Press, 2012, pp. 210-219.

Graves, Heather. "Disclaimer: 'Professional Academic on a Closed Course: Do Not Attempt This at Home." Rewriting Success in Rhetoric and Composition Careers, edited by Donna LeCourt, Amy Goodburn, and Carrie Leverenz, Parlor Press, 2013.

Greenwood, Davydd J. "Doing and Learning Action Research in the Neo-Liberal World of Contemporary Higher Education.” Action Research, vol. 10, no. 2, 2012, pp. $115-132$.

Griffiths, Brett M. "Professional Autonomy and Teacher-Scholar-Activists in Two-Year Colleges: Preparing New Faculty to Think Institutionally.” Teaching English in the Two Year College, vol. 45, no. 1, 2017, pp. 47-68.

Gunner, Jeanne. "Iconic Discourse: The Troubling Legacy of Mina Shaughnessy." Journal of Basic Writing, vol. 17, no. 2, 1998, pp. 25-42.

Hansen, Kristine. "Face to Face with Part-Timers: Ethics and the Professionalization of Writing Faculties." Resituating Writing: Constructing and Administering Writing Programs, edited by Joseph Janangelo and Kristine Hansen, Boynton/Cook, 1995, pp. 23-45. 
Harris, Joseph. A Teaching Subject: Composition since 1966. Utah State U P, 2012.

Hassel, Holly. "Research Gaps in Teaching English in the Two-Year College." Teaching English in the Two Year College, vol. 40, no. 4, 2013, pp. 343-363.

Hassel, Holly, Jeffrey Klausman, Joanne Baird Giordano, Margaret O'Rourke, Leslie Roberts, Patrick Sullivan, and Christie Toth. "TYCA White Paper on Developmental Education Reforms." Teaching English in the Two Year College, vol. 42, no. 3, 2014, pp. 227-243.

Hatch, Thomas. Into the Classroom: Developing the Scholarship of Teaching and Learning. Jossey-Bass, 2006.

Holladay, Sylvia A. "Order out of Chaos: Voices from the Community College." Composition in the Twenty-First Century: Crisis and Change, edited by Lynn Bloom, Southern Illinois University Press, 1996, pp. 29-38.

Holmsten, Victoria. “This Site under Construction: Negotiating Space for Wpa Work in the Community College." The Writing Program Administrator's Resource: A Guide to Reflective Institutional Practice, edited by Stuart Brown and Theresa Enos, Lawrence Erlbaum Associates, 2002, pp. 429-438.

Horner, Bruce. Rewriting Composition: Terms of Exchange. Southern Illinois University Press, 2016.

Hull, Glynda, Mike Rose, Kay Losey, and Marsia Castellano. "Remediation as Social Construct: Perspectives from an Analysis of Classroom Discourse." College Composition and Communication, vol. 42, no. 3, 1991, pp. 299-329.

Hutchings, Pat, editor. Opening Lines: Approaches to the Scholarship of Teaching and Learning. The Carnegie Foundation for the Advancement of Teaching, 2000. 
Hyland, Ken. Disciplinary Discourses: Social Interactions in Academic Writing. The University of Michigan Press, 2004.

Hyland, Ken. Disciplinary Identities: Individuality and Community in Academic Discourse. Cambridge University Presse, 2012. The Cambridge Applied Linguistics Series, Carol A. Chapelle and Susan Hunston.

Jacobs, Dale and Laura R. Micciche, editors. A Way to Move: Rhetorics of Emotion \& Composition Studies. Boynton/Cook Publishers, 2003.

Jaschik, Scott. “'Scholarship Reconsidered' as Tenure Policy.” Inside Higher Ed, 2 October 2007, www.insidehighered.com/news/2007/10/02/wcu. Accessed 15 December 2017.

Jensen, Darin L. and Christie Toth. "Unknown Knowns: The Past, Present, and Future of Graduate Preparation for Two-Year College English Faculty." College English, vol. 79, no. 6, 2017, pp. 561-592.

Juergensmeyer, Erik. "Rhetorical Advocacy and the Scholarship of Application." Academic Labor: Research and Artistry, vol. 1, no. 1, 2017, pp. 59-74.

Juszkiewicz, Jolanta. Trends in Community College Enrollment and Completion Data, 2016. American Association of Community Colleges, March 2016, www.aacc.nche.edu/wpcontent/uploads/2017/11/TrendsCCEnrollment_Final2016.pdf.

Kern, Beth, Gwendolyn Mettetal, Marcia D. Dixson, and Robin K. Morgan. "The Role of SOTL in the Academy: Upon the 25th Anniversary of Boyer's Scholarship Reconsidered." Journal of the Scholarship of Teaching and Learning, vol. 15, no. 3, 2015, pp. 1-14. 
Kirsch, Gesa. "Methodological Pluralism: Epistemological Issues." Methods and Methodology in Composition Research, edited by Gesa Kirsch and Patricia A. Sullivan, Southern Illinois University Press, 1992, pp. 247-269.

Kirsch, Gesa and Patricia A. Sullivan. "Introduction." Methods and Methodology in Composition Research edited by Gesa Kirsch and Patricia A. Sullivan, Southern Illinois University Press, 1992, pp. 1-11.

Kitzhaber, Albert R. The Two-Year College and the Teaching of English. NCTE, 1963.

Klausman, Jeffrey. "Mapping the Terrain: The Two-Year College Writing Program Administrator." Teaching English in the Two Year College, vol. 35, no. 3, 2008, pp. $238-251$.

---. "Toward a Definition of a Writing Program at a Two-Year College: You Say You Want a Revolution?" Teaching English in the Two Year College, vol. 40, no. 3, 2013, pp. 257-273.

Kreber, Carolin. "Conceptualizing the Scholarship of Teaching and Idenitifying Unresolved Issues." Scholarship Revisited: Perspectives on the Scholarship of Teaching, edited by Carolin Kreber, vol. 86, Jossey-Bass, 2001, pp. 1-18. New Directions for Teaching and Learning, Carolin Kreber.

---. "Scholarship Revisited: Perspectives on the Scholarship of Teaching." New Directions for Teaching and Learning, vol. 86, Jossey-Bass, 2001.

Kroll, Keith. "Building Communities: Joining the Community of Professional Writing Teachers." Teaching English in the Two Year College, vol. 17, no. 2, 1990, pp. 103-108. 
Kroll, Keith and Barry Alford. "Scholarship, Tenure, and the Two-Year College." Academic Advancement in Composition Studies: Scholarship, Publication, Promotion, Tenure, edited by Richard C. Gebhardt and Barabara Genelle Smith Gebhardt, Lawrence Erlbaum Associates, 1997, pp. 57-70.

Laster, Ann, and Beverly Fatherree. "Reminiscing About a Two-Year Regional Conference: Two Voices/One Viewpoint." The Profession of English in the TwoYear College, edited by Mark Reynolds and Sylvia Holladay-Hicks, Boynton/Cook, 2005, pp. 113-124.

Lierman, Kyle. "Three Years of Progress on Free Community College." Forbes, 8 January 2018, www.forbes.com/sites/civicnation/2018/01/08/three-years-ofprogress-on-free-community-college/\#6262ab181388. Accessed 26 March 2018.

Lovas, John. "All Good Writing Develops at the Edge of Risk." Views from the Center: The CCCC Chairs'Addresses: 1977-2005, edited by Duane Roen, Bedford/St. Martin's, 2006, pp. 395-415.

Lu, Min-Zhan. "Redefining the Legacy of Mina Shaughnessy: A Critique of the Politics of Linguistic Innocence." Journal of Basic Writing, vol. 10, no. 1, 1991, pp. 2640.

Madden, Frank. "A Job at a 'Real' College: Or, How I Became a Faculty Member at a Two-Year College." ADE Bulletin, no. 111, 1995, pp. 17-19.

---. "Crossing Borders: The Two-Year College." College English, vol. 61, no. 6, 1999, pp. $721-730$.

Matijevich, Elke. "Encouraging Scholarship at the Community College." ADE Bulletin, no. 131,2002 , pp. $58-61$. 
Matsuda, Paul Kei, Maria Fruit, and Tamara Lee Brown Burton Lamm. "Second Language Writers and Writing Program Administrators." WPA: Writing Program Administration, vol. 30, no. 1-2, 2006, pp. 11-14.

Maxwell, Joseph A. Qualitative Research Design: An Interactive Approach. 2nd edition, Sage Publications, 2005. Applied Social Research Methods Series, Leonard Bickman and Debra J. Rog.

McCulloch, Sharon. “The Importance of Being Ref-Able: Academic Writing under Pressure from a Culture of Counting." London School of Economics (LSE) Impact of Social Sciences Blog, London School of Economics and Political Science, 9 February 2017, blogs.lse.ac.uk/impactofsocialsciences/2017/02/09/theimportance-of-being-ref-able-academic-writing-under-pressure-from-a-culture-ofcounting/. Accessed 22 March 2018.

McKinney, Kathleen. "Introduction to SOTL: In and across the Disciplines." The Scholarship of Teaching and Learning in and across the Disciplines, edited by Kathleen McKinney, Indiana University Press, 2013, pp. 1-11.

---, editor. The Scholarship of Teaching and Learning in and across the Disciplines." Indiana University Press, 2013.

McLeod, Susan H. Notes on the Heart: Affective Issues in the Writing Classroom. Southern Illinois University Press, 1997.

McNenny, Gerri and Sallyanne H. Fitzgerald. "Mainstreaming Basic Writers: Politics and Pedagogies of Access.” Lawrence Erlbaum Associates, 2001.

Micciche, Laura. Doing Emotion: Rhetoric, Writing, Teaching. Boynton/Cook, 2007. 
Mitchell, Michael, Michael Leachman, and Kathleen Masterson. "Funding Down, Tuition Up: State Cuts to Higher Education Threaten Quality and Affordability at Public Colleges." Center on Budget and Policy Priorities, August 15, 2016, www.cbpp.org/research/state-budget-and-tax/funding-down-tuition-up. Accessed 10 February 2018.

---. "A Lost Decade in Higher Education Funding: State Cuts Have Driven up Tuition and Reduced Quality," Center on Budget and Policy Priorities, August 23, 2017, www.cbpp.org/research/state-budget-and-tax/a-lost-decade-in-higher-educationfunding. Accessed 10 February 2018.

Miller, Susan. "The Feminization of Composition.” The Politics of Writing Instruction: Postsecondary, edited by Richard Bullock and John Trimbur, Boynton/Cook Publishers, 1991, pp. 39-53.

---. "Writing Theory : : Theory Writing." Methods and Methodology in Composition Research, edited by Gesa Kirsch and Patricia A. Sullivan, Southern Illinois University Press, 1992, pp. 62-83.

Miller, Thomas P. "Lest We Go the Way of Classics: Toward a Rhetorical Future for English Departments." Rhetorical Education in America, edited by Cheryl Glenn, U of Alabama Press, 2004, pp. 18-35.

Minter, Deborah and Amy M. Goodburn. "Introduction: Why Document Postsecondary Teaching?" Composition, Pedagogy, and the Scholarship of Teaching, edited by Deborah Minter and Amy M. Goodburn, Heinemann, 2002, pp. xv-xix. ---, editors. Composition, Pedagogy, and the Scholarship of Teaching. Boynton/Cook, 2002. 
Moran, Michael G. and Martin J. Jacobi. Research in Basic Writing: A Bibliographic Sourcebook. Greenwood Press, 1990.

Moretti, Franco. “Conjectures on World Literature.” New Left Review, vol. 97, no. 1, 2000, pp. 54-68.

Newkirk, Thomas. The Performance of Self in Student Writing. Boynton/Cook, 1997.

---. "Seduction and Betrayal in Qualitative Research." Ethics and Representation in Qualitative Studies of Literacy, edited by Peter Mortensen and Gesa E Kirsch, NCTE, 1996, pp. 3-16.

Nist, Elizabeth and Helon Howell Raines. "Two-Year Colleges: Explaining and Claiming Our Majority." Resituating Writing: Constructing and Administering Writing Programs, edited by Joseph Janangelo and Kristine Hansen, Boynton/Cook, 1995, pp. 59-70.

---. "Writing in the Margins: A Search for Community College Voices." Writing Ourselves into the Story: Unheard Voices from Composition Studies, edited by Sheryl I. Fontaine and Susan Hunter, Southern Illinois UP, 1993, pp. 293-321.

North, Stephen M. The Making of Knowledge in Composition: Portrait of an Emerging Field. Boynton/Cook, 1987.

“Open Admissions: American Dream or Disaster?” Time, vol. 96, 19 October 1970, pp. $81-86$

Osborn, Jan. Community Colleges and First-Generation Students: Academic Discourse in the Writing Classroom. Palgrave Macmillan, 2015.

Ostman, Heather. Writing Program Administration and the Community College. Parlor Press, 2013. 
Pahl, Kate. "Materiality." Materializing Literacies in Communities: The Uses of Literacy Revisited, Bloomsbury, 2014, pp. 51-79.

Palmer, James C. "Scholarship and the Professional Identity of Community College Faculty." New Directions for Community Colleges, vol. 171, Fall 2015, pp. 37-48.

Palmer, James C. and George B. Vaughan, editors. Fostering a Climate for Faculty Scholarship at Community Colleges. AACC, 1992.

Payne, Michelle. Bodily Discourses: When Students Write About Abuse and Eating Disorders. Boynton/Cook, 2000.

Powell, Farran. "These States Offer Tuition-Free College Programs." U.S. News \& World Report, 1 February 2018, www.usnews.com/education/best-colleges/paying-forcollege/articles/2018-02-01/these-states-offer-tuition-free-college-programs. Accessed 26 March 2018.

Powell, Katrina M. and Pamela Takayoshi. "Revealing Methodology.” Practicing Research in Writing Studies: Reflexive and Ethically Responsible Research, edited by Katrina M. Powell and Pamela Takayoshi, Hampton Press, 2012, pp. 128.

Powers-Stubbs, Karen and Jeff Sommers. “Where We Are Is Who We Are': Location, Professional Identity, and the Two-Year College.” The Politics of Writing in the Two-Year College, edited by Barry Alford and Keith Kroll, Boynton/Cook, 2001, pp. 19-41.

Preto-Bay, Ana Maria and Kristine Hansen. "Preparing for the Tipping Point: Designing Writing Programs to Meet the Needs of the Changing Population.” WPA: Writing Program Administration, vol. 30, no. 1-2, 2006, pp. 37-57. 
Raines, Helen Howell. "Teaching Writing in the Two-Year College." WPA: Writing Program Administration, vol. 12, no. 1-2, 1988, pp. 29-37.

---. "Is There a Writing Program in This College? Two Hundred and Thirty-Six TwoYear Schools Respond.” College Composition and Communication, vol. 41, no. 2, 1990, pp. 151-165.

Ray, Ruth E. The Practice of Theory: Teacher Research in Composition. National Council of Teachers of English, 1993.

Reynolds, Mark. "Introduction.” Two-Year College English: Essays for a New Century, edited by Mark Reynolds, NCTE, 1994, pp. 1-5.

---. “Building a Two-Year College Teacher-Scholar Community: A Primer.” Teaching English in the Two Year College, vol. 32, no. 1, 2004, pp. 71-77.

---. "Two-Year-College Teachers as Knowledge Makers.” The Profession of English in the Two-Year College, edited by Mark Reynolds and Sylvia Holladay Hicks, Boynton/Cook Publishers, 2005, pp. 1-15.

Rice, R. Eugene. “Ernest Boyer's 'Scholarship of Engagement' in Retrospect.” Journal of Higher Education Outreach and Engagement, vol. 20, no. 1, 2016, pp. 29-33.

Rose, Mike. Lives on the Boundary: The Struggles and Achievements of America's Underprepared. The Free Press, 1989.

Schell, Eileen E. "Austerity, Contingency, and Administrative Bloat." Composition in the Age of Austerity, edited by Nancy Welch and Tony Scott, University Press of Colorado, 2016, pp. 177-190. 
---. "Materializing the Material as a Progressive Method and Methodology." Practicing Research in Writing Studies, edited by Katrina M. Powell and Pamela Takayoshi, Hampton Press, Inc, 2012, pp. 123-140.

---. "Toward a New Labor Movement in Higher Education: Contingent Labor and Organizing for Change." Tenured Bosses and Disposable Teachers: Writing Instruction in the Managed University, edited by Marc Bousquet, Tony Scott, and Leo Parascondola, Southern Illinois UP, 2004, pp. 100-110.

Schilb, John. "Scholarship in Composition and Literature: Some Comparisons." Academic Advancement in Composition Studies: Scholarship, Publication, Promotion, Tenure, edited by Richard C. Gebhardt and Barbara Genelle Smith Gebhardt, Lawrence Erlbaum Associates, 1997, pp. 21-30.

Schneider, Barbara. "The Rhetorical Situation: Examining the Framing of Professional Development." Pedagogy, vol. 8, no. 3, 2008, pp. 509-522.

Schon, Donald A. “Knowing-in-Action: The New Scholarship Requires a New Epistemology." Change, vol. 27, no. 6, 1995, pp. 26-34.

Schwalm, David E. "Teaching Basic Writing: The Community College on the University Campus." WPA, vol. 13, no. 1-2, 1989, pp. 15-24.

Scott, Tony. Dangerous Writing: Understanding the Political Economy of Composition. Utah State University Press, 2009.

---. "How We Do What We Do: Facing the Contradictory Political Economies of Writing Programs.” The Writing Program Interrupted: Making Space for Critical Consciousness, edited by Donna Strickland and Jeanne Gunner, Boynton/Cook, 2009, pp. 41-55. 
Selfe, Cynthia L. and Gail Hawisher. "Exceeding the Bounds of the Interview: Feminism, Mediation, Narrative, and Conversations About Digital Literacy.” Writing Studies Research in Practice: Methods and Methodologies, edited by Lee Nickoson and Mary P. Sheridan, Southern Illinois University Press, 2012, pp. 36-62.

Shaughnessy, Mina P. "Diving In: An Introduction to Basic Writing." College Composition and Communication, vol. 27, no. 3, 1976, pp. 234-239.

---. Errors and Expectations: A Guide for the Teacher of Basic Writing. Oxford University Press, 1977.

Sheehy, Kelsey. “Obama's Free Community College Plan: What Students Need to Know." U.S News \& World Report, 16 January 2015, www.usnews.com/education/community-colleges/articles/2015/01/16/obamasfree-community-college-plan-what-students-need-to-know. Accessed 13 September 2016.

Shulman, Lee S. "Course Anatomy: The Discussion and Analysis of Knowledge through Teaching." The Course Portfolio: How Faculty Can Examine Their Teaching to Advance Practice and Improve Student Learning, edited by Lee S. Shulman, 1998, pp. 5-12.

---. “From Minsk to Pinsk: Why a Scholarship of Teaching and Learning?” The Journal of the Scholarship of Teaching and Learning, vol. 1, no. 1, 2001, pp. 48-53.

---. "Taking Learning Seriously.” Change: The Magazine of Higher Learning, vol. 31, no. 4,1999 , pp. 10-17.

---. "Visions of the Possible: Models for Campus Support of the Scholarship of Teaching and Learning." The Scholarship of Teaching and Learning in Higher Education, 
edited by William E. Becker and Moya L. Andrews, Indiana University Press, 2004, pp. 9-23.

Slaughter, Sheila and Gary Rhoades. Academic Capitalism and the New Economy: Markets, States, and Higher Education. The Johns Hopkins U Press, 2004.

Smith, Ashley A. "Promise Provides Enrollment Boost." Inside Higher Ed, 24 November 2015, www.insidehighered.com/news/2015/11/24/promise-program-sharply-liftstennessee-college-freshman-enrollment. Accessed 28 July 2016.

---. “Tuition-Free, with Strings.” Inside Higher Ed, 23 February 2018, www.insidehighered.com/news/2018/02/23/states-add-restrictions-tuition-freecollege-plans. Accessed 26 March 2018.

Snyder, Laura Bartlett. "Feminisms and the Problem of Complicity in Writing Program Administrator Work.” The Writing Program Interrupted: Making Space for Critical Discourse, edited by Donna Strickland and Jeanne Gunner, Boynton/Cook, 2009, pp. 28-40.

Soliday, Mary. The Politics of Remediation: Institutional and Student Needs in Higher Education. University of Pittsburgh Press, 2002. Pittsburgh Series in Composition, Literacy, and Culture, David Bartholomae and Jean Ferguson Carr. Sommers, Jeff. "Two-Year College English Faculty and the Scholarship of Teaching and Leraning: The Journey Awaits." Teaching English in the Two Year College, vol. 32, no. 1, 2004, pp. 14-25.

Starr, Al. “Community College Teaching: Endless Possibilities.” Two-Year College English: Essays for a New Century, edited by Mark Reynolds, National Council of Teachers of English, 1994, pp. 165-174. 
Strickland, Donna. The Managerial Unconscious in the History of Composition Studies. Southern Illinois University Press, 2011.

Sullivan, Patrick. "What Is 'College-Level' Writing?" Teaching English in the Two Year College, vol. 30, no. 4, 2003, pp. 374-390.

---. "The Two-Year College Teacher-Scholar-Activist." Teaching English in the Two Year College, vol. 42, no. 4, 2015, pp. 327-350.

Sullivan, Patricia A. "Passing: A Family Dissemblance." Coming to Class: Pedagogy and the Social Class of Teachers, edited by John McMillan Alan Shepard, and Gary Tate, Boynton/Cook, 1998, pp. 231-251.

Sullivan, Patrick and Howard Tinberg. "What Is “College-Level” Writing?" NCTE, 2006.

Tamburin, Adam. “College Enrollment Jumps under TN Promise.” The Tennessean, 12 September 2015, www.tennessean.com/story/news/education/2015/09/11/collegeenrollment-jumps-under-tn-promise/72096194/. Accessed 28 July 2016.

Taylor, Tim N. "Writing Program Administration at the Two-Year Colege: Ghosts in the Machine.” WPA: Writing Program Administration, vol. 22, no. 3, 2009, pp. 120139.

“Tennessee Promise.” TN State Government, tnpromise.gov/about.shtml. Accessed 23 March 2018.

“Tennessee Promise Sees Increased Enrollment, Strong Retention Rates in Year 2." Tennessee Higher Education Commission and Student Assistance Corporation, 2 February 2017, www.tn.gov/thec/news/2017/2/2/tennessee-promise-sees- 
increased-enrollment-strong-retention-rates-in-year.html. Accessed 23 March 2018.

“Tennessee Reconnect.” TN State Government, www.tnreconnect.gov/. Accessed 23 March 2018.

Tinberg, Howard. "Seeing Ourselves Differently: Remaking Research and Scholarship at the Community College." Teaching English in the Two Year College, vol. 20, 1993, pp. 12-17.

Tinberg, Howard, Donna Killian Duffy, and Jack Mino. “The Scholarship of Teaching and Learning at the Two-Year College: Promise and Peril.” Change: The Magazine of Higher Learning, vol. 39, no. 4, 2007, pp. 26-33.

Tobin, Lad. Writing Relationships: What Really Happens in the Composition Class. Boynton/Cook, 1993.

---. Reading Student Writing: Confessions, Meditations, and Rants. Boynton/Cook 2004. Tolman, Deborah and Mary Brydon-Miller. “Transforming Psychology: Interpretive and Participatory Research Methods.” Journal of Social Issues, vol. 53, no. 4, 1997, pp. 597-603.

Toth, Christie, Brett M. Griffiths, and Kathryn Thirolf. “'Distinct and Significant”: Professional Identities of Two-Year College English Faculty." College Composition and Communication, vol. 65, no. 1, 2013, pp. 90-116.

Toth, Christie. "Unmeasured Engagement: Two-Year College English Faculty and Disciplinary Professional Organizations." TETYC, vol. 41, no. 4, 2014, pp. 335353. 
Toth, Christie, Patrick Sullivan, and Carolyn Calhoon-Dillahunt. "A Dubious Method of Improving Educational Outcomes: Accountability and the Two-Year College.” Teaching English in the Two Year College, vol. 43, no. 4, 2016, pp. 391-410.

Toth, Christie and Darin Jensen. "Responses to the TYCA Guidelines for Preparing Teachers of English in the Two-Year College." Teaching English in the Two Year College, vol. 45, no. 1, 2017, pp. 29-46.

Townsend, Barbara K. and Nancy LaPaglia. “Are We Marginalized within Academe? Perceptions of Two-Year College Faculty.” Community College Review, vol. 28, no. 1,2000 , pp. 41-48.

Trainor, Jennifer Seibel and Amanda Godley. "After Wyoming: Labor Practices in Two University Writing Programs." College Composition and Communication, vol. 50, no. 2,1998 , pp. 153-181.

Vaughan, George B. The Community College Story. 3rd edition, American Association of Community Colleges, 2006.

---. "Scholarship and Teaching: Crafting the Art." Two-Year College English: Essays for a New Century, edited by Mark Reynolds, NCTE, 1994, pp. 212-221.

"Watching the Economy for Enrollment Trends." American Association of Community Colleges, April 2015, www.aacc.nche.edu/research-trends/datapoints/. Accessed 7 December 2015.

Weedin, Dustin and Suzanne Hultin. "Free Community College." National Conference of State Legislatures, 25 April 2016, www.ncsl.org/research/education/freecommunity-college.aspx. Accessed 28 July 2016. 
Weimer, Maryellen. "The Disciplinary Journals on Pedagogy." Change, vol. 25, no. 6, 1993, pp. 44-51.

Welch, Nancy and Tony Scott, editors. Composition in the Age of Austerity. Utah State University Press, 2016.

Worthen, Helena. "The Problem of the Majority Contingent Faculty in the Community Colleges." The Politics of Writing in the Two-Year College, edited by Barry Alford and Keith Kroll, Boynton/Cook, 2001, pp. 42-60. 


\section{APPENDICES}

Appendix A

Recruitment Email

Dear [Name],

I would like to invite you to participate in a research study I am conducting for my dissertation. Through this study, I hope to deepen my understanding of the professional practices, identities, and experiences of those who teach writing classes in a two-year college setting. This project is part of my dissertation on the professional, scholarly, and disciplinary identities of two-year college writing faculty. This study is being sponsored by the Department of English at the University of Louisville under the guidance of Dr. Bronwyn T. Williams.

I would like to interview you about your experiences working in a two-year college setting. The interview would last approximately an hour and would be audio-recorded; after the interview, you would also be invited to review and give feedback on what I write about your interview. Anyone who is currently employed at a two-year college and teaching writing courses is eligible to participate. I hope to recruit up to 10 participants for this project.

The study will take place during the spring of 2017, and we can schedule an interview at your convenience. Your participation is completely voluntary and confidential, and you can withdraw from the study at any time.

If you are interested in participating, or would like additional information before deciding, please let me know. I am happy to answer any questions you may have about this study, and can be reached by email or phone. Thank you for your time.

Sincerely,

Laura Sceniak Matravers

Ph.D. Student in Rhetoric and Composition

Department of English University of Louisville

laura.matravers@louisville.edu

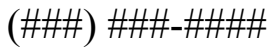


Appendix B

Interview Questions

- What does a typical day/week/semester look like for you? What is your typical workload (e.g., teaching, class size, research, administrative work, other responsibilities, etc.) like?

- What has most surprised you about this job/the work you do here?

- How much time do you usually put toward different work or professional responsibilities/tasks?

- What kinds of writing do you do for/outside of work? What kinds of things do you read for/outside of work (e.g., journals, books, etc.)?

- Do you ever go to conferences? (How often? Where? Which conferences? Where? Do you present?)

- Do you ever write or submit things for publication (scholarly or otherwise)? (What? What journals do you submit to? How often?)

- What kinds of support do you get from your department/college to do things like go to conferences or write for publication?

- How do you usually find or hear about things to read, places to submit your writing, or conferences to attend?

- What kinds of professional organizations, groups, or communities do you participate in or consider yourself to be a member? 
Appendix C

Tables 7,8 , and 9

Table 7: Results Breakdown by Journal-Articles in Four-Year Journal Group

\begin{tabular}{|c|c|c|c|c|}
\hline Journal & $\begin{array}{c}\text { Total \# Articles } \\
\text { w/ TYC } \\
\text { Author }\end{array}$ & $\begin{array}{c}\text { \# Single- } \\
\text { Authored, TYC } \\
\text { only }\end{array}$ & $\begin{array}{c}\text { \# Co-authored, } \\
\text { TYC only }\end{array}$ & $\begin{array}{c}\text { \# Co-authored, } \\
\text { TYC and 4- } \\
\text { Year }\end{array}$ \\
\hline$W P A$ & 3 & 1 & 0 & 2 \\
\hline$C E$ & 6 & 3 & 2 & 1 \\
\hline$J B W$ & 8 & 5 & 1 & 2 \\
\hline$C C C$ & 9 & 2 & 2 & 5 \\
\hline CandC & 10 & 4 & 1 & 5 \\
\hline TOTAL & $\mathbf{3 6}$ & $\mathbf{1 5}$ & $\mathbf{6}$ & $\mathbf{1 5}$ \\
\hline
\end{tabular}

* Journal data for 2016 issues of JBW unavailable at the time of data collection; average based on nine years of issues, instead of ten.

Table 8: Results Breakdown by Journal-Articles in Two-Year Journal Group

\begin{tabular}{|c|c|c|c|c|c|c|}
\hline Journal & $\begin{array}{c}\text { Total \# } \\
\text { Articles } \\
\text { w/ TYC } \\
\text { Author }\end{array}$ & $\begin{array}{c}\text { Avg. \# } \\
\text { Articles/Year } \\
\text { w/ TYC } \\
\text { Author }\end{array}$ & $\begin{array}{c}\text { \# Single- } \\
\text { Authored, } \\
\text { TYC only }\end{array}$ & $\begin{array}{c}\text { \# Co- } \\
\text { authored, } \\
\text { TYC only }\end{array}$ & $\begin{array}{c}\text { \# Co- } \\
\text { authored, } \\
\text { TYC and } \\
\text { 4-Year }\end{array}$ & $\begin{array}{c}\text { \# Co- } \\
\text { authored, } \\
\text { TYC, 4- } \\
\text { Year, } \\
\text { and K-12 }\end{array}$ \\
\hline TETYC & 111 & 11.1 & 75 & 27 & 8 & 1 \\
\hline TOTAL & $\mathbf{1 1 1}$ & $\mathbf{1 1 . 1}$ & $\mathbf{7 5}$ & $\mathbf{2 7}$ & $\mathbf{8}$ & $\mathbf{1}$ \\
\hline
\end{tabular}

Table 9: Comparison of Articles in Four-Year and Two-Year Journal Groups

\begin{tabular}{|c|c|c|c|c|c|c|}
\hline Journal & $\begin{array}{c}\text { Total \# } \\
\text { Articles } \\
\text { w/ TYC } \\
\text { Author }\end{array}$ & $\begin{array}{c}\text { Avg. \# } \\
\text { Articles/Year } \\
\text { w/ TYC } \\
\text { Author }\end{array}$ & $\begin{array}{c}\text { \# Single- } \\
\text { Authored, } \\
\text { TYC only }\end{array}$ & $\begin{array}{c}\text { \# Co- } \\
\text { authored, } \\
\text { TYC only }\end{array}$ & $\begin{array}{c}\text { \# Co- } \\
\text { authored, } \\
\text { TYC and } \\
\text { 4-Year }\end{array}$ & $\begin{array}{c}\text { \# Co- } \\
\text { authored, } \\
\text { TYC, 4- } \\
\text { Year, } \\
\text { and K-12 }\end{array}$ \\
\hline $\begin{array}{c}\text { 4-Year } \\
\text { Journals }\end{array}$ & 36 & 3.60 & $\begin{array}{c}15 \\
(41.67 \%)^{*}\end{array}$ & $\begin{array}{c}6 \\
(16.66 \%)\end{array}$ & $\begin{array}{c}15 \\
(41.67 \%)\end{array}$ & $\begin{array}{c}0 \\
(0.00 \%)\end{array}$ \\
\hline $\begin{array}{c}\text { 2-Year } \\
\text { Journals }\end{array}$ & 111 & 11.1 & $\begin{array}{c}75 \\
(67.57 \%)\end{array}$ & $\begin{array}{c}27 \\
(24.32 \%)\end{array}$ & $\begin{array}{c}8 \\
(7.21 \%)\end{array}$ & $\begin{array}{c}1 \\
(0.90 \%)\end{array}$ \\
\hline
\end{tabular}

*Percentages of total number of articles 


\title{
CURRICULUM VITA
}

\author{
Laura Sceniak Matravers \\ laura.matravers@louisville.edu \\ (\#\#\#) \#\#\#-\#\#\#\#
}

Education

University of Louisville

Ph.D., Rhetoric and Composition: May 2018

Dissertation: A Fractured Conversation: The Professional, Scholarly, and Disciplinary Identities of Two-Year College Writing Faculty

Committee: Bronwyn T. Williams (chair), Mary P. Sheridan, Susan Ryan, Jenn Fishman

\section{University of Tennessee, Knoxville}

M.A., English - Rhetoric, Writing, and Linguistics: May 2012

Thesis: Bridging the Gap: Understanding the Skills and Writing Knowledge of Entering College Composition Students

Committee: Michael L. Keene (chair), Kirsten F. Benson, Russel Hirst

B.A., Summa cum Laude: May 2010

Double major in Religious Studies and English - Rhetoric and Writing

Publications

"On Multimodal Composing." Kairos: A Journal of Rhetoric, Technology, and

Pedagogy, vol. 21, no. 2, 2017. With Sara P. Alvarez, Michael Baumann, Michelle Day, Khirsten L. Echols, Layne M.P. Gordon, Ashanka Kumari, Jessica Newman, Amy McCleese Nichols, Caitlin E. Ray, Jon Udelson, Rick Wysocki, and Dànielle Nicole DeVoss.

“(Im)Mobilities and Networks of Literacy Sponsorship. (Response) Working Paper Series on Mobility Work in Composition: Translation, Migration, Transformation. Louisville: Thomas R. Watson Conference on Rhetoric and Composition, October 2016. Web.

"Lingering Questions: The Delay of Free Two-Year College Tuition in KY," NCTE Policy Analysis Initiative Blog Post, June 2016. With Rachel Gramer and Mary P. Sheridan. 


\section{Forthcoming}

"On Multimodality: A Manifesto." Bridging the Gap: Multimodality in Theory and Practice. Santosh Khadka and J.C. Lee, eds. With Sara P. Alvarez, Michael Baumann, Michelle Day, Khirsten L. Echols, Layne M.P. Gordon, Ashanka Kumari, Jessica Newman, Amy McCleese Nichols, Caitlin E. Ray, Jon Udelson, Rick Wysocki, and Dànielle Nicole DeVoss.

\section{Under Review}

Mobility Work in Composition. Edited with Bruce Horner, Megan Faver Hartline, and Ashanka Kumari. Under review with Utah State University Press.

\section{In Progress}

"The Role of Friendship and Co-Mentorship in Graduate Student Professionalization Efforts." With Keri E. Mathis. For submission to Peitho.

Conference Presentations

"“We're All on the Front Lines': Stories from Community College Writing Teachers." Conference on College Composition and Communication. Kansas City, MO. March 2018.

"The Case of (and for) the Community College Perspective." Conference on College Composition and Communication. Portland, OR. March 2017.

"On Multimobile, Multimodal Composing." Thomas R. Watson Conference on Rhetoric and Composition. Louisville, KY. October 2016.

"Why We Should Listen: Two-Year College Voices in a Fractured Conversation." Council of Writing Program Administrators' Conference. Raleigh, NC. June 2016.

"On the Fringe: Two-Year Colleges in College English and College Composition and Communication, 1940-2009." Two-Year College English Association-Southeast Conference. Knoxville, TN. February 2016.

"Community and Digital Spaces: An Examination." Conference on Community Writing. Boulder, CO. October 2015.

"Altering History, Altering Books: Reading Women into the Postbellum Record." Conference on College Composition and Communication. Atlanta, GA. April 2011.

Teaching Experience

University of Louisville

Graduate Teaching Assistant (Instructor of Record) $2014-2018$

English 101: Introduction to College Writing 
English 102: Intermediate College Writing

English 303: Scientific and Technical Writing

English 306: Business Writing

University of Tennessee, Knoxville

Part-Time Lecturer; Graduate Teaching Associate/Assistant

$2010-2013$

English 101: Composition I

English 102: Composition II-Inquiry into Grassroots Social Change

English 102: Composition II-Inquiry into Faith Journeys

\section{Pellissippi State Community College (Knoxville, TN)}

Part-Time Instructor

English 0810/0820: Learning Support English—Developmental Writing

\section{ITT Technical Institute (Knoxville, TN)}

Part-Time Instructor

EN1320: Composition I

EN1420: Composition II

GS1145: Strategies for the Technical Professional

Tutoring Experience

Pellissippi State Community College (Knoxville, TN)

Developmental English Tutor, Transitional Studies Learning Commons

$2013-2014$

ITT Technical Institute (Knoxville, TN)

Composition Tutor, Campus

University of Tennessee, Knoxville

Writing Tutor, Thornton Athletics Student Life Center

Writing Tutor, University Writing Center

Research and Administrative Experience

\section{University of Louisville}

Research Assistant,

School of Interdisciplinary and Graduate Studies

$2017-2018$

- Worked to revitalize efforts promoting best practices for graduate student mentoring across disciplines, including creating mentoring resources for 
faculty and students

- Organized discussion panel, "Mentoring Women Graduate Students"

- Conducted survey of graduate program directors on current programmatic mentoring initiatives

- Co-authored grant proposal to implement a pilot mentoring and research opportunity program for faculty, graduate students, and undergraduate students

Assistant Director,

Thomas R. Watson Conference on Rhetoric and Composition

$2015-2017$

- Provided feedback on keynote speakers' essays; reviewed proposals; formed panels

- Reviewed conference themes, CFPs, and invited speaker proposals

- Collaborated to organize symposium (approx. 45 attendees) and conference (approx. 375 attendees), including coordinating with invited scholars, advertisers, publishers, vendors, volunteers, and conference committee

- Coordinated production of conference program, from initial drafting to printing

- Maintained conference website; managed email and conference communications

Co-Developer,

Digital Media Academy

- Co-developed free digital media summer camp curriculum for twenty middle school girls from historically under-performing Louisville area schools

- Co-taught digital image manipulation, video editing, and collaborative digital text creation and presentation

- Assisted in planning as logistics team lead, including reviewing applications, coordinating with vendors and campus affiliates, and maintaining records

Co-Organizer,

Graduate Network in Arts and Sciences Annual Spring Event

$2014-2015$

- Co-authored grant to secure event funding (approx. 80 attendees)

- Assisted coordination between co-organizers, venue, and funding organization

Awards and Grants

Graduate Dean's Citation Award, University of Louisville (2018)

Graduate Network in Arts and Sciences travel grant, College of Arts and Sciences, University of Louisville (2015, 2017): \$100

Graduate Student Council Conference travel grant, School of Interdisciplinary and Graduate Studies, University of Louisville $(2015,2016)$ : \$350 
PLAN Professional Development Workshops Active Attendee Certificate, School of Interdisciplinary and Graduate Studies, University of Louisville (2015, 2016)

Club Programming Committee Grant, Graduate Network in Arts and Sciences Annual Spring Event for Graduate Students in Arts and Sciences, University of Louisville (2015): $\$ 1,500$

Nominee, John C. Hodges Award for Excellence as a New Tutor, University of Tennessee, Knoxville (2011)

John C. Hodges First-Year M.A. Fellowship, University of Tennessee, Knoxville (2010 2011)

Professional Development

Participant, Winter Dissertation Writing Mini-Retreat, University Writing Center, University of Louisville (January 2018)

Work-in-Progress Presenter, Qualitative Research Network, Conference on College Composition and Communication. Portland, OR (March 2017)

Workshop Co-Presenter, "Be Searchable: Developing an Online Portfolio for the Job Search." School of Interdisciplinary and Graduate Studies, University of Louisville (June 2016)

Workshop Co-Presenter, "Embracing the Short Form: Visual Arguments for Research and Teaching." English Department, University of Louisville (February 2016)

Participant, Grant Writing Academy, School of Interdisciplinary and Graduate Studies, University of Louisville (September - December 2015)

Participant, Principles of Online Course Design, Delphi Center for Teaching and Learning, University of Louisville (May 2015)

Professional Service

National

Reviewer, Teaching English in the Two-Year College (2016 -Present)

Task Force Committee, Graduate Labor Census, Council of Writing Program Administration-Graduate Organization (2017)

Planning Committee, Council of Writing Program Administrators' Conference Graduate Social, Writing Program Administration-Graduate Organization (2017)

\section{University of Louisville}

Contributing Writer, UofL Me/We Banner Art Installation Project (2018) 
Assessment Reader, General Education Assessment of Written Communication (2017)

Graduate Student Representative, Teaching Innovation Learning Lab Steering Committee $(2015-2016)$

Department Representative, Graduate Network in Arts and Sciences (2014 - 2016)

Organizing Committee, Graduate Network in Arts and Sciences Annual Spring Event (2014-2015)

Departmental Service

Guest Contributor, "What I Learned in Year One" Blog Series, English Graduate Organization (2018)

Conference Committee, Thomas R. Watson Conference on Rhetoric and Composition $(2015-2017)$

Guest Contributor, "What I'm Working On” Blog Series, English Graduate Organization (2016)

Peer Mentor to Prospective Ph.D. Student in Rhetoric and Composition (2015)

\section{University of Tennessee, Knoxville}

Departmental Service

Teaching Mentor to First-Year M.A. Student (2013)

Part-Time Lecturer Representative, Composition Committee (2013)

Organizing Committee, UT Writes: A Celebration of UT Writing (2010)

Graduate Coursework

\section{Composition Studies}

Writing Program Administration History, Theory, and Practice (Bruce Horner, UofL) Composition Theory and Practice (Mary P. Sheridan, UofL)

Research Methods in Composition (Mary P. Sheridan, UofL)

Multimodal Composing (Dànielle Nicole DeVoss, UofL)

Composing Identities: Exploring Literacy, Culture, and Agency (Bronwyn Williams, UofL)

Research Methods in Rhetoric, Writing, and Linguistics (Kirsten Benson, UTK)

Language and Popular Education (Jenn Fishman with the Highlander Folk School, UTK)

\section{Pedagogy}

Literature and Pedagogy (Beth Boehm, UofL)

Teaching College Composition (Brenda Brueggemann, UofL)

Composition Pedagogy (David Gold, UTK) 


\section{Rhetorical Theory and History}

Rhetoric of Social Movements (Stephen Schneider, UofL)

History of Rhetoric II (Stephen Schneider, UofL)

History of Rhetoric I (David Gold, UTK)

Issues in Rhetoric, Writing, and Linguistics (Russel Hirst, UTK)

Advanced Studies in Rhetoric: Kenneth Burke (Michael L. Keene, UTK)

\section{Literature/Literary Theory}

Contemporary Theories of Interpretation (Karen Hadley, UofL)

The Cultural History of American Authorship (Susan Ryan, UofL)

Contemporary American and British Poetry (Ben Lee, UTK)

Memberships and Affiliations

Conference on College Composition and Communication

Council of Writing Program Administrators

Council of Writing Program Administrators - Graduate Organization

National Council of Teachers of English

Two-Year College English Association - Southeast

Gamma Beta Phi Society

Phi Beta Kappa Society

References

Available upon request. 